\title{
Mosher
}

A classification of the Lepidoptera baskd on characters of tre pupa. 
THE UNIVERSITY

OF ILLINOIS

LIBRARY

1915

M85 


\section{A CLASSIFICATION OF THE LEPIDOPTERA BASED ON CHARACTERS OF THE PUPA}

BY

EDNA MOSHER

B. S. A. Cornell University, 1908.

M. S. University of Illinois, 1913.

\section{THESIS}

Submitted in Partial Fulfillment of the Requirements for the

Degree of

DOCTOR OF PHILOSOPHY

IN ENTOMOLOGY

IN

THE GRADUATE SCHOOL

OP THE

UNIVERSITY OF ILLINOIS 
LIOTAHY
OF THE

ERSITY OF ILLINO 


\section{UNIVERSITY OF ILLINOIS}

THIS IS TO CERTIFY THAT THE THESIS PREPARED UNDER MY SUPERVISION BY Edna Nosher, B.S.A., M.S.,

ENTITLED A Classification of the Lepidoptera based on Characters of the pupa

IS APPROVED BY ME AS FULFILLING THIS PART OF THE REQUIREMENTS FOR THE

DEGREE OF .. Doctor of Philosophy

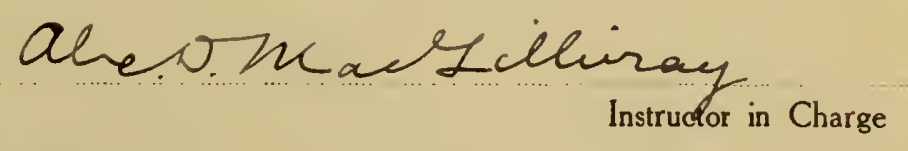

APPROVED:

Stifina a. Forles HEAD OF DEPARTMENT OF....... Eectomolegy 
(4).,497s

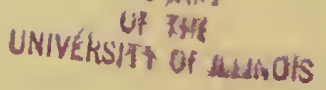


195

Contents

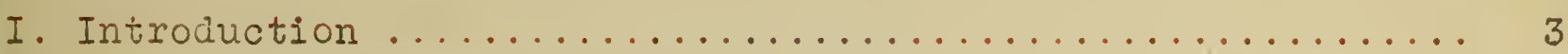

II. Changes Preceding Pupation ..................... 5

III. Txterna. llorphology ......................... II

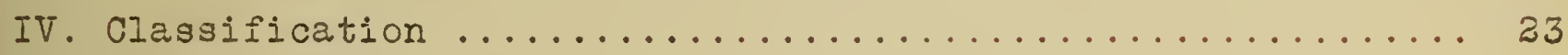

Analytical table of superfamilies ................ 24

A. Pupae with functional mandibles ................ 28

Superfamily licropterygoldea ............. 28

AA. Pupae without functional mandibles ............. 32

B. Generalized pupae without maxillary palpi ....... 32

Superfamily Ferialoidea ................. 33

Superfamily Cossoidea ................... 34

Superfemily Eucleoidea .................. 38

BB. Generalized pupae with maxillary palpi ......... 43

Superfamily Tineoidea .................. 43

Superfamily Aegerioicea ................. 49

Superfamily Tortricoidea ................. 53

Superfamily Gracilarioidea ................ 64

C. Specialized pupae with piliters $\ldots \ldots \ldots \ldots \ldots, 80$

Superfamily Pyralidoliea ............... 80

Superfamily Papilionioidea ................ 92

CC. Specialized pupae without pililfers .......... Il7

Superfamily Yronomeutoicea ............... 118

Superfamily Gelechioidea ............... I2I

Superfamily roctuoidea ................. 133

Superfamily Bornbycoidea ................ 156 
OF THE ILINOIS

UNIVERSITY Of ILLINOIS

Uum

UIUC: 
Superfamily Notodontoidea ............ 159 Superfamily Sphingoidea .................. Superfamily Saturnioidea ........... 174

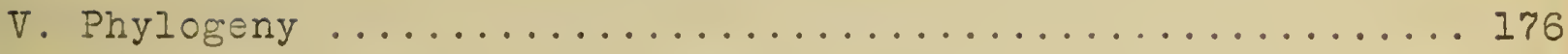

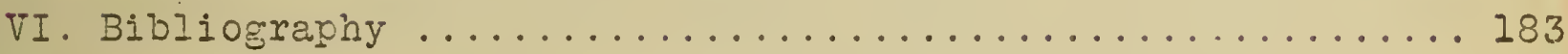

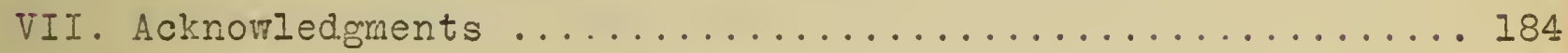

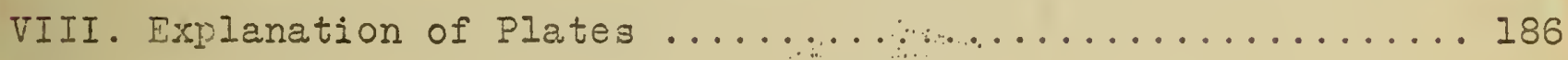





\section{INTRODUCTION}

It is within comparatively recent times that the immature stages of insects have been considered of any taxonomic value. The economic entomologist early realized the value of being able to recognize the immature stages, for in many orders of insects the larval stages alone were responsible for many ravages upon crops and orchards. Still the matter was not taken up by the systematists and the workers in the field of economic entomology contented themselves by rearing the adult to determine the species, and then describing, perhaps all the stages, or, more probably the larval and adult stages as being those of economic importance. Now-a-days we are beginning to see that it is impossible to construct an adequate classification of any group of insects unless we use every bit of information obtainable on the life history and habits of the group in question.

It is possible to multiply instances of the value of the larval stages in classification, so that one scarcely needs to clte examples; but the pupae have been less frequently used. There are, hovever, instances of insects in their pupal stage possessing the only good taxonomic characters available. Such instances are found among the nematocerous Diptera, particularly in the family Chironomidae. Scudder 189 was the first to attempt a clasaification of lepidopterous pupae, but his keys to the chrysalids were based, not on structural characters, but on the various projections from the body, the cuticular appendages, the coloration and the mode of suspension. 



\section{Vita}

The writer was born at Kemot Shore, Nova Scotia, and educated in the public schools of that province, graduating from the Provincial Normal school in 1902. For three years she held a position in one of the units of Sir William MacDonald's consolidated school garden system and then entered Cornell University, graduating in 1908 with the degree of Bachelor of Science in Agriculture. The next two years were spent as teacher of agriculture in the High School at Hampton, Virginia, and supervisor of nature study and school gardening in the public schools of that city. A similar position was held in the public schools of Gary, Indiana, until 1812. The surners of 1909-1911 were spent as instructor in agriculture and nature study in the state Normal Institute at Emory, Virgiria. From September, 1912, until the present time the writer has been a graduate student at the University of Illinois, as scholar in Entomology during the year 1912-1913 and as fellow in 1914-1915. She received the degree of liaster of Science in 1913.

The writer is a member of the Entornological Society of of America and the honorary society of Sigma Xi. She has published: "A Ciassification of the Pupae of the Ceratocampidae and Hemileucidae", Annals of the Entomological Society., 1914; "Homology of the Mouth Parts of the Preimago in the Lepidoptera", Journal of Entomology and Zoology, 1915; "A Classification of the Pupae of the Saturnildae", Annals of the Entomological Society of America, 1915. 

Among the Lepldoptera a great deal of work has been done towards the classification of the larvae, but until 1893 nothing of importance had been done towards a study of the pupae. In this year Dr. T. A. Chapman in a paper entitied "Some Neglected Points in the Pupae of Heterocerous Lepldoptera" called attention to the fact that the pupae possessed some remarkable taxonomic characters which might be used to clear up many of the disputed points in the classification of the order. This he endeavored to do for the groups in which material was available for study and, has since published other articles as additional material was obtained. However, Dr. Chapman attempted no classification of the Lepidoptera on this basis, merely pointing out the pupal characters of the major groups and also calling attention to instances in which a study of these characters would apparently alter the existing schenes of classification.

The attention of American entomologists was called to the question by Dr. A. S. Packard 195 in a paper entitled "Attempt at a New Classification of the Lepidoptera." He made a new grouping of the order based upon pupal characters and figured a large number of species. His determinations of the homology of the various parts of the pupae studied were far from correct and this, of course, invalidated many of his conclusions.

Since that time nothing has been done in America towards a classification of the Lepidoptera based on pupal characters. is the attempt of the present investigation to present such a classification as far as material has been avallable for study. It also attempts to throw some light on the relationships existing between the different groups. 



\section{II.CHANGES PRECEDING PUPATION}

The person who begins the study of pupae with the preconceived notion that the pupal stage is an interpolated one in the insect's life and that a pupa bears littie or no resemblance to either larva or adult, will probably find abundant cause for a change of mind before his study is completed. In the case of Lepidoptera one is apt to think that no similarities could possibly exist between any of the three stages of the insect's development after it leaves the egg. After careful study, however, one is surprised with the resemblance between the stages, for it is of the highest importance in the study of any group to be able to homologize larval, pupal and imaginal characters. This has been done to some extent in certiin orders of insects, particularly in those groups where the resemblance between the larva and adult is more striking than in the case of the Lepidoptera. Attempts have been made, however, even in this order, to homologize the mouthparts of the larva and adult, and some of the larval structures have been homologized with certain structures in the pupa, but apparently the idea that all three stages should be studied has been left for other minds to entertain.

The first striking difference between larva and pupa is that of size. This difference is easily explained by the great difference in the size of the alimentary canal. Another striking difference is the apparent absence of legs and prolegs. As w1II be shown later the legs are always present, but folded and not in use, while the scars of all the prolegs remain to show their location and are very easily identified in the majority of cases. 
Nany lepidoptercus larvae possess striking tubercules and warts, usually with an abundance of setae. All larvae possess setae, but they are often inconspicuous. In so far as observed on the exposed portions of the body surface, the pupa always retains the scars of these warts and tubercules and the pupal body possesses setae arranged in most cases in the exact order in which they occurred in the larva. Many other structures of the larva can be easily identified in the pupa, and these will be discussed later.

In the case of insects with complete metamorphosis the name pupa is applied to the stage of the insect in which it is more or less quiescent while undergoing the changes which are necessary to fit it for its adult life. This word pupa, from the Latin meaning baby, was applied to this stage by Linnaeus from the resemblance of certain pupae to a baby which has been swathed or bound up, as was the custom in many parts of Europe at that time. This name was perhars more appropriate for the pupae of the Lepidoptera than for those of any other order of insects because the appendages are usually all soldered to the thorax.

The change from larva to pupa in the Lepidoptera has been observed by many workers and is full of surprises for the amateur who wishes to breed these insects. The caterpillar when ready to pupate stops feeding, and in many instances leaves the food plant and wanders about, often apparently in the greatest of haste. Many are then seen on sldewalks, garden paths and other travelled places especially during the autumn months when the majority of larvae are seeking a place to spend the winter. These larvae, if confined, will refuse food and many of them 


\section{1}

(1)

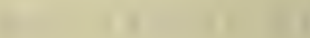


spin silk threads which are used to suspend the pupa or form a coccon. The alimentary canal is always freed of any food mater1als. The larval skin at this time loses its luster, becomes more and more wrinkled, the body becomes shorter and shorter and appears swollen, which is due to the moulting fluid glands pouring their secretion between the outer and inner layers of cuticle. Some drops of a yellowish or redaloh fluid are usually found in the place where larvae are confined and this, together with their peculiar appearance, often leads the amateur breeder of Lepidoptera to think that decomposition is taking place, and results in the hasty disposal of the now helpless insect. In the case of larvae which spin a cocoon these changes are not so easily observed, unless the cocoon is a very frall one, because most of the changes described take place inside of the cocoon. These changes may occupy but a few hours, or may last for nearly a week. In the case of the comon tomato worm, Protoparce carolina, the transformation process usually requires five days; certain species of Papilio observed took but three days, but the time varies much with different individuals and the conditions under which they I1ve.

When the moulting fluid has done its work in locsening the larval cuticle, this splits along the meson of the thorax, and is gradually worked to the caudal end of the body, liberating the enclosed pupa. The liberated pupa is covered with a more or less transparent cuticle and resembles the pupa of the more generalized Neuroptera, Trichoptera and Coleoptera. In all of these orders, the insects on casting their larval skins show the first resemblance to the adult insect. In the Neuroptera, Tri- 


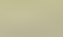

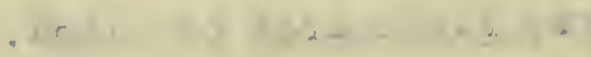


choptera and Coleoptera, the appendages, as well as the body, are encased in a pupal skin, are free from each other and the body, and together with the body segments possess considerable freedom of motion. This does not mean that they have any power of $1000-$ motion; on the contrary they are quite helpless and for this reason are frequently, in common with the great majority of pupae, protected by some sort of a cocoon, or earthen cell. The lepidopterous genus Micropteryx, which is supposed by many to be the most generalized of its order, retains freedom of motion of all the appendages and in all but the fixed caudal segments of the abdomen. This freedom of motion is gradually lost in lepidopterous pupae as specialization advances, and the adult appendages are not as fully developed when the pupal stage is assumed, although the cases of the appendages of the pupa are fully formed. Specialization in the pupa consists also in the hardening of the exposed parts of the cuticle, through the deposition of chitin, and the soldering of the appendages to each other and to the body of the pupa. In the generalized families the appendages are soldered to each other but often remain free from the body surface; later the wings become attached to the body surface, but any parts of the anternae, legs or maxillae extending beyond their caudal margins remain free. The tips of these appendages are provided for in varlous ways in the higher families, but are always found soldered firmly to the surface of the body of the pupa. Proceeding hand In hand with the soldering down of the appendages is the loss of motion in the abdominal segments. Among certain families there is motion between all of the adjacent segments. There is, however, 

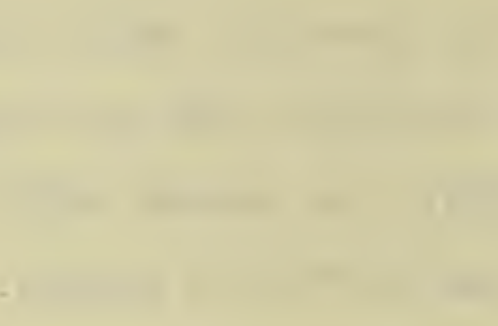
a successive loss of motion between segments, until the conjunctiva between all but two of the segments is inflexible in some forms; and even in some of the Lepldoptera, entire freedom of motion has been lost.

Among generalized forms where the appendages are soldered together, the cuticle of the exposed parts of the body contains but very little chitin, and is but slightly differentiated in texture from the cuticle of the hidden surfaces. When the Imago emerges, or even before that time, if the body is slightly pressed, the appendages separate very readily from each other and are not torn upon the emergence of the insect, so that the pupal skin often remains complete except for the slit on the dorso-meson through which the 1mago emerged. A very different condition exists, however, among highly specialized forms. Here the exposed portions of cuticle become very hard and firm, while those which are not exposed are very thin and delicate and are almost entirely destroyed at the emergence of the imago. The outer covering, of course, being so firmly soldered together, remains in one piece and is apparently complete except for the slit through the insect emerged. This has led many to think that this outer chitinized portion was the entire pupal skin and that it was a structure, analogous perhaps to an egg shell, in which the pupa had been enclosed.

Another remarkable difference between the generalized and the highly specialized Lepidoptera lies in the fact that in the latter the appendages are not fully formed when pupation takes place, but consist of the transparent cuticular coverings through 
whlch one or more slender tracheae may be seen. The duration of the pupal stage doubtless influences this, there being a stronger tendency for highly specialized forms to hibernate as pupae.

During the life of the pupa the adult parts are developing, and before it is time for the imago to emerge, the cuticular parts of the adult are fully formed. In the generalized families previously mentioned and in some specialized forms where the pupal cuticle remains more or less transparent, one is able to see a part of the development taking place, especially in the case of the appendaces. The scales appear on the legs and wings and the color pattern may often be easily traced on the latter several days before the emergence of the insect. This stage of the insect, after the cuticular parts are fully formed, and while it still retains its pupal skin, has been designated as the preimago. Where the pupal skin is not already dark in color, it grows considerably darker in the last few days before the insect emerges, and one is thus able to determine when the preimago stage is reached 


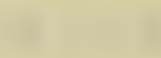

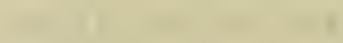

(1)

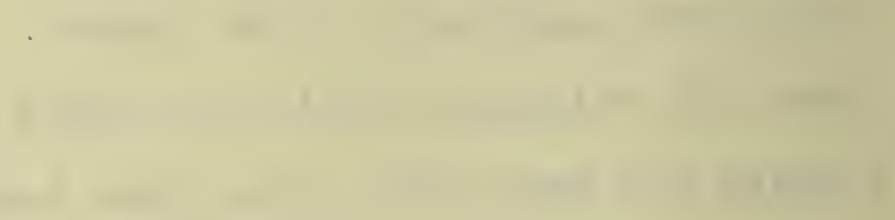




\section{EXTERNAL MORPHOLOGY}

The most important work on pupal morphology has been done by E. B. Poulton and Dr. T. A. Chapman. Poulton 'Gl in his paper on the "External Morphology of the Lepidopterous Pupa" discusses a few pupal structures but does not attempt to name all of the parts or to locate any of them. So far as known he was the first to point out that the pupal structures were more than cases for the imaginal structures and objected to the terms pterothecae, ophthalmothecae, etc., as applied to pupae. Believing that Poulton's theory is correct, such terms have not been used in this discussion, nor the terms wing cases, antennal cases, leg cases, etc., but these are spoken of simply as wings, antennae, maxillae, etc. Chapman's papers, already referred to, discuss very fully some of the structures and describe their exact location; but included only few figures and one was left very much in doubt as to the identity of many of the structures and their location. W. Hatchett Jackson 'SI published a very valuable paper on the "Morphology of the Lepidoptera" in which he discussed the external determination of sex in the pupa. A short discussion of the chrysalis was given by Dr. S. H. Scudder 189 and some of the parts were named. In a paper previously cited, Dr. A. S. Packard 's5 gives many figures of pupae and names the parts, but his homologies were far from correct. It seems necessary, therefore, before proceeding further, to discuss the principal pupal structures and indicate their location by means of figures.

The homologies given in this paper were determined by a series of dissections of pupae in various stages of development, 


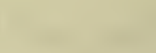


the preimago being found most valuable for this purpose. Pupae of nearly every family mentioned in this discussion have been studied in this way, beginning with the Micropterygoidea and extending through the Hepialoidea, Cossoidea and other generalized families and including the Saturnioidea, which are believed to be the most specialized of lepidopterous pupae. The change from larva to pupa has been watched in many species and the subsequent folding and soldering down of the appendages carefully noted. A large number of species have been bred and a study of the method of dehiscence, as shown by the pupal skin, has thrown considerable light on many instances where there was doubt as to the number of free abdominal segments, or where a suture was obscured by folds or other modifications of the integument.

The three regions of the body, head, thorax, and abdomen, are easily recognized and each will be discussed in turn. There occur, on all of the regions of the body, in different families prominent projections and ridges of various types especially in the Paplilonoldea. These projections have no morphological significance.

\section{The Head}

The usual sclerites found in the head of generalized insects may be located in lepidopterous pupae. The sutures are distinct in generalized pupae, but are obliterated in the more specialized groups.

Vertex. -This is an area found on the dorsum of the head. It reaches 1 ts highest development in the Gracilarioidea, but is usually distinct in all generalized pupae. It is bounded cephalad 

by the $Y$-shaped epicranial suture, and may be seen in Figs. 3,10 , $29,46,49,53$ and 56 ; v. This area was referred to by Chapman and Packard 38 the dorsal head-piece.

Front.-The front is the sclerite to which the antennae are attached. It $1 \mathrm{~s}$ bounded by the epicranial suture on the dorsal surface and on the ventral surface by the fronto-clypeal suture, which normally extends for a short distance caudad from the base of each antenna and then transversely to the median line. In some pupae where there is a "ghoving back" of the head parts as in the Pyraustidae and Sphingidae, the front is located on the dorsum of the head. The fronto-clypeal suture is usually not distinct except in very generalized forms. The superfamily Gelechioldea, however, shows it very distinctly. It is indicated in Figs. 1, 8, 26, 30 and 36; $f$. The front bears two setae on each side the meson in generalized pupae, which are often very conspicuous.

Genae.-These sclerites are distinctly bounded in Eriocranildae and Hepialidae (Figs. 1 and $8 ;$ g.) They are found laterad of the front and clypeus and mesad of the glazed eye. The mandibles are always adjacent to the genae at their lateral margins.

Clypeus.-But very few pupae have the clypous definltely bounded. The suture between the clypeus and labrum is seldom present, although it is often indicated by a furrow. It is then impossible to determine accurately as to its presence, but has been considered as if it were present. The boundaries of the clypeus are shown very distinctly in Fig. 1 ; cl. In the Hepia- 

lidae (Fig. 8) there is no clypeo-labral suture present although all the other head sutures are distinct. The clypeus can usually be identified by the presence of the invaginations for the anterior arms of the tentorium which are associated with its lateral margins. This sclerite often bears prominent setae, and in the pupae of borers, often a distinct cutting plate or ridge.

Anterior arms of the tentorium.-These invaginations are very distinct and are either small pores or slit-like openings. They are associated with the lateral margins of the clypeus and are distinct in most pupae (Figs. 1, 14, 19, 23; at).

Labrum.-The labrum is usually distinct along its lateral and distal margins, but seldom separated from the clyceus by a distinct suture. Like the clyceus it usually bears setae which are especially conspicuous in the Eriocraniidae (Figs. 1, 2; 1b). A peculiar development occurs in the Heliozelidae and some others where the labrum extends caudad over the appendages (Fig. 50). P1llifers. - This term is applied to the caudo-lateral projections of the labrum, which are so well developed in many Lepidoptera. They are very large in certain superfamilies, notably the Pyralidoidea and the Papilionioidea and their presence is easily detected by the lobes which are adjacent to the caudo-lateral angles of the labrum and often come to meet on the meson caudad of 1t, or are separated by a narrom piece of the labial palpi. (Figs. 70, 72, 74, 76, 77, 78, 79, pf). The mandibles figured by Scudder 89 (Vol. 3, PI. 87, fig. 25) are the pillifers. There are often well developed pillifers present, however, when there are no external indications of their presence. 

Eye-pieces.-These are situated laterad of the genae and mesad of the antennae. There are always two regions to be noted, a smooth mesil portion, sometimes only a narrow band, but often a wider lunate piece, called the glazed eye-piece and the larger lateral portion, the sculptured eye-piece. The latter is so called because it is always sculptured like the adjacent parts of the thorax. The sculpturing on the head is seldom like that found on the thorax and abdomen and, strange to say, the sculptured eyepiece is always like the thorax, although it is probably an extension of the vertex. On the dehiscence of most generalized pupae the eye-pleces are separated from the face-parts and remain attached to the conjunctiva which joins the vertex to the prothorax (Fig.43). In the specialized forms they remain attached to the face-parts. A peculiar modification is found in the Eucleoidea (Figs. 17, 19, 23; se, ge) in which the eye-pieces form movable flaps seemingly to protect and to cover the prothoracic spiracles which lie underneath. The glazed eye-piece probably represents the pupal eye.

$$
\text { Antennae. -These are always attached to the front and }
$$
extend laterad, curving to the ventral surface of the body mesad of the mesothoracic wings. They may always be identified without any trouble (Figa. 1, 8, 11, 15, 28; a). In pupae with broadly pectinate antennae as the Saturnildae the mesal portion is frequently elevated and has been referred to as the "stem of the flagellum" of the antennae.

Labial Palpi.-These appendages lie adjacent on the meson caudad of the labrum except in the Eriocranildae (Fig. 1; Ip). They are visible in the majority of pupae (Figs. 1, 8, 15, 28, 

45, 61). They are frequently overlald and concealed by the maxillae at their proximal end as in Figs. 61 and $67 ; 1$. Often they are entirely concealed by the maxillae with the exception of a small V-shaped piece just caudad of the labrum (Fig. 72). This was thought by Scudder to be a special piece for covering the base of the tongue.

Max1llae.- Where labial palpi are visible they occupy a mesal position, caudad of the labrum, with the maxillae laterad of them. When they are invisible and apparently absent, the maxillae lie adjacent on the meson, often overlying and concealing the proximal ends of the labial palpi as mentioned above. The maxillae (Figs. 1, 8, 17, 24, 25; $\mathrm{mx}$ ) vary greatly in length but are never entirely lacking or concealed in the pupa. They often extend beyond the caudal margin of the wings, sometimes free and sometimes soldered to other appendages. The greatest development is found in certain of the Sphingidae where the maxillae do not extend beyond the caudal magin of the wings but the extra length is taken up in a loop at the proximal end which forms the so-called "jug handle" of Sphinx pupae. The maxillae are always measured on the meson from the caudal margin of the labrum to their distal end and are usually compared in length with the wings which are measured from the caudal margin of the labrum to their caudal margin on the mezon.

Maxillary PaIp1.- Each palpus is represented on each side by a subrectangular or triangular area caudad of the eyepleces and lying along the cephallc margins of the prothoracic and mesothoraclc legs, frequently reaching as far mesad as the proximo-lateral angle of each maxilla. The normal position of 


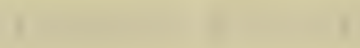

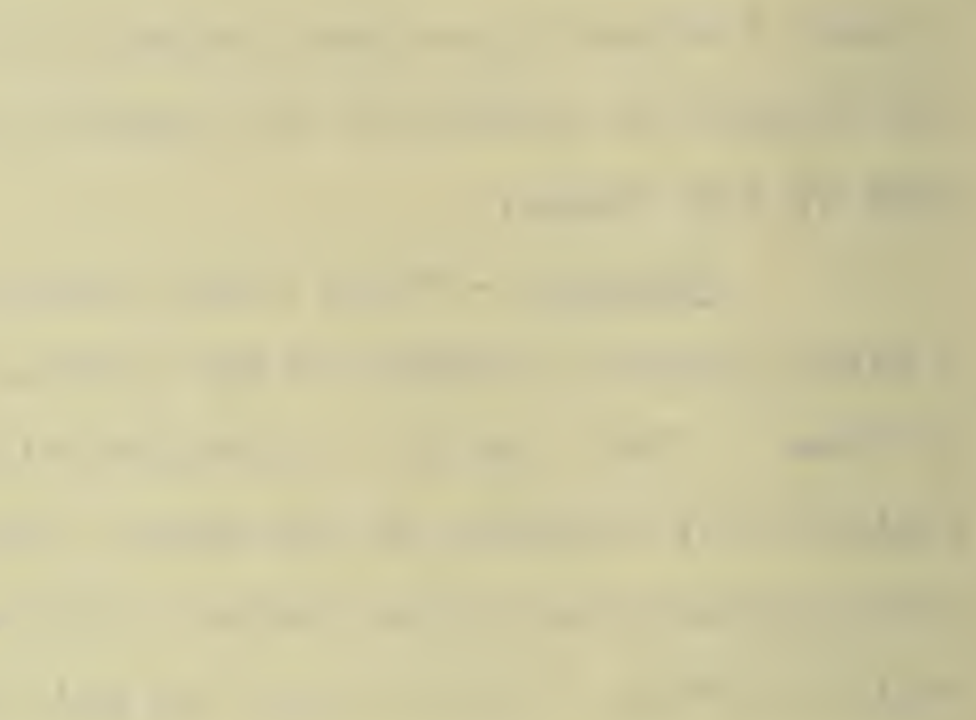


these appendages is discussed under the family Eriocraniidae and shown in part in Fig. I; mp. They may also be seen in Figs. 28, $30,32,36,38$; mp. Structures which may be maxillary palpi are found in the genus Gracilaria (Fig. 47). The peculiar extensions of the maxillae in the Cossoidea and Eucleoidea are not considered as maxillary palpi (Fig8. 15, 19, 23).

\section{Thorax}

The three segments of the thorax are always distinct. They are only visible on the dorsum, because the ventral and lateral surfaces are covered by the appendages.

Prothorax.- This segment probably varies more in size and shape than any of the others. There are some forms as in the Gracilarioidea, Yponome $u$ toidea and others where the prothorax is very short on the meson (Figs. 53,56,58,64; p) or even invisible (Fig. 54), but is very wide at each lateral margin. It is longer in the Galleridae and certain families of Noctuoidea than any other pupae examined.

Prothoracic Lega.- These lie adjacent to the maxillae at their proximal end. The coxae are frequently excosed, especially in generalized pupae where the appendages are free (Fig. I, 11, 19; cxI) and dissection frequently showed a segment cephalad of the coxa, the trochantin, although there was no distinct suture indicated on the exterior, this being covered by the mouth-parts. The trochanter is a very small segment usually found at the caudal end of the femur when the leg is folded and would therefore be generally concealed by the tibla and tarsus. The femur extends from the trochanter cephalad to the caudal margin of the head. 

It is frequently concealed by the tibia and tarsus which are the only portions of the prothoracic leg always visible, but they are often shoved slightly laterad so that a portion of the femur is exposed (Figs. $1,8,24,32,36 ; f l$ ). The tibia and tarsus are seldom divided by a suture except in generalized pupae, where all the segments, even of the tarsi are readily distinguished (Figs. 1 , $8,24,32,36,45 ; 1)$.

Prothoracic Spiracle. - This is usually located on the dorsum between the prothorax and mesothorax sunk deep in the conjunctiva between the segments with an opening adjacent to the caudo-lateral angles of the prothorax. Its primitive position appears to have been much farther ventrad (Fig. $2 \mathrm{ps}$ ) and it is found in this position in the specialized Trichoptera. It retains this primitive position in the superfamily Eucleoidea and in the family Nepticulidae. The caudal margin possesses curious modifications in different families in the way of elevated ridges, tubercules, setae, etc., and in some of the Papilionoidea, particularly in the familieg Hesperiidae and Lycaenidae there seems to be a definite external closing apparatus in many of the genera. Sometimes there is a tuft of setae, in others a plug or plate of some rhat honeycombed appearance.

Mesothorax. - The mesothorax is usually considerably longer than the other segments in specialized forms, but in generalized pupae all the segments are more nearly equal.

Mesothoracic Legs. - These are folded in exactly the same manner as the prothoracic legs and the femora are very seldom exposed, but may be seen in Fig. 1 ; 12 . The coxae are frequently visiole (Figs. 1,$48 ;$ cx2). The mesothoracic legs 

are usually longer than those of the prothorax. The tibia and tarsus of each leg are always exposed (Figs. 1, 8, 23, 30; 12). They lie on the venter between the prothoracic legs and the antennae.

Mesothoracic Wings. - The wings of the mesothorax almost conceal those of the metathorax, except in the most generalized forms where the appendages are free. In most families they are the only wings visible on the ventral surface (Figs. 1, 8, 16, 17; พI).

Tegulae.- The tegulae are the large lobes which cover in the adult, the proximal end of the wing. They do not form separate pupal pieces but are indicated in some pupar (Fig. $2 ; t)$. The tegulae are referred to by many authors es the patagia. The patagia are lobes of the pronotum which project over the mesonotum.

Alar Furrows.- The furrows along each lateral margin of the mesonotum are designated as the alar furrows. They are best developed in the Aegerioldea (Fig. 37; af) although there are distinct depressions in many families.

Axillary Tubercules. - In the genera Tropea and Telea of the Saturnildae, there is found a large tubercule at the base of each wing, with sometimes an additional smaller one. The edges of these tubercules are strongly chitinized and somewhat roughened and serve to cut the cocoon for the emergence of the moth. They are probably assisted in this by the peculiar development of the wing sclerites of the preimago, which protrude into these tubercules and are sometimes found to have cut the pupal skin at the apex of the tubercule. 

Metathorax. - This segment is longest in generalized forms where its length is nearly equal to that of the mesothorax.

Metathoracic Legs.- The tibiae and tarsi of the metathoracic legs are never normally exposed for their entire length but are concealed by the other appendages excepting at their distal end. Only a small portion is visible in specialized pupae, and the appendages are often wholly concealed (Figs. 1, 8, 36, 45; 13).

Metathoracic Wings. - These are usually covered by the mesothoracic wings excepting for a narrow strip along their dorsal margin. In a few families a narrov strip of the metathoracic wings is visible on the ventral surface caudad of the mesothoracic wings (Figs. 2, 9, 12; $w_{2}$ ).

The Abdomen

The abdomen consists of ten segments of which three, segments 8-10 are always "fixed", that is, they possess no power of independent motion. In the generalized forms there is motion possible between all of the others. A segment is sald to be movable when there is movement between its caudal margin and the segment caudad of it. In many pupae the movable segments are capable of being "telescoped" so that only their caudal margins are visible.

Proleg Scarg. - The scars of the larval prolegs are found on the ventral surface near the meson (Fig. 11, psc) and are often conspicuous.

Tubercule Scars. - Those families in which the larvae have prominent tubercules show very definite scars in the pupae. These are especially noticeable in the Saturnildae. 

Setae.- There are usually setae present on the abdomen and these are arranged much as those of the larvae. They are often very inconspicuous, otherwise they might furnish good taxonomic characters. There is often a dense covering of secondary setae over the entire surface as in some gelechiids and 1asiocampids. The Pterphoridae retain a spiny armature similar to that found in the larvae.

Spines.- These are found covering the dorsum of the abdomen in generalized pupae (Fig. 49) and larger ones are also found at the caudal end of the body (Figs. 27, 31). They are arranged in rowrs on the segments in Tineoidea and Tortricoidea (Figs. 27, 31, 39, 42).

Flanged Plateg.- In the pupae of borers the flanged plates are best developed, but are found in other pupae as well. Figure 9. shows them well developed on the dorsum and also shows a well developed ventral plate on the seventh segment. They are usually developed along the cephalic margin of the segment and prevent the telescoping of the segments.

Genital Openings. - In the male the genital opening is situated on the ventro-meson of the ninth abdominal segment. It is usually either a slit-like opening as in Fig. 5 without any adjacent elevations, or with a distinctly elevated tubercule on each side as in Fig. Sgo and occasionzlly is situated in a slight depression. In the females there are two openings which may or may not become confluent. These may be mere rounded pores or slit-like openings and are associated apparently with the elghth and ninth segments. The boundary lines between segments 8 and 9 , 

and 9 and 10 are rarely distinct on the meson and where they are distinct it seems as if the caudal opening were associated with the tenth segment. In the more specialized pupae the caudal margins of the eighth and ninth segments are more strongly curved cephalad near the meson than in the male (Figs. 34, 44go) and the segments are dove-tailed together. The presence of the two openings apparently represents the more generalized condition (Figs. 7, 17, 28). They are confluent in Podosesia gyringae (Fig. 36) and Archipg argyrospila (Fig. 44).

Anal Opening. - This is always situated on the meson near the caudal margin of the tenth segment. It sometimes shows as a circular opening (Fig. 7,ao) but is usually slit-like (Figs. 8, 14, 17). It is usually surrounded on each side with several prominent wrinkles or folds.

Anal Rise.- The anal opening is frequently situated on the summit of a mound-like elevation know as the anal rise. The setae on this rise are very conspicuous in certain families of Tortricoidea (Fig. 38, ar).

Abdominal Spiracles.- Spiracles are always present on abdominal segments 1-8. The spiracles of the first segment are covered, so far as observed, by the wings, except in the superfamily Eucleoidea and the family Nepticulidae. The spiracles of the eighth segment are never functional and show no distinct opening.

Spiracular Furrows. - On the cephalic margin of the movable segments cephalad of the spiracles are found furrows which frequently extend almost to the meson on both dorsal and ventral aspects. They occur in several families, as the Liparidae and 
Geometridae, but are best developed in the Sphingidae where they are lacking in but a few genera. They are usually separated by sharply carinated ridges and are of various types but their function is unknown.

Cremagter. - The cremaster is a prolongation of the tenth segment and is not found in the more generalized pupae. It was homologized by $C$. V. Riley with the suranal plate of the larva. It is of various lengths and shapes and often bears setae at the distal end. Two types of cremaster are show in Figs. 41 and 44 , cr. Its length is measured on the ventral surface from its junction with the curve of the ventral surface of the body as in Fig. 44 where ab represents the cremastral length.

\section{CLASSIFICATION}

As no classification of the Lepidoptera based on pupal characters has been attempted hitherto, consequently nothing had been done to determine what characters were of value in defining superfamilies, families and genera. It has been necessary, therefore, to base specific,generic and other characters on those found in such material as could be secured. The present investigation has been limited by the difficulty in obtaining representatives of many groups. It is not expected, however, that the tables and descriptions given here will do more than furnish a basis for later work upon the subject. It is hoped that these will call the attention of entomologists to the vast posililities opened up by the use of the taxonomic characters available in pupae. More than that, further studies on the different groups will make it possible to identify the insect at another otage in 
its life cycle which cannot fail to be of importance in the case of our economic species.

\section{Analytical Table of Superfamilies}

A. Mandibles present, large, functional, decussating and extending beyond the lateral margins of the body.

MICROPTERYGOIDEA

AA. Mandibles, if present, never large, parallel or subparallel and usualiy represented by small elevated tubercules.

B. Movable abdominal segments present cephalad of the fourth, or if no segments are movable cephalad of the fourth then the appendages free from each other and never soldered to the body wall, and the vertex longer than the prothorax measured on the meson.

C. True maxillary palpi never present, but sometimes lateral extensions of the maxillae (Figs. 15 and 19).

D. Body heavily chitinized and bearing transverse rovs of spines or setae on the abdominal segments; spiracles never visible on the first abdominal segment.

E. Mesothorax never more than twice the length of the metathorax; seventh abdominal segment with a large flanged plate on the ventral surface; antennae filiform, short, only reaching caudad to the proximal end of the mesothoracic legis; head sutures all present except the clypeo-labral.

HEPIALOIDEA

EE. Mesothorax always more than twice the length of the metathorax; seventh abdominal segment never with a large flanged plate on the ventral surface; antennae, if present, pectinate and reaching farther caudad than the proximal end of the mesothoracic legs; none of the head sutures distinct for the whole length.

COSSOIDEA

DD. Body never heavily chitinzed, and never bearing rows of spines or setae on the abdominal segments; spiracles always visible on the first abdominal segment.

EUCLEOIDEA

CC. True maxillary palpi usually present; if absent, then the appendages free from each other, or the vertex longer than the prothorax on the meson, or the body possessing a distinct cremaster. 

D. Dorsum of abdomen with a covering of small spines, usually over the entire length of the segment and not arranged in distinct rows; if spines are arranged in rows then the maxillary palpi are absent; vertex always longer than the prothorax on the meson.

GRACILARIOIDEA

DD. Dorsum of the abdomen with a distinct row of spines along the cephalic margin of the segment, with or without a caudal row; spines seldom found elsewhere on the segment but, if present, then the maxillary palpl present and well developed.

E. Caudal row of spines never present on the dorsum of the abdominal segments; maxillary palpi always present.

TINEOIDEA

EE. Caudal row of spines alvays present on the dorsum of the abdominal segments; maxillary palpi usually present.

F. Distinct cremaster never present; setae never present on the anal rise; wings narrow and pointed; large spines always present on the venter of the tenth abdominal segment.

AEGERIOIDEA

FF. Distinct cremaster usually present, if not then setae present on the anal rise; wings broad and never pointed; large spines never present on the venter of the tenth abdominal segment.

TORTRICOIDEA

BB. Movable abdominal segments never present cephalad of the fourth; appendages never free from each other and usually soldered to the body wall.

C. Lobes indicating the presence of pillifers always present, except in Gallerinae (Fig. 69) and Oeneinae (Fig. 80).

D. Maxillary palpi usually present, if absent, then abdominal segment seven is movable in the male, the body covered with a spiny armature and both prothoracic and resothoracic legs extending cephalad cetween the eyejpieces and the antennae, the former reaching nearly to the cephalic margin of the glazed eye, or a deep furrow lined with setae present on the dorsum between the ninth and tenth abdominal segments; antennae never clubbed at the distal end; femora of the prothoracic legs usually visible; labial palpi very seldom visible, except as a small triangular or polygonal area caudad of the labrum and between the pililfers. 

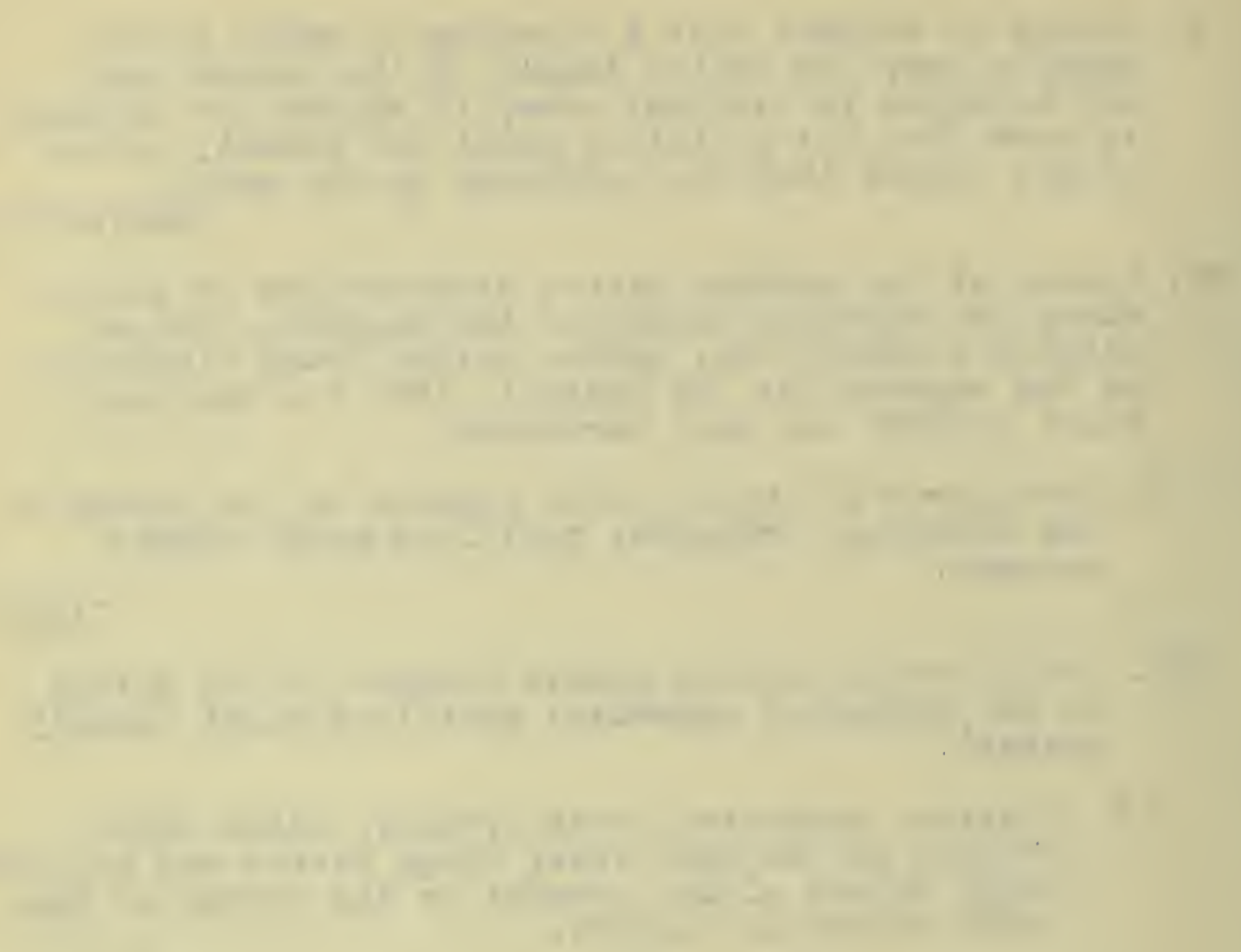

f
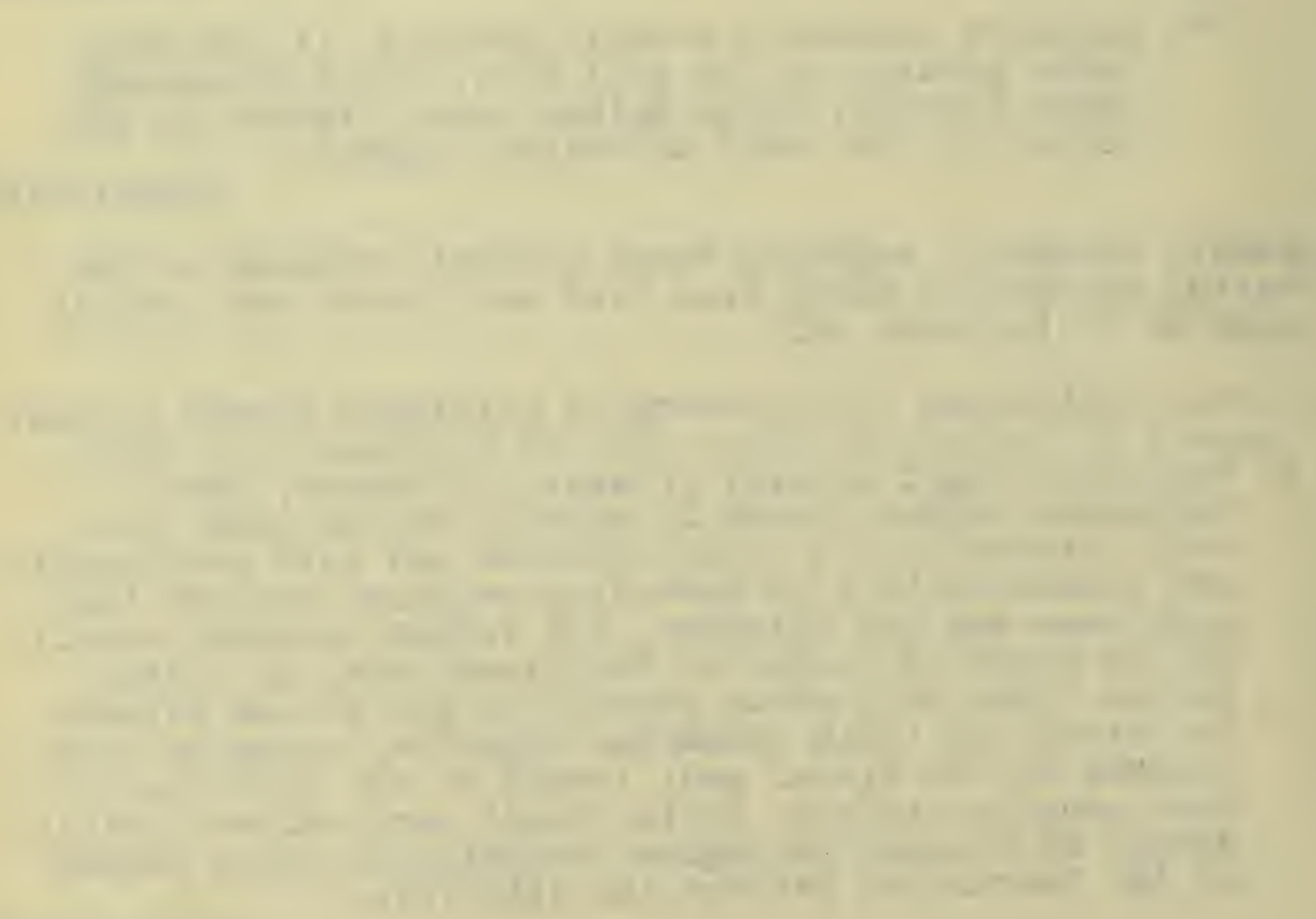
DD. Maxillary palpi never present; antennae always clubbed at the distal end; femora of the prothoracic legs never visible; a deep furrow lined with setae never present on the dorsum between the ninth and tenth abdominal segments; labial palpi never visible except as small triangular or polygonal areas caudad of the labrum between the pillifers and often entirely concealed.

PAPILIONOIDEA

CC. Lobes indicating the presence of pilfifers never present.

D. Mesothoracic wings on the ventral surface at meson usually extending considerably beyond the caudal margin of the fourth abdominal segment, if not, then the body depressed, mostly in the thoracic region, the incisions between the movable segments very deep on the dorsum and venter and less deep at the lateral margins and the caudal part of the antennae always adjacent on the meson for a considerable distance; abdominal segments 1-4 usually longer than the other segments; epicranial suture always present.

E. Maxillary and labial palpi present and well developed, and a large portion of the prothoracic femora always exposed; if maxillary palpi are not present then the fronto-clypeal suture never visible; prothorax distinctly shorter on the meson than at each side, so that each half is triangular in outline; appendages aoldered to each other but not to the body wall; fronto-clypeal suture never visible; antennae with the caudal portion very rarely touching and not moniliform in appearance.

YPONOMEUTOIDEA

EE. Maxillary palpi usually present, but labial palpi and prothoracic femora seldom visible, if visible, then the fronto-clypeal suture distinct; prothorax usually the same length on the meson and at each side so that each half is subquadrangular in outline; appendages usually soldered firmly to each other and to the body wall; body usually ovate in outline, broadest in the thoracic region and usually strongly depressed; frontoclypeal suture usually visible; antennae usually moniliform in appearance, the caudal portion always adjacent on the meson, usually for some distance; if only touching, then the fronto-clyoeal suture is distinct.

GELECHIOIDEA

DD. Mesothoracic wings on the ventral surface of the body at meson rarely extending beyond the caudal margin of the fourth abdominal segment; if so then maxillary palpi never present; abdominal segments $1-4$ or $1-5$ rarely longer than the other segments; epicranial suture seldom visible. 

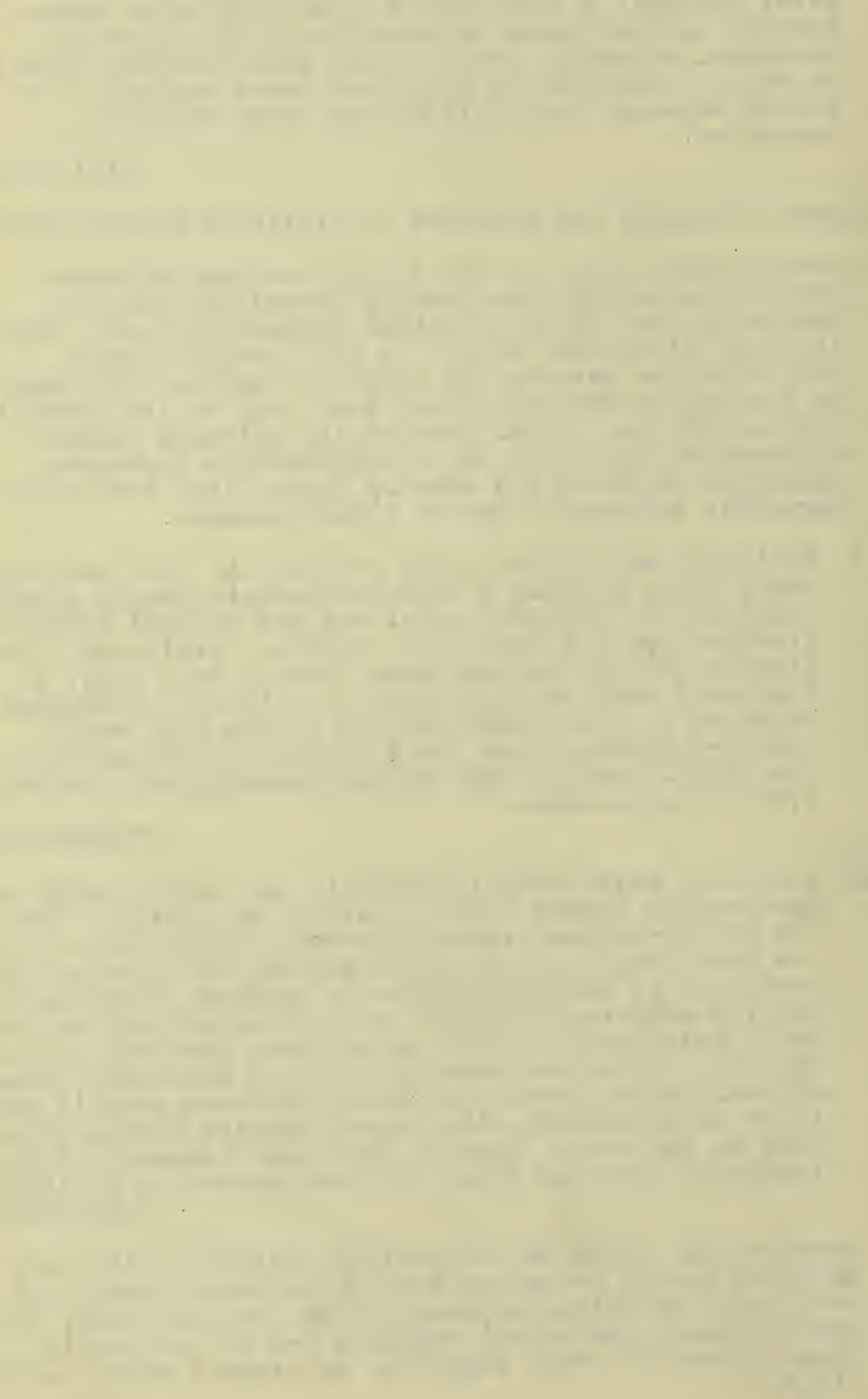
E. Labial palpi usually present and well developed and from one-fourth to one-fifth the length of the wings, if not visible then the body usually shaped as in Fig. 104, the abdomen with setae arranged around the larval verrucae, and usually flanged plates on the ablomen and a cremaster present, or with a more or less dense covering of setae never arranged around larval verrucae, the body never of the shape in Fig.104 and flanged abdomen nor a distinct cremaster.

F. Labial palpi usually present and well developed and the prothoracic femora usually exposed, or if not then both prothoracic and mesothoracic legs reaching cephalad to the eye-pieces; if both labial palpi and prothoracic femora are wanting then the body of the type in Fig.104, the abciomen with setae arranged around larval verrucae, flanged plates usually present on the abdominal segments and a distinct cremaster often present; body never with a more or less dense covering of setae, except arranged as mentioned above; maxillary palpi occasionally present.

NOCTUOIDEA

FF. Labial palpi sometimes present, body never with a cremaster and always with a more or less dense covertng of setae which are never arranged around larval verrucae; prothoracic femora never exposed; maxillary palpi never present.

BOMBYCOIDEA

EE. Labial palpi never visible, unless represented by small triangular or polygonal areas caudad of the labrum; body very seldom with viaible setae.

F. Suture extending between the proximal ends of the antennae and separating the clypeus and front always present and very distinct; antennae never broady pectinate so that the width is one-fifth of the length; spiracular furrows often present.

G. Antennae usually considerably broader near the proximal end, their greatest width greater than that of the prothoracic legs; antennae usually more than three-fourths the length of the wines, if not, then the epicranial suture is present, or the cremaster is wanting, or if present bifurcate at the distal end or bears hooked setae; dorsum of the abaomen usually with a deep furrow between the ninth and tenth segments; scar of a caudal horn never present on the dorsum of the eighth abdominal segment; labial palpi. as small triangular or polygonal areas caudad of the labrum.

NOTODONTOIDEA 

GG. Antennae rarely very much broader near the proximal end, usually filiform, their greatest width seldom greater than that of the prothoracic legs, if so, then the cremaster is never wanting, nor bifurcate, nor with hooked setae; antennae never more than three-fourth the length of the wings; epicranial suture never present; dorsum of the abdomen never with a deep furrow between theninth and tenth segments; scar of a cavdal horn usually present on the dorsum of the eighth abdominal segment; labial palpi never vigible.

SPHINGOIDEA

FF. Suture between the proximal ends of the antennae and separating the front and clypeus obsolete for the greater part of its length; antennae always broadly pectinate and the width at least one-fifth of the length and often vider; spiracular furrows seldom present.

SATURNIOIDEA

\section{A. Pupae with Functional Mandibles.}

Among the Trichoptera, from which the Lepidoptera are supposed to have descended, and which are known to be very closely related, there are many pupae which have functional mandibles. They function, though, merely to assist the pupa to escape from the cocoon. Among the generdized Lepidoptera the pupae of one superfamily, the Micropteryeoliea, have large mandibles which serve the same purpose as in the Trichoptera.

Superfamily Micropterygoidea

The most generalized lepidopterous pupae known belong to the superfamily Micropterygoidea, which includes two families, the Micropterygidae and the Eriocranidae, characterized by the presence of functional mandibles. Except for fragments of the head, no pupae of the lifiopterygidae have been described, but they are undoubtedly the most generalized, because they possess 

functional mandibles in the adult.

The first complete life history of any American species of Eriocraniidae was worked out by Busck and Boving and published in the proceedings of the Entomological Society of Washington in 1914 (Vol. XVI, pp. 151-163). These authors gave a short description of the pupa and included some excellent figures. A more detailed description is given here as this species furnishes a working basis for the study of ali other lepidopterous pupae. This was made possible by the generosity of Dr. I. O. Howard, Curator of the U.S. National Museum, who presented some excellent material of Mnemonica auricyanea mlsm. collected this year by Mr. August Busck at Falls Church, Va.

The pupae of this species (Figs. 1, 2, 3) are very small, averaging $3 \mathrm{~mm}$. in length in the males and $4 \mathrm{~mm}$. in the females. The body is covered by a thin transparent cuticle, which shows all the inaginal parts in mature pupae making it exceedingly difficult to distinguish pupal structures from similar structures in the adult. It is also very difficult to determine the number and position of the setae.

The head shows all the sutures usually present in generalized insects. The vertex is short, the epicranial suture fairly distinct and extending to the lateral margins of the head. The fronto-clypeal suture extends transversely between the caudolateral angles of the antennae. The front bears two long straight setae on each side the meson about half way between the antennae and the cephalic margin of the head. In the midile of the cephalic aspect, between the antennae arises a long, fleshy, beak-like 

projection which contains the long tuft of hairs present in the adult. Just caudad of the front 1 s the clypeus and laterad of these are the genae in their usual position for the Lepidoptera. The suture between the clypeus and labrum is broad and somewhat chitinized and closely appressed to its ental surface is the tentorium to which the mandibles are attached. The labrum is a large fleshy projection bearing on its ectal surface six paire of very long setae which extend beyond the lateral margin of the body, and on the ental surface two groups of much shorter setae, which project slightly beyond its caudal margin. All of the appendages of the head are free. The labial palpi are rather short, with three segments and are somewhat enlarged and blunt at the distal end. The mandibles are exceedingly large and are attached to the ental surface of the clypeus extending beyond the lateral margin of the body. They are heavily chitinized and serrate along the cephalo-lateral margin. The distal end is broadened and thickened, somewhat circular in outline, concave and strongly toothed. The maxillae are short and the halves are widely separated. Each half is strongly bent near the distal end, which is directed cephalad and mesad. The maxillary palpi are long, apparently with six segments, and pass from the mouth dorsad and then out towards the lateral margin of the head, making a series of curves which finally bring them between the eyes and the antennae. The distal end is folded close to the body and lies just caudad of the eye. The antennae show a long pedicel with many shorter segments and extend for more than half the length of the wings. 

The thoracic segments are all more or less movable. The prothorax is short, strongly elevated and moves freely, the greater part of its exposed portion being conjunctiva. The mesothorax and metathorax are nearly equal in length, but seem to possess little power of independent motion. On the dorso-meson of these two thoracic segments and the first abdominal segment is found a strap-like cuticular thickening which is apparentiy for strengthening the thorax. The tegulae are indicated by the dotted lines in Fig. Z because they do not seem to be distinct pupal structures. The thoracic appendages are also free. All of the corae are visible and usually the femora of the prothoracio and mesothoracic legs. The metathoracic legs are usually hidden beneath the wings, except at the distal end, which normally curve around the caudal end of the body. The wings never extend to the caudal margin of the body.

The first seven abdominal segments are movable in both sexes. The remaining segments are not distinctly sutured and possess no power of independent movement. The genital openings are rather difficult to locate. That of the male is found as a slit-like opening on the ventro-meson of the ninth segment (Fig.4). There are tiro openings in the female (Fig. 7, go) apparently located on the ventro-meson of the eighth and ninth abdominal segments.

The tenth segment is longer in the female than in the male, presumably on account of the ovipositor. The females always have the eighth, ninth and tenth segments curved ventrad and closely appressed to the ventral surface of the body. This 

is show slightly separated in Fig. 2 and Figs. 6 and 7 show dorsal and ventral views of these caudal segments, and Figs. 4 and 5 show the same segments of the male. The anal opening in both sexes is found near the cardal end of the body on the tenth segment. The spiracles are small, circular, and not produced. The prothoracic spiracle is situated in the conjunctiva connecting the prothorax and mesothorax. Functional abdominal spiracles are visible on segments $2-7$. The dorsum of the abdomen is practically covered by very minute spines arranged in groups.

Specieg examined:

Vinemonica auricyanea $\mathbb{W} \mathrm{sm}$.

AA. Pupae without Functional Mandiles.

This includes all the superfamilies of Lepidoptera known, except the Micropterygoidea. Many of the other families possess mandibles, but they are functionless, and only indicated as small paraliel tubercules or lobes.

B. Generalized Pupae without Naxillary Palpi.

The Hepialoidea, together with the Cossoidea and Eucleoidea, differ from all other generalized pupae possessing free abdominal segments cephalad of the fourth, because of the absence of the maxillary palpi. Some of the families included here possess lateral proiongations of the maxillae which resemble maxillary palpi (Figs. 15 and 19) and have been considered as such by some authors. These prolongations never separate from the maxillae at dehiscence and dissection has failed to find any maxillary palpi present in the mature pupae. None of these superfarilies possess all of the sutures found in the head of the 

generalized type and none of them show the long jointed antennae Fresent in the Eriocraniidae.

\section{Superfamily Hepialoidea}

This includes a single family Hepialidae, the larvae of all the species of which are borers. The pupae in thiscountry are of rare occurrence and their larvae are borers in the stem of shrubs, or trees. In Europe some of the species are abundant and injurious. The specimens of Sthenopis thule were obtained through the courtesy of Mr. J. M. Swaine of the Canadian Department of Agriculture who obtained them from the stems of willow at MacDonald College, Quebec.

\section{Family Hepialidae}

The pupae of this family are very generalized as to the number of sutures present in the head, the number and arrangement of appendages, the comparative length of the mesothorax and metathorax and the nearly equal length of the first seven abdominal segments. These are easily seen in Figs. 8-10 and need no further description. They are, however, exceedingly specialized as to the chitinization of the body, the spines, toothed ridges and cutting plates on the abdominal segments and more than all to the soldering dow of alI the appendages to each other and the body exactly as in the most specialized of pupae. The head, thoracic segments and the first two abdominal segments are firmly soldered together, but abdominal segments $2-7$ are free in the male and $2-6$ in the female.

The only consolidation of the head parts is that of the 

clypeus and labrum between which the suture has been lost. The antennae, as well as all the other appendages are very short in comparison with the length of the body. These pupae are of considerable size, that of Sthenopis thule being about $30 \mathrm{~mm}$. In length. The larvae are borers and the pupae have special adaptations for cutting their way to the surface. The most peculiar of these adaptations is the ventral plate on the seventh abajominal segment, best seen in Fig. 9 which has not been found in any other pupae examined. The sharp ventral projections on the front also serve as cutting surfaces, but similar projections are found in many pupae particularly among other species whose larvae are borers and in very many of the leaf-mining species. The opening of the prothoracic spiracle has reached the normal position for most lepidopterous pupae, between the prothorax and the mesothorax at the caudo-lateral angles of the former. The genital opening is found in the male on the meson of the ninth segment between two slightly elevated tubercules. In the female there is a single opening apparently on the eighth segment.

Species examined:

Sthenopis thule strecker.

\section{Superfamily Cossoidea}

The pupae of this superamily are less generalized as to head parts than the Hepialoldea, but nevertheless resemble them very closely in size, shape and arrangement of the appendages, in the number of free segments, and in the fact that all the apperdages are firmly soldered to each other and to the body. 

The antennae, however, are of a different type, being pectinate in the Cossoidea. The metathorax varies considerably from the generalized type being very much shorter so that the mesothorax is about four times its length, measured on the median line. Although many of the pupae of this superfamily are borers, the ventral plate of the seventh abdominal segment which was so distinct in the Hepialoidea, is not present. All of the pupae have some of the body segments armed with spines and strongly toothed chitinized ridges, and a strong ridge or projeotion is generally present on the head.

The families may be separated as follows:

A. Abdorninal segments 2-6 movable in the female and $2-7$ in the male; dorsum of abdominal segments armed with a row of sharp spines on the cephalic margin and a row of setae, which are directed cephalad, on the transverse conjunctiva at the caudal margin; females without wings and antennae and larva-like in appearance.

Psychidae

AA. Abdominal segments 3-6 movable in the female and $3-7$ in the male; dorsum of abdominal segments armed with a toothed ridge along each margin; sexes similar.

Cossidae

\section{Family Psychidae}

In this family there are no suturesapparent on the head except between the clypeus and labrum and the mandibles. The antennae are short and pectinate. The prothorax is longer and the metathorax much shorter than in the Hepialoidea, to which these pupae show many resemblances. The dorsum of the abdomen has toothed chitinized riciges along the cephalic margin of some of the segments and rows of setae along the caudal margins on the transverse conjunctiva. The caudal end of the body bears two 



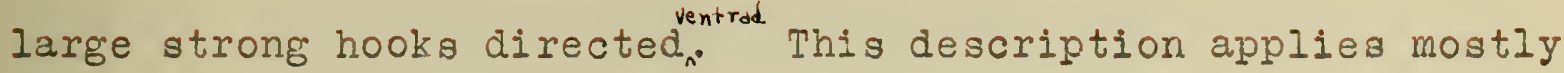
to the males (Figs. 12-13) as the females are entirely different as seen in Fig. 14 .

The females never leave the cocoon during their entire Iife and have no provision for locomotion, even in the adult. It is an astonishing fact that no pupal wings are developed because in all other families, where the adult females are apterous, the pupal wings are always developed, sometimes as much so as in the males. Neither are thers any pupal antennae present, no eyepieces, nor traces of maxillae. The labrum, labiel palpi and mandibles show very distinctly, all being considerably elevated. The legs are scarcely developed and are represented by transverse chitinized elevations on the venter of the thoracic segments. The abdorninal segments are much as in the male. They show on the venter the proleg scars, on the dorsum the rows of toothed chitinized ridges and setae, but the body setae are much smaller and difficult to distinguish and are not represented in the figure. A single genital opening is found in the female on the eighth abdominal segment. No hooks are present at the caudal end of the body. The abdominal spiracles are present on the first eight abdominal segments, but there is no opening for the prothoracic spiracle visible in either sex. The only genera avalable for study were Thyridopteryx and oiketicus. These resemble each other very closely and the differences between the pupae can hardly be considered as generic. The pupae of oiketicus are larger and stouter, the males exarnined averaging 18ma. in length, while those of Thyridopteryx were slenderer and only $15 \mathrm{~mm}$. in 

length. The two genera may be separated thus:

A. Abdominal segments $2-6$ with a caudal row of setae, the row on the sixth interrupted and shorter than the others; caudal spines stout and simple; spiracles scarcely produced beyond the surface of the body except at their cephalic mareins.

Thyridopteryx Stephens

AA. Abdominal segments $2-5$ with a caudal row of setae, the row on the sixth never present; caudal spines slender and with a distinct tooth; spiracles distinctly produced beyond the surface of the body.

Oiketicus Guilding

Species examined:

Thyriopteryx ephemeraeformis Haworth Oiketicus abbotii Grote

\section{Family Cossidae}

The Cossidae are borers and seem to be very closely related to the Hepialidae, although they resemble them less than do the Psychidae. This family has segments $3-7$ of the abdomen free in the male and $3-6$ in the female. There is another sexual difference to be noted, viz., the presence of an extra row of spines on the abdornen of the male. In this sex the seventh segment has two rows of spines and the succeeding segments one, in the female the sixth is the last segment with two rows, the remaining caudal segments having one. The epicranial suture is not distinct in any species, but at dehiscence, Prionoxystus robiniae showed a small piece of the vertex on each side the meson and this with the conjunctiva bears the eye-pieces. The lateral part of the fronto-clypeal suture is distinct and the clypeo-labral suture is always visible.

This family is usually divided into subfamilies of which two, the Cossinae and Zeuzerinae, are represented here. Figure 15 
shows the ventral surface of the head and its appendages, a member of the Cossinae, the arrangement of the other parts being the same as in the Zeuzerinae Figure 16.

The maxillae have prominent lateral projections in Cossinae which resemble maxillary palpi. These always adhere to it at dehiscence and are not found in the Zeuzerinae. Only one genus of each subfamily was studied. The pupae are very large, that of Prionoxystus robiniae being $45-50 \mathrm{~mm}$. in length and Zeuzera pyrina $30-35 \mathrm{~mm}$. The two genera may be separated as follows:

A. Head without a prominent cephalic projection; maxillae with an apparently segmented lateral projection on each side resemoling a maxillary palpus, but adhering to the maxillae at dehiscence; antennae more than half the length of the wings and gradually tapering; abdominal segments with the cephalic ridges much larger than the caudal ones and armed with long even teeth.

Prionoxystus Grote

AA. Head with a prominent cephalic projection; maxillae never with an apparently segmented lateral projection on each side; antennae less than one-half the length of the wings and narrowed abruptly near the midale; abdominal segments with the cephalic and caudal ridges similar, the teeth short and uneven.

Zeuzera Latreille

Species examined:

Prionoxystus robiniae Peck.

Zeuzera pyrina L.

Superfamily Eucleoidea

The pupae of this superfamily are quite specialized as

to the head parts, the epicranial suture being the only one

visible in all the families. They have followed a very different line of development from the Cossoidea and Hepialoidea, because all 


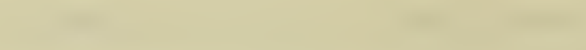

$+2$
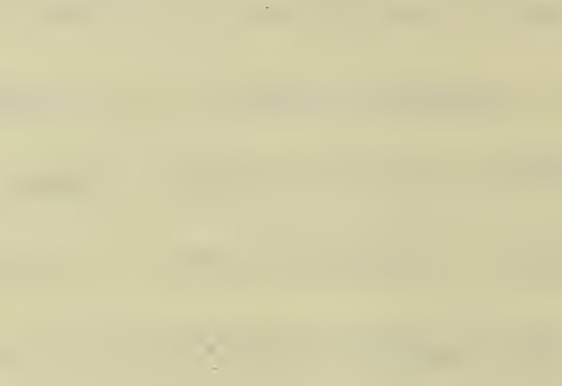

-
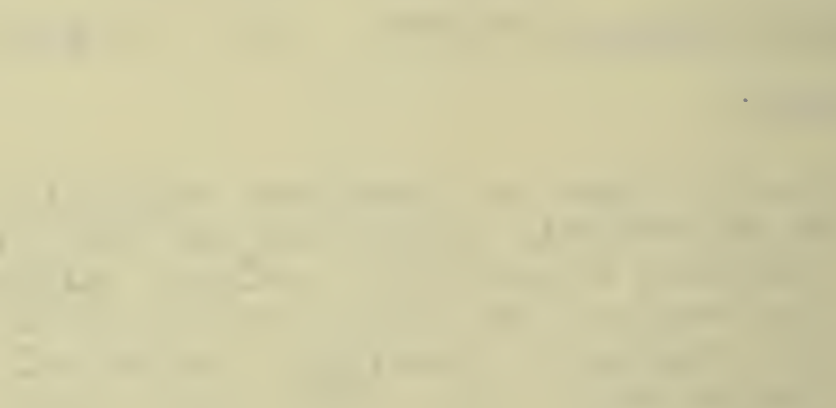

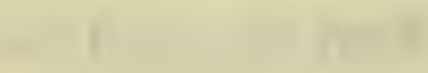

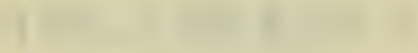


of the generalized families retain freedom of motion between all the segments, except those fixed at the caudal end of the abdomen, and between all of the appendages. The cuticle is very thin and transparent in almost all genera and the dorsum of the abdominal segments in all has a covering of small spines over the greater part of the segment. All of the families show the spiracles distinctly on the first abdominal segment. The only other family in which this was observed, the Nepticulidae has a mell developed maxillary palpus. The prothoracic spiracle of each side is in a rather unusual position in this superfamily. The opening is on the dorsum in the normal position, and is very large with a strongly arched cephalic nargin, but the spiracle is on the ventral surface directly under the sculptured eye-piece in Megalopygidae and Eucleidae, and a little farther laterad in Pyromorphidae so that it comes partly under the antennae. The spiracle with the adjoining parts slightly pushed aside, to show their relation is seen in Figure 21. The family Pyromorphidae is more specialized than the other two and therefore differs considerably, but shows evident relationship to them.

The three families included here may be separated as follows:

A. Dorsum of abdominal segments with spines on the cephalic part and a covering of coarse setae on each caudo-lateral part which does not usually extend to the meson; maxillae simple quadrangular pieces, without any lateral prolongations; a large conical tubercule caudad of each abdominal spiraole on segments 2-6; mesothorax never extending caudad to the first abdominal segment. 

AA. Dorsum of abdominal segments with short spines but never with a covering of coarse setae on any part; tubercules never present caudad of any of the abdominal spiracles.

B. Labial palpi present; mesothorax with a long mesal lobe reaching on to the first abdominal segment; maxillae always less than half the length of the wings.

Eucleidae

BB. Labial palpi absent; mesothorax never with a long mesal lobe reaching on to the first abdominal segment; maxillae more than half the length of the wings.

Pyromorinidae

Family Megalopygidae

The Megalopygidae have the head and thoracic segments free, also abcominal segments $1-7$ in the male and $1-5$ in the female. The appendages are entirely free from each other and the body-wall. The body is soft and covered with a thin, delicate, transparent cuticle which is slightly chitinized. There are always setae on the dorsum of the abdominal segments as well as spines. The setae are found on each side the meson on the caulal half of all the aegments. The epicranial suture is distinct but all the other head sutures are obliterated. The front has a distinct projection and the mandibles show as distinctIy elevated tubercules. The size and arrangement of the parts way be seen in Figs. 17 and 18. This family together with the Eucleidae possesses a very peculiar eye-piece. Chapman in 1894 (Trans. Ent. Soc. London 94 p. 349) called attention to this structure and called it the "eye-flange". This eye-piece, in reality the sculptured portion, is free along its lateral and caudal margins and extends well out on to the antennae. It is, however, much more wrinkled and sculptured than any other portion 

of the body. These move up and down in living pupae during respiration and allow one to see the prothoracic spiracle underneath. The mesothorax possesses some well defined alar ridges and its caudal margin extends in a broad curve nearly to the caudal margin of the metathorax. The large conical tubercules are found caudad of the spiracles on abdominal segments $2-6$. The body of Lagoa crispata Packard, the only species studied is strongly arched on the dorsum of the abdomen and is short and thickly set. Its length is about $18 \mathrm{~mm}$. and the greateat breadth $10 \mathrm{~mm}$.

\section{Family Eucleidae}

The Eucleidae retain the same movable segments as the family Hegalopygidae which they strongly resemble. The pupae of Eucleidae are usually only half the size of these, averaging about $9 \mathrm{~mm}$. In length. They also retain the same head sutures but, as in Prolimacodeg, they often show a distinct furrow marking the position of the lateral part of the fronto-clypeal suture. The eye-pieces are identical with those described for Megalopygidae. The gize and arrangement of parts may be seen in Figs. 19, 20 and 22. In two of the genera studied, Sibine and Euclea, the maxillae, in addition to the usual cephalo-lateral extension found throughout the family, Fig. 22, have peculiar modifications in the form of long lateral prolongations extending to the antennae. Usually only the distal end of this prolongation is seen between the eye-piece and the antennae as in Fig. 19 and the dotted line shows the connecting part. These two genera also have a 
distinct groove in each half of the maxillas, into the caudal part of which the femur of the prothoracic leg is fitted. The cephalic margin of the pronotum has a distinct median notch, which makes it appear bi-lobed, and each lobe is prolonged cephalad over the caudal margin of the head. The mesonotum is prolonged into a rounded or pointed lobe which reaches on to the first abdominal segment. Only three genera were available for study. These may be separated by the following table:

A. Maxillae never with a lateral projection reaching to the antennae; mesothorax with a strongly carinate median line; caudal love of the mesonotum broadly rounded.

Prolingacodes Schaus

AA. Maxillae with lateral projections reaching to the antennae; mesothorax never with a strongly carinate median line.

B. Mesonotum with the caudal lobe pointed.

Euclea Hubner

BB. Mesonotum with the caudal lobe broady rounded, almost truncate.

Sibine Herrich-Schaeffer

Species examined:

Prolimacodes scapha Harris.

Euclea delphinii Boisduval, chloris Herrich-Schaeffer.

Sibine stimulea Clemens.

\section{Family Pyromorphidae}

This farnily is much more specialized than either the Hegalopygidae or Eucleidae and resembles then but little. The body is flattened and has lost the power of motion except in the abdomen. The segments $2-7$ are free in the male and $2-6$ in the female. The appendages are also very slightly soldered together. The presence of spines on the abdominal segment, together with the absence of maxillary palpi are considered sufficient evidence 

that it belongs to the superfamily Eucleoidea. Figures 24 and 25 will show the essential points of its structure. The only genus available for study was Harrigina Packard.

Species examined:

Harrisina americana Guerin-Meneville.

BB. Generalized Pupae with liaxillary Palpi

The remaining pupae which retain either free segments cephalad of the fourth abdominal segment or free appendages, have followed two distinet lines of development. In the first group the generalized condition of the body found in the Eriocraniidae has been retained as to comparative length of segments and the covering of the dorsum of the aboomen with fine spines. The metathorax is nearly always more than half the length of the mesothorax, while the prothorax tend to become shorter at the meson and broader at the lateral margins, so that each half appears triangular. In the second group, the covering of spines on the dorsum of the abdomen has been gradually changed and there is found one very well developed row of gpines at the cephalic margin of each segment, with or without a similar caudal row. In these the prothorax is longer and somewhat quadrangular in shape and the metathorax is relatively shorter. This group includes the superfamilies Tineoidea and Tortricoidea, and being much smaller than the other will be considered first.

\section{Superfamily Tineoidea}

The families included here possess one row of spines along the cephalic rargin of the dorsum of the abdominal segments, 

and rell developed maxillary palpi. In one family, Prodoxidae, the primitive coverin§o of fine spines has been retained, but it may be easily differentiated from all other pupae bearing spines of two sizes in a similar position on account of the large maxillary palp1.

The family Heliodinidae is included here for the sake of convenience as it possesses but the cephalic row of spines on the dorsum of the abdominal segments. It is, however, much more nearly related to the Tortricoidea. The families Prodoxidae and Acrolophidae are more nearly related to the Tineidae. Of these the Prodoxidae are undoubtedly the most generalized, retaining more head sutures, a greater number of free segments, in addition to the spines mentioned above. The Acrolophidae are more generalized than the Tineidae in the matter of free segments, but have the appendages firmly soldered to each other and to the body wall. This is probably due to the fact that they are borers. The families may be separated as follows:

A. Hesonotum not produced into a long caudal lobe; mesothorax seldom more than twice the length of the metathorax.

B. Abdominal segments $2-7$ movable; dorsurs of abdominal segments with a covering of spines on the caudal part; maxillae more than trice as long as the labial palpi.

Prodoxidae

BB. Abdominal segmenta 3-? movable; maxillae shorter than the labial palpi; dorsum of abclominal segments never with a covering of spines on the caudal part.

c. Antennae never extending to the caudal morgin of the wings; wings broadly rounded; appendages firmly soldered to each other and the body; a lateral projection never present on each side of the tenth abdominal segment. 

CC. Antemnae extending beyond the caudal marein of the wings; Wings pointed; appendages only slightly soldered together and separating at the slightest touch; tenth abdominal segment with a prominent lateral projection on each side encing in a spine.

Tineidae

AA. Mesonotum produced into a long caudal lobe; metathorax never more than one-fourth the length of the mesothorax measured on the meson.

Heliodinidae

\section{Family Prodoxidae}

In this family abdorinal segments $2-7$ are free in both sexes. The head shows the eplcranial suture plainly and dehiscence always takes place on the front of the head along what is apparently the fronto-clypeal suture, at least for a part of the distance as show in Fig. 26. The front bears a prominent chitinized projection armed with two stout teeth. The lateral margin of the eye-piece extends on to the antennae for a very short distance. The appendages are very slightly soldered to each other, but scarcely to the body wall and separate very easily. The lateral view, Fig. 37 , shows the relative length of the segments. The abdominal segments, although they have develooed a prominent cephalic row of spines on the dorsum still retain the covering of very fine spines on the remainder of the segment. The eighth abdominal segment beara a pair of very stout hooks at the apices of rounded tubercules. The pupae examined measured about lomm. in length.

Species examined:

Prodoxus quinquepunctella Cham. 



\section{Family Acrolophidae}

In this family segments $3-7$ of the abdomen are movable in both sexes, but the appendages are quite firmly soldered to each other and to the body-wall so that they do not readily separate even at deniscence. There is probably also dorsal movement of the second segment, as the conjunctiva is well developed and both the first and second segments separate at dehiscence. The larvae of members of this family are sod borers and its seems quite natural that pupae with tinis mode of life should have their appendages soldered down at a much earlier stage than those of the leaf miners for instance, or of the pupae that live in cocoons. There are none of the small spines of the generalized type present on the dorsum of the abdomen in this family, but a well developed row of spines at the cephalic margin of the segments. There are also short lateral and dorsal projections of the tenth segment with very sharp, chitinized edges which are evidently to aid the pupa in working its way to the surface. The head bears a strongly chitinized trangverse ridge near the cephalic margin of the ventral surface. Figures 28 and 29 will show the arrangement of parts in a pupa of this family, which have a remarkable development of the labial palpi. The pupae are from 15-20 mm. in length. The genera may be separated as follows:

A Labial palpi never with distinct cutting plates near their proximal margin, the palpi not extending much over half the distance to the distal ends of the prothoracic legs; two pairs of coxae visible; spines of the abdominal segments long and narrow. 

AA. Labial palpi with distinct cutting plates near their proximal margin, the palpi extending as far as the distal ends of the prothoracic legs; a single pair of coxae visible; spines of the abdominal segments triangular.

Pseudanaphora Walsingham

Species examined:

Hypocolpus mortipennellus Grote.

Pseudanaphora arcanella Clemens.

\section{Family Tineidae}

In this family the free abdominal segments are $3-7$ in the male, and no females were available for examination. Segments 1-3 separate dorsally at dehiscence. The appendages are very slightly soldered together and separate readily, except the metathoracic legs and antennae which extend beyond the caudal margin of the wings, and are quite firmly fastened together, the legs being underneath the antennae.

The appendages are also slightly soldered to the body as far as the third abdominal segment. The arrangement of parts is shown in Figs. 30 and 31. The fronto-clypeal suture is indicated by a clear line in the otherwise fairly well chitinized cuticle. Segment 3-8 of the abdomen bear a cephalic row of spines on the dorsum directed caudad, while the ninth segment bears an interrupted group of spines directed cephalad. There are none of the fine spines of the generalized type of pupa present in this farnily. The tenth abdominal segment shows a prominent lateral projection on each side ending in a spine. The setae of the body are very conspicuous. The pupae are about $4 \mathrm{~mm}$. in length.

Species examined:

Tinea pellionella L. 

Family Heliodinidae

This family has usually been associated with the Yponomentidae, but it aeems from pupal characters to be more closely related to the Tortricids. It is very similar to these in arrangement of parts; the Heliodinidae, however, have longer maxillae and they plainly show that dorsal motion is possible between the second and third abdominal segments. There are also curved setae at the caudal end of the body in the genus Brenthia, (Figs. 32 and 33), strongly resembling those found in the Epiblemidae. Choreutis (Figs. 34 and 35 ) has a small dorsal plate on the tenth segment with a strong seta at each end which appears to represent an early state in the development of a cremaster. The possession of a single row of dorsal spines on the abdominal segments, however, is like the remainder of the Tineoldea, and makes it easier to classify them as such. They differ from the remainder of the superfamily in having one more free segment in the male, abdominal segments $3-7$ being free in the male and $3-6$ in the female. The thorax differs markedly, too, the prothorax and metathorax being much shorter. The mesonotum has its caudal margin produced into a long lobe, while in the other farnilies the caudal margin of the metanotum is very slightly curved. The appendages are very slightly soldered to each other and the body, and the wings reach onto the fourth abdominal segment. The spiracles are small, circular, and very slightly produced. They are from 6-8nm. in length. The genera may be separated as follows: 

A. Body setae longer than the abdominal segmenta, heavily chitinized and forked at the end; maxillae measured on the meson, about half the length of the wings; abdominal segments without deep punctures along the cephalic margin, but with a row of sharp triangular spines.

Brenthia Clemens

AA. Body with very short inconspicuous setae; maxillae extending to the caudal margin of the wings; abdominal segments $2-6$ with a row of deep punctures along the cephalic margin and with a row of sharp triangular spines just cephalad of the punctures.

Chorentis Hübner

Species examined:

Brenthia pavonacella Clem.

Chorentis inflatella Clem., gnaphiella Kearf.

Superfamily Aegerioidea

The Aegerioidea, together with the Tortricoidea retain freedom of movement in abdominal segments $3-7$ in the male and 3-6 in the female. The appendages are soldered to the body so that there is no ventral movement possible between the first two abdominal segments, but there is undoubtedy dorsal movement and at dehiscence these segments separate very distinctly from each other and the thorax, indicating that they have only recently lost their power of motion. In this superfamily is included the one family Aegeriidae. They form a very compact group in which it is hard to find satisfactory characters differentiating the genera. Moreover, pupae in good condition are difficult to obtain, but it is hoped that the characters used here in separating the genera and in defining the superfamily will hold good for those groups to which they are aprlied. The sexes vary considerably and in all cases it has not been possible to see both male and female. This superfamily has most often been assoclated with the Tineoidea, 

but pupal characters indicate a much closer relationship to the Tortricoidea. It is apparently somewhat nearer to the primitive families, Eriocraniidae and Nepticuliciae than the Tortricoidea, owing to the fact that a very large marillary palpus is present in all genera, and that spines are found on all abdominal segments from 2-10 wich reach well around to the ventral surface, especially on the tenth segment. There are no setae yet developed on the anal rise, and there is also not as much consolidation of the fixed caudal abdominal segments. The seventh segment in the female seems but recently to have lost power of motion. The abdominal segments are more nearly equal in length than in the Tortricoiciea.

\section{Family Aegeriidae}

The pupae of this family vary considerably in size, from the genus Aegeria with species varying from 8 -16rm. in length to the genera Memythrus and Bembecia containing the largest species examined, varying from $20-25 \mathrm{~mm}$. They are all proviced with various forms of cutting plates for working their way to the surface, most of these being on the head, which is heavily chitinized at the cephalic end and which usually has many ridges and projections making it difficult to determine the sutures. The clypeus often bears a sharp transverse ridge, sometimes toothed, which undoubtedly serves the same purpose. The body is elongate, cylindrical, with the abdominal segments approximately equal in length, showing a generalized condition. The arrangement of parts in a pupa of this family is shown in Figs. 36 and 37. 

It will be noted that the maxillary palpi are very large and they remain uniformly so throughout the family. The appendages extend beyond the wings in most of the genera but the caudal part of these are not soldered to the body wall. The fronto-clypeal suture is always distinct along the lateral margins of the front from the proximal ends of the antennae almost to the invaginations for the anterior arms of the tentorium, but only shows transversely as a paler band of color in the strongly chitinized cuticle as indicated by the dotted line in the figure. Dehiscence invariably follows the course of this suture and the front with the antennae are separated from the rest of the head parts. The epicranial suture is often obscured by the numerous elevations of the vertex and front, but'it is always present. The antennae are always enlarged at the proximal end and again at the distal end where they are somewhat club-shaped, thus differing again from the Tortricoidea. The mandibles are distinctly elevated in most genera. The wing are narrow and pointed, differing markedly from those of the Tortricoidea. They are not fastened to the body wall at their distal end. The thorax always has a carinate median ridge, which may be distinct on all the segments, but is always distinct on the prothorax and the cephalic half of the mesothorax. The alar furrows are very deep, and one edge, usually the mesal one is sharp and heavily chitinized. There are always tro rows of spines on the dorsum of some of the abdominal segments, which extend around to the ventral surface. These rows of spines are alvays present on segments $3-6$, the number 

the number varies on segments $z$ and $?$, while there is always one row on segments 8-10. The number of rows of spines on segment 7 varies with the sex, there being tro in the male and only one in the female. The spines on the tenth segment are very broad and this row extends nearly to the ventro-mescn. Each of the spines has a seta inserted near its tip, which are not heavily chitinized and therefore easily broken. There are never any setae present on the anal rise.

The genera of Aegeriiala may be separated as follows:

A. Maxillas always more than one-half the length of the wings, generally nearly or quite equaliing their length; coxae of mesothoracic leg never adjacent on the meson below the maxillae.

B. Clypeus with a prominent elevation near its caudal margin, bearing a heavily chitinized transverse ridge or series of projections which are probably to assist the pupa in cutting its may out of the burrow.

C. Clypeus with the chitinized transverse ridge produced into a distinct point on each side the meson.

D. Mesothorax with the median carinate ridge extending nearly its whole length, very distinct on the metathorax; second abdominal segment with the two rows of spines distinct in both sexes; pupae averaging $20-25 \mathrm{~mm}$. in length.

Sanninoidea Beutenmüller

DD. Mesothorax with the median carinate ricie usually extending only along the cephalic half, never distinct on the metathorax; second abdominal segment never with two distinct rows of scines in either sex; pupa lisually 8-15mm. in length.

Synanthedon Fübner

CC. Clypeus with a transverse rov of separate projections. Parharmonia Beutenmüller

BB. CIypeus not prominently elevated at ita caudal margin and never bearing ridgeg or projections which could be used in cutting. 

c. Tenth abojominal segment with eight spines in a row; caudal end of body just cephalad of the anal opening without setae.

Podosesia lioschler

CC. Tenth abdominal segment with ten large spines in a row and two smaller ones, one on each side the meson; caudal end of body just cephalad of the anal opening with a row of four setae which are inserted under small projections.

Memythrus Nerman

AA. Naxilize about two-fifth the length of the wings; coxae of mesothoracic legs and their tarsi adjacent on the meson caudad of the maxillae.

Bembecia Hïbrer

\section{Species examined:}

Sanninoidea exitiosa Say.

Synanthedon tipuliformis Clerck, acerni Clemens, pictipes $G$ \& $R$, pyri Harris, scitula Harris.

Parharmonia pini Kellicott.

Podosesia syringae Farris.

Memythrus asilipennis Boisciuval, dollii Neumoegen.

Bembecia marginata Harris.

\section{Superfamily Tortricoidea}

This superfamily, like the Aegerioidea, is distinguished by the presence of two rows of spines on the dorsum of most of the aboominal segments. The Tortricoidea form a more compact group than the Aegerioidea in regard to the arrangement of appendages, which varies so little throughout the family that any meraber of the superfamily may be easily recognized by this arrangement, together with the presence of spines on the abdominal segments. This characteristic arrangement is shown in Figs. 38, 40, 41, 44. There are often projections from the head much as in the Aegerioidea but there are never as many head sutures present. The thorax shows the alar furrows in many instances but they are never as well developed as in the preceding superfamily, and never have 

sharp chitinized edges. The abdomen shows a greater degree of specialization and its fixed caudal segments are much more strongIy consolidated, the sutures being very difficult to determine in many cases. The seventh segment has also becore firmly fixed in the female.

It was found impossible to group the pupae of this superfamily according to any of the schemes of classification now in use. The four groups into which the Tortricoidea in the following pages have been divided are designated as Epiblemidae, Olethreutidae, Tortricidae and Sparganothidae. These names, however, are without any significance whatever as far as previou classifications are concerned, and are merely used as a matter of convenience. Lack of material has prevented further study in this group at present, so it has been impossible to determine the correct family names. No attempt has been made to bring the nomenclature up to date. The generic names used by Meyrick and Talsingham have been followed as nearly as possible.

The four groups or families of Tortricoidea must have had a common ancestor, but owing to the development of the maxillary palpus within the groups it would be impossible to consider one as derived from another. The line of development appears to have been towards (I.) a reduction of the spines on the dorsum of the abdominal segments, these disappearing first from the tenth segment and then from the segments cephalad of it; (2) the loss of setae on the anal rise; and (3) the development of a long cremaster.

The familieg of Tortricoidea may be separated by the 
following table.

A. Body without a distinct cremaster; setae always present on the anal rise.

Epiblemidae

AA. Body with a well developed cremaster.

B. Ninth abdominal segment always with a distinct row of spines, especially in the males; tenth abdominal segrnent sometimes possessing soines; cremaster broader than long; setae always present on the anal rise.

C. Cremaster never curved ventrad, the caudo-lateral angles not produced into prominent hooks; the caudal margin usually showing three short lobe-like projections; second abdominal segment with the cephalic row of spines present and the caudal row well developed; setae of the anal rise always laterad of the anal opening.

olethreutidae

CC. Cremaster curved ventrad, the caudo-lateral angles produced into prominent hooks; second abdominal segment lacking the cephalic row of spines and the caudal row poorly developed; setae of the anal rise always on the caudal part of the elevation.

Tortricidae

BB. Ninth abdominal segment lacking a distinct row of spines, although a few spines are sometimes present in the males; setae never present on the anal rise; cremaster nearly always longer than broad; tenth abdominal segment never possessing spines.

Sparganothidae

Family Epiblemidae

The pupae belonging to this family (Figs. 38, 39) have no cremaster and there are always setae present on the anal rise. They are usually less than lomm. in length and slender, tapering gradually from the thoracic region to the somewhat blunt end of the body. The genus Carpocapsa is sometimes an exception as the body is often very stout, and the genus Eucosma has a cylinarical body strongly resembling the pupae of the Aegeridala. The maxillary palpl usually extend to the proximo-lateral angles of the 

maxillae, only Epinotia and Enarmonia of the genera studied had shorter palpi. The maxilzae are about two-fifths the length of the wings and the labial palpi are usually one-half this length. The rows of spines on the dorsum vary somewhat in the different genera. All have two rows present on abdominal segments 2-7 although the cephalic row of segment two is weak in Eucosma, Hemimene and some species of Ancylis. Occasionally the caudal row of segment seven is weak in the females of some species. As a general rule the eighth segment has but one row of spines, the cephalic one, but two rows have been found in the species of Exinotia and Eucosma, usually in the males. There is, in most genera, considerable difference between the sexes. The antennae do not vary as greatly in this family as in some others, but there is a great variation in the rows of spines, these being usually smaller and less numerous on the caudal row of segment seven and on segment eight in the female. The genus Melligopus did not show characters of sufficient importance to allow for its retention as a separate genus, and it was therefore included with Carpocapsa. The only points of difference between that genus and Carpocapsa pomonella, its nearest ally, are that the spiracles are oval, somewhat rectangular and slightly produced, while in Mellisopus latiferreanus they are large and circular but not strongly produced. There is, however, considerable variation. Mellisopus shows a slight carinate ridge on the metathorax, but this again is extremely variable.

The phylogeny of the group is extremely doubtful. If the spines on the dorsurn of the abdominal segments in Eucosma were 

homologous with those found in the generalized pupae of Nepticulidae and others, it would certainly be the most generalized form and the others would probably follow the sequence of the table to genera. The spines, hovever, are much broader than any observed in the generalized types. Eucosma also shows a remarkable resemblance to the Aegeriidae so it is probable that it is the most generalized of the Tortricoidea examined.

The genera of Epiblemidae may be separated as follows:

A. With two long distinct setae present on each side of the anal rise.

B. Caudal end of body with one row of long, heavily chitinized, flattened setae inserted along the line of the row of spines on the tenth abdominal segment.

C. Dorsal surface of abdominal segments between the cephalic and caudal rows of spines covered,at least in part, with short triangular spines; cephalic row of spines composed of alternating large and small spines.

Eucosma Hübner

CC. Dorsal surface of abdominal segments between the caudal and cephalic rows of spines always smooth; cephalic row of spines which are of approximately the same size.

D. Portion of first coxae exposed on the meson below the maxillae more than half the length of the second coxae; body often stout with the length scarcely three times the greatest width, but extremely variable; length averaging $10 \mathrm{~mm}$.

Carpocapsa Treițchke

DD. Portion of first coxae exposed on meson below the maxillae never more than half the length of the second coxae; body always slender with the length about four times the greatest width; average length $8 \mathrm{~mm}$.

Tmetocera Lederer

BB. Caudal end of body with two rows of setae showing, one row of four setae inserted along the line of the row of spines on the tenth abdominal segment and another row at the caudal margin of the body.

C. Caudal row consisting of four setae; maxillary palpi always touching the proximo-lateral angles of the maxillae. 

D. Caudal row of setae of two kinds, the mesal ones much slenderer than the lateral ones; maxillae measured on the meson less than one-third the length of the wings; labial palpl about two-thirds the length of the maxillae; maxillary palpus only touched by the prothoracic leg.

Heraimene Hübner

DD. Caudal row of setae similar; maxillae, measured on meson, never less than one-third the length of the wings; labial palpi about one-half the length of the maxiliae; maxillary palpus touched by both prothoracic and mesothoracic legs.

Ancylis Hübner

CC. Caudal row consisting of two setae; maxillary palpi never reaching the proximo-lateral angles of the maxillae.

Epinotia Hübner

AA. Never with two long, distinct setae on each side of the anal rise.

B. Lateral spines of the tenth row noticeably larger than the others; setae at the caudal end of the body very short and slender, not heavily chitinized; setae of the anal rise very small and difficult to locate, usualiy two present on each side.

Thiodią Hübner

BB. Lateral spines of the tenth row not noticeably larger than the others; setae at caudal end of body long and heavily chitinized; one seta on a distinct papilia on each side of the anal rise.

Enarmonia Hübner

Species examined:

Eucosma strenuana Walker, scudderiana Clem.

Carpocapsa pomonella L., saltitans Testw., latiferreanus Wlsm.

Tmetocera ocellana Schif.

Hemimene incanana clem.

Ancylis comptana Frolich, platanana Clen., dimiutana Kearf.

Epinotia saliciana Clem.

Thiodia signatana Clem.

Enarmonia fana Kearf.

Family Olethreutidae

The Olethreutidae (Fig. 40) include those species which possess a well developed cremaster, usually broader than long and somewhat flattened, bearing eight strongly chitinized, flattened, 

hooked setae, and usually bearing similar but smaller setae on the anal rise. Exceptions to this latter character are found in the genus Polychrogie, and in Exartema ferriferanum which does not agree with the remainder of the genus in this respect. The group is further characterized by the presence of a well developed row of spines on the ninth abdominal segment in all the males examined and in nearly all of the females, the exceptions being in the genus Exartema, where the spines were smaller and fewer in number. In most genera this row of spines has several additional spines on each side, usually near the meson. The only other species of the superfamily which resemble the member of this groups are the species of Archips in group (b), but these have no setae on the anal rise, and very seldom have spines present on the ninth abdominal segment. Exartema ferriferanum is the only species among those examined which might be confused, as the row of spines on the ninth segment of the female is not well developed, while the males of Archips cerasivorana sometimes have a few spines present. This particular species of Exartema, however, has a prominent cephalic projection ending in a point directed ventrad, while the species of Archips are blunt at the cephalic end, and the bodies are usually larger and prominently enlarged in the region of the thorax. The antennae show marked sexual differences, being much longer in the males. The rows of spines on the dorsum of the abdominal segments also vary in the sexes, the caudal row of segment eight being poorly developed or lacking in many females, whlle well developed in the males. The row on the ninth segment is much better developed in the males. The genus Polychrosis 

shows a peculiar development of the spiracles. Instead of the small, produced tubular spiracles common to the Tortricoidea they appear to have them very much enlarged. This prominent enlargement around the splracle has a deeply concave surface and the very small tubular spiracle in the center is about one-eixth of 1ts width. A similar condition, but not so well developed, is found in Exartema sclotanum. The maxillary palpi are well developed and reach the proximo-lateral angles of the maxillae in Olethreutes (b) and Polychrosis, but in Eplsimus, Olethreutes (a) and Exartema they are not well developed.

The genera of Olethreutidae may be separated as follows:

A. Tenth abjominal segment with spines, usually three or four rows closely approximated, seldom with a single row.

B. Long chitinized setae present on the anal rise, usually slightly shorter and narrower than those of the cremaster.

C. With two setae on each side of the anal rise, very similar to those on the cremaster.

Ep16inus WIsm.

CC. With one seta on each side of the anal rise, smaller than those of the cremaster.

Olethreutes (a) Hübner

BB. Setae never present on the anal rise.

Polychrosig Ragonot

AA. Tenth abdominal segment wi thout spines.

B. Mell developed setae present on each side of the anal rise.

C. Maxillary palpi well developed, reaching the proximolateral angles of the maxillae.

Olethreutes (b) Hubner

CC. Maxillary palpi short, never reaching the proximolateral angles of the maxillae.

Exartema (a) Clemens

BB. W1thout setae on the anal rise.

Exartema (b) Clemens 

Species examined:

Episimus argutanus Clem.

Olethreutes (a) niveiguttana Grt., (b) malachitana Zell.

Polychrosis slingerlandana Kearf., viteana Clem., botrana Schif. Exartema (a) sciotoanum Kearf., concinnanum Clem., nigranum Kearf., inornatum Clem., permundanum Clem.

Exartema (b) ferriferanum Walker.

\section{Family Tortricidae}

This group is distinguished by its peculiar tyce of cremaster and the presence of setae on the anal rise. The maxillary palpi are not present in Peronea but are found in Argyrotoxa where they are shorter in the male than in the female. The maxillae are usually about two-fifths the length of the wings, with the labial palpi nearly half this length. There are no spines fresent on the tenth abdominal segment, and they are not well developed on the second and third segments. There 18 always a well developed cephalic row on the dorsum of the tenth segment, but the caudal one does not extend as far laterad in the male and is usually lacking in the female. In Asgyrotoxa the cephalic row of spines on the eighth and ninth segments are on a prominent ridge which can be plainly seen on the lateral margin in dorsal view. There are always two setae present on each side the anal rise and these are always on the caudal part of the elevation. Figures 41 and 42 show arrangement of parts in this family and Fig. 43 the dehiscence of part of the head, showing the eye-piece. The genera of Tortricidae may be separated by the following table:

A. Maxillary palpi present in both sexes; spines of the cephalic row on abdominal segments $7-9$ on distinct ridges which show plainly on the lateral mareins of the body, the spines extending laterad beyond the spiracles in some segments; setae 


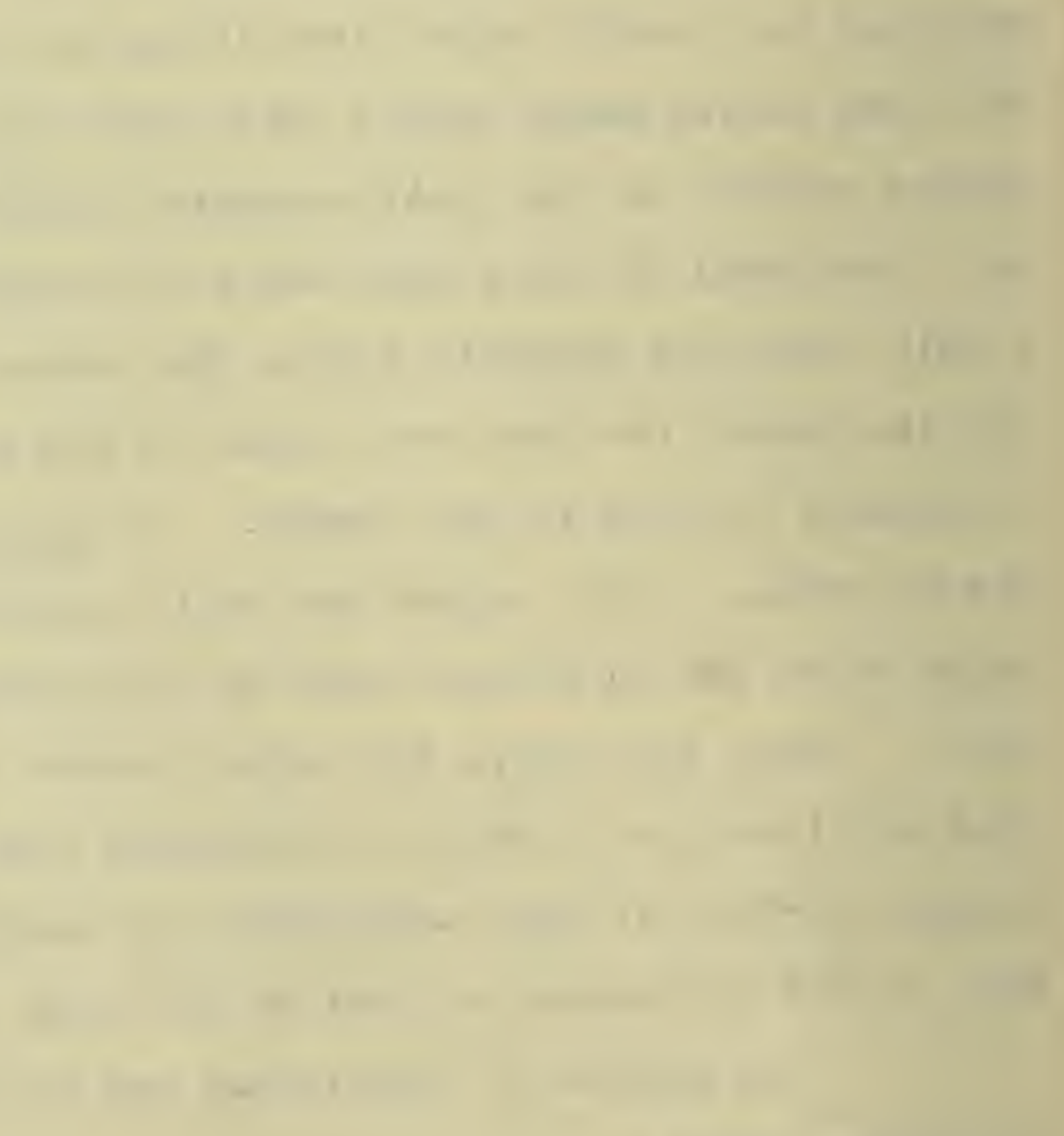


on the ventral side of cremaster and between cremastral hooks not heavily chitinized and resembling the ordinary body setae.

Aroyrotoxa Stephens

AA. Maxillary palpi not present in either sex; spines of the cephalic row on abdominal segments $7-9$ not on distinct ridges, the spines never extending laterad beyond the spiracles; setae on the ventral side of cremaster heavily chitinized, and usualiy not extending far beyond the caudal marsin of the body.

Peronea Curtis

Species examined:

Argyrotoxa albicomana Clen., bergmanniana $L$.

Peronea sp., minuta Rob., logiana Schif. var. viburnana Clem.

\section{Family Sparganothidae}

This family (Fig. 44) includes the species in which the cremaster is well developed and much longer than broad except in Archips (ㅁ) and Phaecasiophora. The cremaster in nearly all species bears eight strong hooked setae which are usually not much flattened except in the genera mentioned above. There are never any setae present on the anal rise, and most of the species have no spines present on the ninth abdominal segment, and never a well developed row. The caudal row of the elghth segment is often lacking in the female and is poorly developed in the male. The female of Platynota flavedana have no cenhalic row on the second abdominal segment. The members of this group include the largest of the Tortricoidea examined, most of them congiderably over lomm. in length, and the thoracic region usually apoears considerably enlarged, and the abdomen is long and tapering. The vertex is shorter than in the other grouns. The maxillary palpi do not reach the proximo-lateral angles of the maxillae in both sexes, but sornetimes do in the females. In Platynota flavedana 

the palpi appear to extend only along the cephalic margin of the prothoracic leg. The setae of the body are usually very long and prominent in this group. Sexual differences are noticed in the length of the maxillary valpi and antennae and in the development of the rows of spines on the dorsum of the abdominal segraents. There are no avallable characters by which all the species of the genus Archips can be associated in a single group and it undoubtedly represents two genera, because there are two distinct types of cremaster present. It is also difficult to find good structural characters to separate the genera Harmologa and Archips (․ㅡ). The color markings are very distinct in Harmologa, and the body is also very noticeably enlarged in the region of the firgt three abjominal segments so that in ventral view the lateral margins of the wings appear curved, instead of approximately parallel as in Archips (a). The genera Epagoge and Platynota are also closely related and are grouped together by some writers.

The genera of Sparganothidae may be separated as follows:

A. Transverse conjunctiva showing prominent dark brown spines scattered over a lighter brown surface.

B. Cremaster much longer than broad, not flattened.

C. With four setae inserted at the cavdal end of the cremater

D. Dorsum of second abdominal segment showing a slightly crenulate, chitinized cephalic margin, the cephalic row of spines on this segment not well developed in the males and wanting in the females; head never with a cephalic projection; abdomen never with prominent cavities on the dorsum of the second and third segments; dorsum of abdomen always with darker transverse bands and spots of color. 

DD. Dorsum of second abdominal segment without a crenulate cephalic margin; cephalic row of spines well developed on this segment in both sexes; head often with a cephalic projection, or if not, then prominent cavities are present on the dorsum of the second and third abdominal segments; body of uniform color.

Archips (a) Hübner

CC. Fith two setae inserted at the caudal end of the cremaster. Cenopis Zeller

BB. Cremaster broader than long, flattened.

Phaecasiophora Grote

AA. Transverse conjunctiva never showing prominent dark brown spines, surface of uniform color.

B. Cremaster Ionger than broad, not flattened; labial palpi alvays considerably more than one-half the length of the maxiliae.

C. Cephalic row of spines on second abominal segment lacking in the female; cremastral setae noticeably flattened.

Platynota Clemens

CC. Cephalic row of spines on the second abdominal segment present in the female; cremastral setae not noticeably flattened.

Epagoge Hiibner

BB. Cremaster broader than long, distinctly flattened; labial palpi not more than half the length of the maxillae.

Archipg (b) Hübner

Species examined:

Harmologa fumiferana clem.

Archips (a) argyrospila Walk., magnoliana Fernald, parallela Robinson, obsoletane Walk., rosaceana Harx.

Archips (o) cerasivorana Fitch, fervidana Clem.

Cenopis chambersana Kearf.

Phaecasiophora confixana TaIk.

Platynota flavedana Clem.

Evagoge sulfureana Clem.

Superfarnily Gracilarioidea

This superfamily name is given to a number of families apparently of common origin, which have proceeded along similar lines of development. The species are all leaf miners and are 

very small, the pupae of the largest species examined being 7mm. in length. Very few of the generalized families have been available for study so that it is exceedingly difficult toftrace the relationships existing between the more specialized families without first having carefully studied a number of more generalized forms. There is included in this group the Nepticulidae, in many respects the most generalized pupae studied next to the Eriocranildae and certainly resembling them more than any of the other generalized forms exanined. It is just at this point in our investigation that more naterial is needed to clear up the relationships of the groups which have apparently branched off at this point and have had a common ancestor with the Nepticulidae. From all the evidence at hand it seems probable that development has proceeded along two well defined lines, the first, represented by the superfamily Gracllarioldea, having early lost the maxilfary palpi while still retaining the covering of spines on the dorsum of the abdominal segments and having developed the triangular type of prothorax; the second having retained the maxillary palpi for a much longer time, but lost the covering of spines, while developing the sarne type of prothorax.

of the second type no material has been examined which would show any intermediate stages between the families Nepticulidae and Epermenildae. The latter has apparently continued the line of development begun in the Gracilarioidea as it still retains the seventh abdominal segment free in the male but fixed in the female. The presence of the maxillary palpi precludes its derivation from this family and would lead us back to some point below 

the Heliozelidae because this family also has lost them. As we only have the family Nepticulidae for comparison, it has been assumed that this branch has arisen co-ordinately with them.

In the superfamily Gracilarioidea, with the exception of the family Lyonetildae, all the pupae have free appendages, the cuticle is very slightly chitinized and the dorsurn of the abdomen is covered, in part at least, with fine spines. There is a tendency in some genera as Iithocolletis and Ornix towards the development of a single row of spines, so that there is often one or more rows of larger spines at one or both margins of the segment. This seems to indicate the way in which the rows of spines were developed in the Tineoidea and Tortricoidea. The characters which are comnon to all the members of the superfamily are the long vertex, which is always longer than the prothorax at the median line, scarcely ever less than twice its length and often much longer, and the long metathorax, with the los of a well developed maxillary palpus above the Nepticulidae. Chapman described the genus Gracilaria as possessino maxillary palpi, and in two species, sassafrasella and negundella a structure has been found (Fig. 45, 47) which may be the maxillary palpus, but there never is a distinct, oblong piece lying caudad of the eye-plece as is usually the case when the maxillary palpi are present, and of all the species of the superfamily these two were the only ones in which there was any doubt as to its absence. The head is in most families either produced into a prominent projection or there is a heavily chitinized cutting plate near the cephalic margin on the ventral surface. The prothorax has a tendency to become 

shorter on the median line and longer on its lateral margins so that each half is triangular. In such cases the length along the lateral margin is about four times the length on the median 1ine. In the more generalized forms the prothorax is more like the rectangular type found in the Tineoidea, but it is depressed or sunken, giving it a neck-like appearance. The metathorax still retains its primitive condition, and is usually more than one-half the length of the mesothorax. In nearly all of the families the wings are long in proportion to the body, and in the majority they are about two-thirds its length. The bodies of most of the families included here retain the generalized type found in the Eriocranildae with a slight depression near each lateral margin in the region of the spiracles. The spiracles are usually small, circular and slightly produced appearing tubular. The Lyonetildae seem to be an exception to almost every rule. They have no free segments, the appendages are all soldered to the body, and there are no spines visible on the abdomen. They seem to be more nearly related to the Bucculatrigidae than any other family, although there are strong reasons for considering them related to the Phyllocnistidae.

The following table will serve to separate the families of Gracilarioidea:

A. Maxillary palpi well developed and extending along the caudal margin of the eye; spiracles visible on the first abdominal segment.

AA. Maxillary palpi never well developed, and if present never extending as an oblong piece along the caudal margin of the eye. 
B. Antennae never extending more than one-half the length of the wings; labrum very long and lobe-like, extending over the labial palpi for about one-fourth of their length; spines on the dorsum of the abdomen very fine and not easily distinguished.

Heliozelidae

BB. Antennae always extending at least three-fourths the length of the wings, and usually equalling them in length or extending veyond their caudal margin; labrum never long and lobe-like and never extending down over the labial palpi for one-fourth of their length.

C. Appendages free, never firmly soldered to the body wall; abdomen always with some of the segments movable; dorsum of the abdomen always with spines.

D. Abdominal segments 3-7 movable in the male, 3-6 in the female; antemnae and metathoracic legs not approximately equal in length and both seldom extending beyond the caudal margin of the wings.

E. Labial palpi present; cauda. end of body ending in two stout spines directed dorsad; abdominal segments 3-6 With the two setae nearest the meson on the cephalic half of the segment closed approximated so that their bases touch.

Tischeriidae

EE. Labial palpi never visible; caudal end of body never with curved hooks, but the tenth abdominal segment with a prominent lateral projection on each side ending in a stout straight spine; abdominal segments 3-6 with the setae nearest the meson at the cephalic end of the segrnent never closely approximated.

Bucculatrigidae

DD. Abdominal segment $4-7$ movable in the male, $4-5$ in the female; antennae and metathoracic legs. approximately equal length and both always extending beyond caudal margin of the wings.

E. Abdominal segments 3-7 never with two deep punctures or pits with heavily chitinized edges on the meson at the cephalic margin with one or more heavily chitinized spines adjacent; the length of abdominal segments 8-10 always greater than that of segment?.

Gracilariidae

EE. Abdominal segments 3-7 with two deep punctures on the meson at the cephalic margin with $1-3$ heavily chitinized spines adjacent; abdominal segments 8-10 never showing distinct segmentation, their total length 

less than that of the seventh segment.

Phyllocnistidae

BB. Appendages always firmly soldered to the body; dorsum of abdomen without visible spines; abdomen without any movable segments.

Lyonetiidae

Family Nepticulidae

These tiny species of leaf miners average $2 \mathrm{mrn}$. in length in the females and $1.5 \mathrm{~mm}$. In the males. The body is flattened with a transparent, slightly chitinized cuticle, and are white in color until the adult scales are formed. Although their size made it difficult to determine the number of free segments, it is believed that there is some degree of motion between all of the abdominal segments except the fixed caudal ones. There is some degree of movement between the seventh and eighth abdominal segments in both sexes, but it is apparently greater in the male. The arrangement of parts may be seen in Figs. 48 and 49 . The head does not show all of the sutures found in the Eriocraniidae, but the epicranial and fronto-clypeal sutures are always present. The appendages are all free and segmented as in the Eriocraniidae and the thoracic appendages are widely separated to show all the coxae. There is a strong resemblance between this family and the more generalized members of the Eucleoidea but the presence of the large maxillary palpi prevent their being included in that superfanily. The spiracles are visible on the first abominal segment and the length of the thoracic segments indicates a very generalized condition. The genital opening of the male is located as show in Fig. 48. In the females there was an area covered with setae on the venter of the eighth segment as in the Eriocrani- 

idae, but no openings could be accurately determined. Species examined:

Nepticula nyssaefoliella Cham., platanella Clem.

\section{Family Heliozelidae}

This family includes some very small pupae which measure only 2-3mm. in length. They have all the appendages free and widely separated. The cuticle is transparent and the body white in color, with the conjunctiva so little differentiated that it was impossible to determine the number of free segments with accuracy. Segments $2-7$ in the male and $2-6$ in the female have some power of motion but whether this is movement of the whole segrnent in the case of the second and tinird, or merely dorsal movement, was not determined. The family (Fig. 50) is characterized by its short antennae and its long labrum which projects over the labial palpi. They also have shorter appendages than any of the other families with transparent cuticle and white bodies, because in all others the metathoracic legs and antennae extend considerably beyond the caudal margin of the wings and are often longer than the body. The epicranial suture is near the cephalic margin of the head. While this family may have retained more free segments than the Gracilariidae, it is undoubtedly more specialized than some of the genera in that family. The prothorax is much longer at its lateral margins than on the meson; there is no trace of a maxillary palpus and the labial palpi are not so well developed as in the generalized Gracilarildae.

The genera included in this family have long been associated with the Elachistidae, but the pupae show no resemblance 
whatever to this family. The name Heliodinidae has been applied by some authors to the genera included in this family but Meyrick in 'Lepidoptorun Catalogus" Part 13 uses this name to include the genera Brenthia, Choreutis etc. The name Heliozelidae is used by Spuler (Die Schmetterlinge Europas, 1910) and this name has been adopted here.

The genera may be separated as follows:

A. Abdomen with one or two prominent lateral setae on each side the tenth abdominal segment; mesonotum not produced into a prominent lobe extending down on the metathorax.

Antispila Hübner

AA. Abdomen never with prominent lateral setae on each side the tenth abdominal segment; mesonotum produced into a proininent lowe extending dom on the metathorax. Coptodisce Walsingham

Species examined:

Antispila ampelopsisella Chem., cornifoliella Clem. Coptoaisca juglandiella Cham., splendiforella Clem.

Family Tischeriidae

These pupae are from $3.5-6 \mathrm{~mm}$. In length and have abdominal segments 3-7 free in the male and $3-5$ in the female. They are always considerably chitinized so that the pupae vary in color from yellow to brown. The spines on the dorsum of the abdominal segments are very distinct and in some specieg they are of two sizes. All of the species examined except Tischeria heliopsisella (Fig. 54) had certain of the body setae very long, heavily chitinized and forked at the end. These vary in length, but the shortest are nearly as long as the ablominal segments and are very conspicuous. The dorso-mesal setae nearest the cephalic margin were closely approximated on segments $3-6$ or 7 of the abdomen so that 

their bases were in contact. The caudal end of the abdomen is bifurcate and ends in two heavily chitinized hooks which are directed dorsad. The arrangement of parts may be seen in Figures 51-54. These have become more specialized in certain respects than many of the Gracilariidae, although they retain one more free segment. This is noticeable in the development of the prothorax and in the distinct rows of larger spines on many of the segments, and the strong caudal hooks. The fronto-clypeal suture shows as a clear area, indicated by the dotted line in Figure 51. This family includes two genera coptotriche and Tischeria with no well defined characters ior separating them. The two species of Tiacheria, aenea from blackberry and malifoliella fropte, one time considered identical show distinct differences in the pupae and these two species resemble Coptotriche, while heliopsisella is very different from all the rest. Dyar's list names but one species of Coptotriche, but three distinct types of pupae have been obtained from mines in oak leaves. Unfortunately no adults have yet emerged from these so the species cannot be determined. The genera may be separated as follows:

A. Caudal margin of the dorsum of the second abdominal segment heavily chitinized and toothed, the teeth being larger than the adjoining spines.

Coptotriche Walsingham

AA. Caudal margin of the dorsum of the second abdominal segment not heavily chitinized or toothed.

Tischerią Zeliex

Species examined:

Coptotriche zelleriella clem.

Tischeria aenea $F$ \& B., malifoliella Clem., heliopsisella chem. 



\section{Family Bucculatrigidae}

This family, Bucculatrigidae, including the single genus Bucculatrix Zeller, has been placed in various positions by different authors. It is quite evident that it is more specialized than most other families of the Gracilarioidea in the loss of the labial calpi and that it has proceeded along a different iine of development. Nevertheless, no one can fail to see the relationship between the pupae of the Bucculatrifidae and the other members of this superfamily, particularly to some of the species of Cameraria where there is a lateral projection from each side of the tenth segment and a distinct row of larger spines on the dorsum of the abdominal segments. The lack of labial palpi together with the opines on the abdominal segments are sufficient to distinguish the family from all the others included in the superfamily. The arrangement of parts may be seen in Figures 55 and 56 The pupae examined had an average length of $3 \mathrm{~mm}$.

Species examined:

Bucculatrix sp., oomifoliella clem., trifasciella clem.

\section{Family Lyonetiidae}

This family is a very difficult one to place satisfactorily by pupal characters alone, as it has completely lost the power of motion in the abdominal segments and all the appendages are soldered down. This is another of the families which has been a source of anxiety to many lepidopterists. The shape of the prothorax, the length of the vertex, together with that of the wings and appendages as compared with the body, the small tubular 

spiracles and the absence of maxillary palpi seem without any coubt to indicate its relationship to the members of this superfamily and consequently it is included here. From a careful study of the pupal characters available it seems to be more nearly related to the Bucculatrigidae than any other family. A comparison of Figures 57 or 59 and 67 will show that the development in the Lyonitildae has not been lowarcis the shortening of the segments and the consolidation of abdominal segments 8-10 as in the Phyllocnistidae. Moreover, it still retains the generalized type of body found in the Nepticulidae, while Phyllocnistidae have developed the cylindrical type. The shape of the maxillae, the position of the femur of the prothoracio leg are as in the Bucculatrigidae and like them the Lyonetiicae have no labial palpi visible. The Lyonetildae do not spend their pupal life within the mine, nor in a cocoon, but are exposed and fixed by the caudal end to some cross threads on the under surface of the leaf (Tineina of $\mathrm{N}$. America, Clemens,1872-pp. 189-191). The soldering down of the appendages and the loss of motion of the abdominal segments seems to be a modification to suit the new conditions of life and is analogous to the condition found in certain families of Papilino1dea, and the species of the genus Elachigta in which all power of motion is lost. Bedellia has developed certain ridges and projections similar to those found in the Papilionoiclea which seem to be correlated with this manner of pupal life. Only two genera of Lyonetiidae were studied. These were from 4-6mm. in length and may be separated as follows: 

A. Head blunt, without a prominent projection; antennae and metathoracic legs equal in length; caudal end of body with a few straicht spines on the dorsal surface of the tenth abdominal segment; body without prominent ridges.

Proleucoptera Busck

AA. Head with a long projection; antenrae much longer than the metathoracic legs; caudal end of body with hooked setae; body with prominent ridges.

species examined

Bedellia Stainton

Proleucoptera smilaciella Busck

Bedellia somnelentella zeller

Family Gracilariidae

This large family includes those pupae with free appendages and with abdominal segments $4-7$ free in the male and $4-6$ in the female. The antennae and metathoracic legs are of approximately the same length and both are longer than the wings. The most nearly related family, the Fhyllocnistidae, differ in having two prominent pits or punctures with heavily chitinized edges associated with some large curved spines, in having a much more cylindrical body with large deep furrows between the segments, and in having the fixed caudal segments very short.

The genus Gracllaria is undoubtedly the most generalized, if we consider the peculiar structures (Fig. 47 ) found in some species as maxiliary palpi. The tendency in the Gracilariidae is toward the loss of the maxillary palpi, and the development of the "triangular" type of prothorax, which usually is elevated on the median line. There is also a shortening of the maxiliae and labial palpi and of all the appendages in relation to the rest of the body and a stronger chitinization of the surface of the body tending to a soldering down of the appendages. There is also taking place the development of two sizes of spines on the dorsum of the abdominal segments and the formation of single rows of larger spines. 

Finally there is the development of the cremaster.

There are two distinct divisions of the Gracilariidae to which subfamily nemes have been given. These may be separated as follows:

A. Prothorax depressed and neck-like somewhat quadrangular in outline, the length at the lateral margin never more than twice the mesal length.

Gracilariinae

AA. Prothorax usually with an elevated ridge on the meson, triangular in outline, the length at the lateral margin about four times the mesal length.

Lithocolletinae

Subfamily Gracilariinae

The Gracilariinae (Figs. 45 and 46 ) include all the genera in which the generalized quadrangular type of prothorax has been retained. In all the genera the caudal end of the body is blunt and the tenth segment bears a row of 6 or 8 spines larger than those on the other body segments. The labial palpi are always long and never covered by the maxillae at their proximal end.

Genera of Gracilariinae:

A. Dorsum of abdomen sparsely covered with very coarse spines, sometimes vith additional fine spines.

B. Head with a cutting clate on the ventral surface near the cephallo margin, which is usually serrate; maxillae as long as the mesothoracic legs.

Gracilaria Haworth

BB. Head with a prominent projection at the cephalic end, not a distinct plate; maxillae never as long as the mesothoracic legs.

Ornix Treitschke

AA. Dorsum of abdomen thickly covered with very fine spines which are almost invisible. 



\section{Subfemily Lithocolletinae}

In the Iithocolletinae all the genera but Acrocercops have a strongly elevated median ridge on the prothorax and in all but Acrocercops and Marmara the proximal part of the labial palpi are covered by the maxillae so that the lateral margin cannot be traced cephalad to the labrum. The genus lithocolletis, which seems very distinct from other genera in the subfamily, inciudes two distinct types of larvae. On this basis the genus was divided into two groups designated as the "flat-larval group" and the "cylinarical-larval group". Dr. Chapman in 1902 (Entomologiat Vol. 35, p. 141) proposed the name Cameraria for the flatlarval group and this name is used here, as our investigation shows that the cremaster is a decided genus chracter and furthermore that members of the same genus have the same type of cremaster. It is therefore deemed impossible from a study of the pupal characters that one genus could include both forms with and without a cremaster. The pupae of the cylindrical-larval group studied moreover showed two distinct types of cremaster. That of $\underline{L}$. Iucidicostella (Fig. 65) having a rather broad cremaster with curved setae while in L. tiliacella and I. argentinotella the cremaster is long and slender (Figs. 66, 63) and the setae are T-shaped, the former having one such seta and the latter two. From the standpoint of pupal characters these would properly form three genera. It is interesting to note that Heyrick (Genera Insectorurn part 128) places these in different sections of the genus, and that Miss A. F. Braun in her work on the "Development of the Color Pattern in Lithocolletia" (Journ. Acad. Nat. Scl. Phila. Vol. 16 Series 2 , 

1914) also has them as members of different groups in her phylogenetic tree.

The genera of Lithocolletinae may be separated as

follows:

A. Dorsum of abojominal segments with spines of the same size; caudal margins of abdominal segments never distinctly elevated.

B. Dorsum of abdominal segments covered with spines for its entire length.

C. Maxillae at least $7 / 8$ the length of the wings; labial calpi almost one half this length, their proximal end not covered by the maxiliae; spines on dorsum of abdomen very small and inconspicuous except a row of six spines on the tenth segment.

Acrocercops Wallengren

CC. Maxiliae not more than one-third the length of the wings; labial palpi about one-third of this length, their proximal end covered by the maxiliae; spines on the dorsum of the abdomen small but distinct with a few larger ones on the tenth segment.

Leucanthiza Clemens

BB. Dorsum of abdominal segments covered with spines for about one-fourth their length.

c. Head without a prominent pointed projection; maxillae more than one-half the length of the wings and longer than the prothoracic legs; proximal part of the labial palpl not covered by the maxillae.

Marmara Clemens

CC. Head with a prominent projection; maxillae never one-half the length of the wings nor as long as the prothoracic legs; labial palpi covered by the maxillae at the proximal end.

Cremastobombycia Braun

AA. Dorsum of abdominal segments covered with spines of two sizes, the caudal marging of the segments usually distinctly elevated; labial palpi always covered by the maxillae at the proximal end

B. Caudal end of body never with a distinct cremaster.

Cameraria Chapmen

BB. Caudal end of body glways with a distinct cremaster. 



\section{Species of Gracilariiciae examinea:}

Subfamily Gracilariinae

Gracilaria negunciella Cham., sasaafrasella Cham., violacella Clem.

Ornix prunivorella Cham., crataegifoliella Clem., conspicuella Dietz.

Parectopa salicifoliella Char., lespedezaefollella Clem. Subfamily Iithocolletinae

Acrocercops venustella Clem.

Leucanthiza amphicarpeaefoliella Clem, ostensackenella Fitch. Marmara salictella Clem.

Cremastobombycia solidaginis F. \& B.

Cameraria hamadryadella Clem., ostryella Cham., tubiferella clem.

Iithocolietis lucidicostella Clem., argentinotella Clem., tiliacelia Cham.

\section{Family Phyllocnistidae}

This family is very nearly related to the Gracilariidae and the principal characters used to distinguish them were given under that farnily. The arrangement of parts may be seen in Fig. 67. It will be noted that Phyllocnigtis has long heavily chitinized setae much as in the Tischeriidae except that they are not forked at the tip. There is a fleshy prolongation on each side of the tenth abjominal segment. This family shows a somewhat higher degree of specialization in the prothorax and labial palpi than most of the Gracilariidae. It is, however, not as much specialized as the species of Lithocolletis which have developed a cremaster but is more like Cameraria. It may have 

been developed from the same stem as Cameraria, but its development is more likely to have been parallel with that of the family Gracilariidae. The body is considerably more chitinized, however, than any merner of that family. This family includes a single genus Phyllocnistig Zeller in which the pupae are from 3-4rm in length.

\section{Species examined:}

Fhyllocnistis ampelopsisella Chem., insignis F. \& B.

$$
\text { C. Specialized Pupae with Pillifers. }
$$

There are two superfamilies of Lepicioptera, the Pyralidoidea and Papilionoidea, in which the pillifers are enormously developed, and their presence is incicated in the pupa by the presence of lobea which extend from the caudo-lateral angleg of the labrum torvards the meson and in many instances are adjacent on the meson (Figs. 70, 72, 74, 76, 77, 79; pf.) Besides the presence of these lobes there are many other points of resemblance which would seem to indicate that these two superfamilies had a common ancestor.

\section{Superfamily Fyralioidoidea}

This superfamily includes all those pupae which possess lobes indicating the presence of well developed pillifere and which do not possess clubbed antennae. This comprises the family Pterophoridae, the family Attevidae previougly included in the Yponomeutidae, and probably all of the subfamilies of Pyralididae, although only six of these were examined. The Gallerinae do not fossess the lobes indicating the presence of pillifers, and differ 

in many other respects, from most other pyralids.

The antennae are long, at least five-sixths the length of the wings, and in some instances extend beyond them. The maxillae and mesothoracic legs are both long and extend to the caudal margin of the wings in most genera. The femora of the wrothoracic legs are visible except in some genera of Pterophoridae. In all of these families the appendages are soldered to each other and to the body wall, but in the Pterophoridae they are very slightly soldered and separate readily. The seventh abdominal segment is free in the males of Pterophoridae and Attevidae but fixed in the females. In the Pyralididae it is fixed in both sexes.

The families of Pyralicoidea may be separated as follows:

A. Maxillary palpi never present; the prothoracic and mesothoracic legs always extending cephalad between the sculptured eyepiece and the antennae; body always roughened with short spines or with small groups of long barbed spines and setae arising from small elevations; dorsum of abdomen never with a deep furrow between the ninth and tenth segments.

Pterophoridae

AA. Maxillary palpi usually present, if not, then the dorsum of the abdomen with a dees furrow between the ninth and tenth segments; body surface seldom roughened with spines or setae.

B. Epicranial suture never present; fronto-clypeal suture visible for about half the distance between the proximal end of the antennae and the meson; seventh abdominal segment free in the male and fixed in the female; dorsum of abdomen never with a furrow between segments nine and ten.

Atteviciae

BB. Epicranial suture usually present, if not, then the dorsum of the abdonen with a deep furrow between the ninth and tenth segments; fronto-clypeal suture never indicated; seventh abdominal segment fixed in both sexes. 



\section{Family Pterophoriåae}

This family possesses a curious combination of generalized and specialized characters which make its position rather difficult to determine. It has lost the maxillary palpi, the femora of the prothoracic legs are seldom visible and the epicranial suture is present in but one genus, Pterophorus, where only a small portion of it is visible. On the other hand the seventh abdominal segment is free in the male and fixed in the female. This is clearly seen at dehiscence, for none of the abdominal segments possess much power of motion. The appendages (Fig. 70) are only slightly soldered to each other and to the body wall, and generally separate very readily. The wings are slender and pointed and together with the other appendages project slightly beyond the margin of the fourth abdominal segment. The clypeus, labrum and sculptured eye-piece each bear two prominent setae in Pterophorus and Oxyptilus but in Platyptilia they are very small. There is usually a seta near the caudal margin of each gena. The proximal portion of each antenna is urually considerably widened and ridged and in Pterophoru an axyotilus bears long spines. The prothoracic legs are exceptionally long in this family and reach nearly to the caudal margin of the wings. The maxlliae are often overlaid by the prothoracic legs for a part of their length, and sometimes are only visible for a short distance at their proximal and distal ends, the entire mesal portion being concealed. The location of the genital openings are unusual, appearing to be always on the tenth abdominal segment, which extends very far cephalad and forms a sort of ventral plate 

on the fixed caudal segments. In Platyptilia the plate is not so prominent and the dividing sutures between the segments may be distinguished. At the cephalic margin of this plate is a large group of hooked setae in Pterophorus and Oxyptilus, and in Platyetilia a rounded tubercule bearing four hooked setae. The spiracles are slightly produced. The prothoracic spiracle (Fig. 7I) apparently belongs to the mesothorax and 18 situated mesad of 1 ts usual position. It is also slightly produced. The peculiar spiny armature of most of the genera makes them very easy to distinguish from all other pupae. They are always found exposed, attached by the cremaster, and vary in length from 8-15mm.

The genera may be separated thus:

A. Body with long, prominent barbed spines and setae arising mostly from dorsal and lateral elevations; tenth segment with a mass of hooked setae at its cephalic margin.

B. Femora of the prothoracic legs exposed; dorsal and lateral elevations with barbed spines of varying lengths.

Pterophorus Geoffroy

BB. Femora of the prothoracic legs never exposed; dorsal and lateral elevations usually with two barbed spines which are very broad at base and on the side of each is inserted a stout straight seta.

Oxyptilus Zeller

AA. Body without any long barbed spines or setae, but with short, widely separated triangular projections on most of the abdominal segments; tenth segment with a rounded prominence near the cephalic margin bearing about four hooked setae.

Platyptilia Hubner

Species examined:

Pterophorus paleaceus Zeller.

Oxyptilus tenuidactylus Fitch.

Platyptilia carduidactyla Riley. 

Family Attevidae

The genus Atteva, (Figs. 72, 73), formerly included in the family Yponomeutidae, was found to differ in all its important characters from the members of that family and to be closely allied to the Pyralididae. It retains the same arrangement of setas on the clypeus and labrum as in the Yponomeutidae. The setae at the caudal end of the body are also similar in arrangement, but the subfamily Phycitinae also have setae arranged in this way. It seems very probable that the Attevidae and Yponomeutidae arose from a common stock, but that the former branched off before motion was lost in the seventh segment of the male. In the Attevidae there is a narrow conjunctiva between the geventh and eighth segments in the male and there is slight motion possible. The eighth, ninth, and tenth segments are unusually long and distinctly segmented. There is no epicranial suture present, and at dehiscence the eye-pieces are not separated from the other face-parts, which indicates a high degree of specialization. The maxillary palpi are present, but not as well developed as in most pyralids. The labial palpi are represented by a small polygonal area caudad of the lobes indicating the presence of pillifers which meet on the meson.

The fronto-clypeal suture is present for about half the distance between the proximal ends of the antennae and the meron and it dehisces for this distance at the emergence of the imago.

This family includes the single genus Atteva Walker.

The pupae of this family are from 15-20mm. in length.

Species examined:

At teva aurea Fitch. 



\section{Family Pyralididae}

This family (Figs. 74, 75, 76) includes a number of subfamilies of which only six are discussed here. The epicranial suture is present in all of these except the Epipaschilnae and a few genera of Phycitinae but the vertex is very short in all of the others, and often represented by a small triangular area adjacent to each antenna which does not reach to the meson. The antennae are long, at least seven-eighths the length of the wings and often much longer, and the distal ends never meet on the meson. The labial palpi are visible only as small triangular or polygonal areas, except in the Crambinae which often show a large portion between the halves of the maxillae. The maxillae are always long except in the Gallerinae, usually reaching the caudal margin of the wings and sometimes extending beyond them. The maxillary palpi are present in all subfamilies except the Epipaschilnae. Each prothoracic leg is from one-half to three-fourths the length of the wings and its femur is always exposed. The mesothoracic legs generally extend to the caudal margin of the wings. The abdominal segments never possess spines, except in the Gallerinae, but are smooth or punctate. The spiracles are of different types, some being slightly produced. The location of the prothoracic spiracle is difficult to determine in most species, there being no visible opening. The appendages are always firmly soldered to each other and to the body wall. The pupse vary in length from $8-20 \mathrm{~mm}$.

The following table will serve to separate the subfamilies of Pyralididae: 

A. Maxillary palpi always present; epicranial suture usually distinct, at least for a part of its length.

B. Maxiliae never more than three-fifths the length of the wings; dorsum of thorax and abdomen with a prominent median ridge and the segments covered with small spines.

Gallerinae

BB. Maxillae always more than three-fifths the length of the wings; dorsum of thorax and abdomen never with a median ridge nor with small spines on the segments.

C. Cremaster absent, or never long and well developed; furrows usually present on the dorsum between the ninth and tenth abdominal segments, or on the lateral part of the tenth segment; head usually rounded; body never with a shouldered appearance; labrum in 1 ts normal position.

D. Caudal end of body with all the setae straight and very short; cremaster short and blunt; lateral margins of the dorsum of the tenth abdominal segment with prominent deep furrows extending caudad to the proximal end of the cremaster; a large portion of the labial palpi often exposed.

Crambinae

DD. Caudal end of body never with all the setae straight, usually long and booked; lateral margins of the tenth abdominal segment never with deep furrows unless they are extensions of the dorsal furrow between the ninth and tenth; labial palpi never with more than a very small triangular or polygonal area exposed.

E. Dorsal furrow, if present between the ninth and tenth abdominal segments, with a crenulate margin; prothoracic spiracles never tubular, but slit-like and not plainly Indicated; caudal end of body without a cremaster, and bearing a transverse row of six or elght slender hooked setae.

Pyralinae

EE. Dorsal furrow usually present between the ninth and tenth abdominal segments and never with a crenulate margin, if the dorsal furrow is absent then the prothoracic spiracles produced and tubular; cremaster wanting or very short.

Phycitinae

CC. Cremaster always present and well developed; dorsal furrows never present between the ninth and tenth abdominal segments; or on the lateral part of the tenth segment; head blunt; body with a distinctly shouldered appearance; labrum always cephalad of its normal position. 

AA. Maxillary palpi never present; epicranial suture never visible for any part of its length; dorsal furrow between the ninth and tenth abdominal segments strongly curved caudad and lined with a fringe of short setae.

Epipaschilnae

\section{Subfamily Gallerinae}

The pupae of this subfamily are very different from most Pyralids and there is some doubt as to whether they should be included with this family. The lobes which indicate the presence of pillifers are not well developed and the maxilla are short (Fig. 69). The body is short and thick and covered on the dorsum of the thorax and abdomen with short spines. A strongly elevated median ridge is also present on the thorax and on the first eight abdominal segments. The prothorax is very long, at least onehalf the length of the mesothorax.

\section{Subfamily Crambinae}

The pupae of the Crambinae are easily recognized by the peculiar form of the short, blunt cremaster and the deep lateral grooves on the tenth abdominal segment. Some of the species show a large portion of the labial palpi, indicating that this subfamily is one of the more generalized. The maxillae reach almost to the caudal margin of the wings and the tips of the mesothoracic legs meet on the meson just caudadas me segments are almost smooth, never punctate.

Species examined:

Crambus vulgivagellus Clem., trisectus Walk, caliginosellus Clem. 


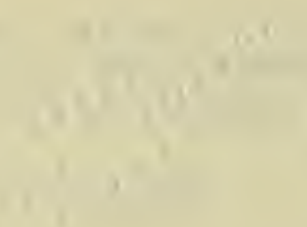

.
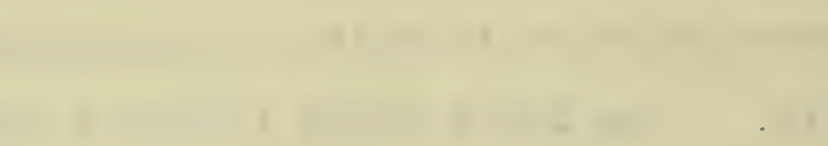

$x^{7}+x^{2}=$

-
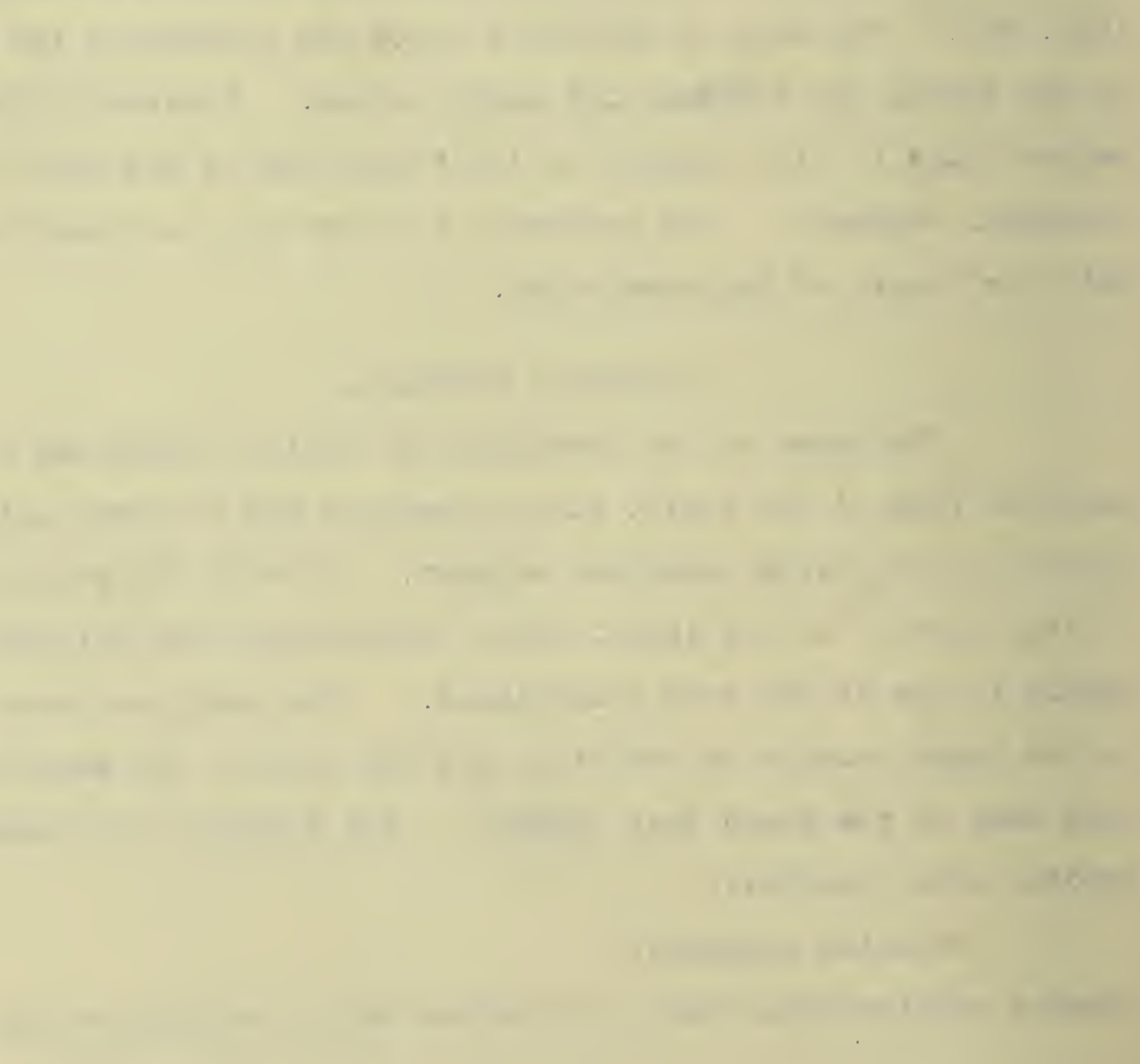


\section{Subfamily Pyralinae}

The species of this subfamily resemble closely the genera Plodia and Ephestia of the Phycitinae. There scarcely seems to be more than generic differences between them. The epicranial suture is present and the vertex always extends to the meson. The maxillary palpi are well developed and usually reach the proximolateral angles of the maxillae. There is never a cremaster present, but a transverse row of hooked setae at the caudal end of the body.

The two genera studied may be separated as follows:

A. Dorsum of abdomen with a furrow between the ninth and tenth segments, the caudal margin of the furrow distinctly crenulate. Pyralis Linnaeus

AA. Dorsum of abdomen without a furrow between the ninth and tenth segments.

Hypsopygia Hübner

Species studied:

Pyralis farinalis $L$.

Hypsopygia costalis Fabr.

\section{Subfamily Phycitinae}

This group is, for the most part, easily distinguished from other pyralids by the presence of the suture on the dorsum of the abdomen between the ninth and tenth segments, the presence of maxillary palpi, and usually the epicranial suture. Of the genera examined, Ephestia and Plodia alone were without this dorsal furrow and they possess tubular spiracles on the prothorax. These two genera seem rather more closely related in many respects to the Pyralinae than to the Phycitinae. The maxillary palpi always extend to the proximo-lateral angles of the maxillae. The 

epicranial suture is present in all genera but Pinipestis, but is very near to the suture between the head and prothorax. The vertex is represented by a small triangular area adjacent to each antenna. The lobes enclosing the plilifers meet on the meson in some genera.

The genera of Phycitinae may be separated as follows:

A. Dcrsal surface without a prominent furrow separating the ninth and tenth abdominal segments; prothoracic spiracles tubular.

B. Abdominal segments punctate; maxillae reaching the caudal margin of the wings.

Ephestia Guenée

BB. Abdominal segments smooth; maxillae never reaching the caudal margin of the wings.

Plodia Guenée

AA. Dorsal surface with a prominent furrow separating the ninth and tenth abdominal segments; prothoracic spiracles never tubular, their exact position usually difficult to determine.

B. Body depressed; tenth abdominal segment with the caudal end distinctly margined and with six straight setae inserted on the ventral side of the margin.

Acrobasis Zeller

BB. Body never depressed; tenth abdominal segment never with the caudal end distinctiy margined and inserted on the ventral side of the margin.

C. Caudal end of body with four long, hooked setae and on each side of these a short spine or hooked seta extanding laterad.

D. Tenth abcominal segment with lateral spines very different from the caudal setae.

E. Ninth abdominal segment with a lateral spine on each side similar to those on the tenth segment, and two hooked setae on the dorsum adjacent to the caudal margin; caudal hooked setae equidistant.

Mineola Hulst

EE. Ninth abdominal segment without lateral spines or hooked setae on the dor sum adjacent to the caudal margin.

F. Caudal spines not adjacent, equidistant; of equal length. 

FF. Caudal spines adjacent; two of them shorter than the other two.

Psorosina Dyar

DD. Tenth abdominal segment with lateral hooked setae similar to the caudal setae.

Canarsia Hulst

CC. Caudal end of body with a transverse row of six long hooked setae of equal length; epicranial suture never present; head with a prominent pointed cephalic projection. Pinipestis Grote

The following species were examined:

Plodia interpunctella Hibner.

Ephestia kuehniella Zeller.

Acrobasis rubrifasciella Packard.

uineola indiginella Zeller.

Heroptera pravelia Grote.

Psorosina hammondi Riley.

Canarsia ulmiarosorella Clemens.

Pinipestis zimmermani Grote.

\section{Subfamily Pyraustinae}

This group is distinguished by the peculiar "shouldered" appearance of the boly, caused by the great width of the thorax as compared with the head and by the position of the laorum, which is always cephalad of its normal position and often located near the cephalic end of the body. There is never a suture on the dorsum between the ninth and tenth abdominal segments. The maxillary palpi are always present and only a very small portion of the labial palpi is exposed. The epicranial suture is present in all genera. The mesothoracic legs and antenna, together with the metathoracic legs which are hidden by them, usually extend beyond the caudal margin of the wings. The prothoracic spiracles often have peculiar ridges along their caudal margin which are sometimes covered rith setae. Similar ridges are found in certain families of Papilionoidea and Notodontoidea. The shape of body and arrange- 

ment of parts in the Pyraustinae resembles that of certain

Sphingidae, and would seem to inilcate that the Pyraustinae were not as closely related to the Phycitinae as the other subfanilies, which all show a very close relationship. The genus Pyrausta as understood at present probably does not represent a natural group. Of the species studied $\underline{p}$. fissalis and $\underline{P}$. illibalis have lons narrow cremasters of similar type, while $\underline{p}$. futilalis and

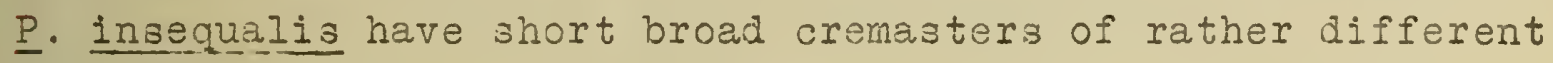
types. There is also great variation in the length of the appendages but this is not such a decided generic character as the form of the cremaster. This subfamily incluces the largeat pyralids examined.

The genera of Pyraustinae may be separated by the following table:

A. Setae of the cremaster always hooked and equal in length to the cremaster or sometimes longer; the other appendages never extending beyond the caudal margin of the wings.

B. Setae of the thorax and abdomen very long, heavily chitinized and forked at the distal end, usually much longer than the segments; mesothorax and metathorax having a deep oblong pit with strongly chitinized edges at the base of each wing.

Phlyctaenia Hibner

$B B$. Setae of the thoraz and ablomen never prominent, scarcely ever visible; mesothorax and metathorax never having deep oblong pits at the base of each wing.

c. Prothoracic spiracle with a prominent elevation adjacent to the caudal margin, which bears several ridges fringed with setae; front with a diatinct tubercule or small ridge at the base of each antenna.

Desmia Westwood

CC. Prothoracic spiracle without any prominent elevation adjacent to the caudal margin; front without a tubercule or ridge at the base of each antenna. 

AA. Setae of the cremaster either straight and equal in length to the cremaster, or hooked and much shorter than the cremaster; the other appendages often extending beyond the caudal margin of the wings.

B. Prothorax with a distinct tubercule on each side the meson; cremastral setae straight and spread out fan-like.

Tholeria Hübner

BB. Prothorax without a distinct tubercule on each side the meson; cremastral setae hooked, and not spread out fan-like.

Pyrausta Schrank

The following species were examined:

Phlyctaenia ferrugalis Hübner.

Desmia funeralis Hubner.

Pantagrapha limata $G$. \& $R$.

Tholeria reversalis Guenee.

Pyrausta fissalis Grote, ilibalis Hübner, futilalis Lederer, insequalis Guenee.

Superfamily Papilionoidea

The members of this superfamily are distinguished by the presence of lobes indicating the presence of well developed pillifers and distinctly clubbed antennae. The genus oeneis is an exception, hovever, in not having the lobes well developed, but this is probably aue to specialization as it seems very closely allied to the Satyrinae, especially in the length of the prothoracic legs. Many of the Papilionoidea have prominent ridges and tubercules on the surface of the body, but there are also many genera in which the body surface is quite smooth and destitute of tubercules and ridges. The epicranial suture is present in three families, Megathymidae, Hesperiidae and Lycaenidae. There has been a great deal of discussion and disagreement over the arrangement and subdivision of the families of the Papilionoidea. Some have divided it into tro superfamilies, Hesperioidea and 

Papilionoldea, but the pupae show no characters to warrant auch a division. The family Lycaenidae has been considered by many as the most specialized or among the most specialized of the families, yet they still retain the epicranial suture. In this family, however, the labial palpi are entirely concealed, except in the case of the aberrant genus Feniseca, and the shortening of the prothoracic legs is similar to the condition found in the Nymphalidae. It is impossible, without further study of existing forms, and a larger series of species, to discuss fully the relationships between the different families. It is sufficient for the present to state that the Lycaenidae seem more nearly related to the generalized Hesperildae, but have developed in a similar manner to the Nymohalidae, and that the Pieridae, Papilionidae, and Nymphalidae seem very closely related.

The families of Papilionoidea may be separated as

follovg:

A. Proximo-lateral angles of the maxillae extending laterad to the eye-pieces.

B. Maxillae never reaching the caudal margin of the wings; wings adjacent on the meson caudad of the maxillae.

Megathymidae

BB. Maxillae always extending to the caudal margin of the wings and sometimes beyond; wings never adjacent on the meson.

Hesperiidae

AA. Proximo-lateral angles of the maxillae never extending laterad to the eye-pieces.

B. Hesothoracic legs never extending cephalad to the eye-pieces. C. Epicranial suture always present; head without projections; exposed part of maxillae never as long as the wings.

Lycaenidae 

CC. Epicranial suture never present; head always with prominent projections; exposed part of maxillae usually as long as the wings.

D. Head with two prominent projections, one at each cephalo-lateral angle; metathoracic wings visible in ventral view.

Papilionidae

DD. Head with a median projection; metathoracic wings not visible in ventral view.

Pieridae

BB. Mesothoracic legos extending cephalad to the eye-piecea and for a short distance between the glazed eye-piece and the antenna.

Nymphalidae

Family Megathymidae

The family Megathymidae, or giant skippers, are evidently the most generalized of the Papilionoidea although they differ but little from the more generalized Hesperiidae and there is some doubt as to whether they show enough difference to warrant their being considered as a distinct family. However, only one specinen of this family has been seen and that had lost some of the face-parts so that a complete description can not be given and no very definite stand taken as to its position in the superfamily. The members of the superfamily Papilionoidea, as a general rule, possess but little freedom of motion in the free segrents and these are rarely capable of being "telescoped". In the lifegathymidae not only are the free segments capable of a great deal of motion and capable of being telescoped, but there appears to be dorsal motion possible between the third and fourti abdominal segments, and the seventh abdominal segment appears to possess freedom of motion in the male. The abdominal segments are of 

nearly equal length, and the eighth, ninth, and tenth are distinctly segmented. These characters, however, appear to be retained in such generalized Hesperiidae as the genera Calpodes and Amblyscirtes, where if all the above mentioned segments do not retain freedom of motion, they have certainly but recently lost it. In placing this family in the Papilionoidea it has been assumed that they possess lobes indicating the presence of pillifers, but these parts were absent in the pupa examined. The labial palpi are represented by a small triangular area, and it is not known whether or not maxillary palpi are retained. The maxillae are much shorter than in the Hesperiidae, being only about two-thirds the length of the wings, but this indicates nothing as to their position, as both generalized and specialized pupae possess short maxillae. None of the other appendages are longer than the maxillae, except the wings, which lie adjacent on the meson caudad of the maxillae. The epicranial suture is prosent and the vertex is of equal length throughout, being about one-fifth the length of the prothorax measured on the meson. The entire body surface is covered with a whitish bloom and on the dorsum of abdominal segments 7-10 there is in addition a dense covering of rather coarse setae. The pupa examined was $40 \mathrm{~mm}$. In length and about $10 \mathrm{~mm}$. In breadth, and belonged to the genus Megathymus scudder. Species exarnined:

Megathymus yuccae Boisduval and Le Conte.

\section{Family Hesperiidae}

The Hesperildae retain considerable freedom of motion 

of the abdominal segments and in many genera it would seem that dorsal motion were possible between the third and fourth abdominal segments and that the seventh abdominal segment were free in the male, or at least that they had only recently lost the power of motion. The epicranial suture is present in all genera and the vertex is about one-fifth the length of the prothorax meaared on the meson, while the lateral margins are consicerably longer. The labrum in most genera is considerably cephalad of its normal position. The antennae never reach to the caudal margin of the wings but are from two-thirds to three-fourths of their length. The prothoracic legs are about one-half the length of the wings, the mesothoracic usually two-thirds, while the metathoracic pair are seldom visible. The maxillae alwayg extend to the caudal margins of the wings and frequently considerably beyond. The prothoracic spiracles usually have a peculiar kind of plug or plate which seems to form an external closing apparatus or guard, While some have prominent tubercules caudad of the opening, usualy with a dense covering of setae. The thorax and abdomen usually have a more or less denee covering of setae and some of the species have the entire body covered with a whitish bloom, which is of comparatively rare occurrence among lepidopterous pupae. The abdomen frequently has a furrow on the dorsum between the ninth and tenth segments, similar to the furrows found in the Pyralididae but never so deep. The cremaster in all genera is more or less triangular, with hooked setae on the distal end, and frequentIy has an impressed triangular area on the dorsum. The classification of the Hesperildae has long been in dispute and it is 

impossible to state with the limited amount of material available for examination just how a classification of the pupae would agree with the proposed schemes. It is believed, however, that Scudder's arrangement would probably be followed, as the material available falls readily into his groups. As to the relationship between these groups there might be some difference of op-inion. The pupae at first sight are readily divided into two groups, one with the abdominal segments caudad of the fourth considerably shortened, possessing narrow flanged plates on the movable segments which prevents the "telescoping" of the body, and with the segmentation distinct between the fixed caudal segments (Fig. 77). This group also has the body prominently convex on the dorsum of the mesothoras and on the entire ventral surface of the thorax and abdomen. The labrum is cephalic in position. The other group possesses abdominal segments of more nearly equal length, having distinct outures between the fixed caudal segments and the movable segrnents capable of being "telescoped". This group has apparently just recently lost the power of motion in the seventh abdominal segment of the male and dorsal motion between the third and fourth abdominal segments. The body is shaped like the majority of lepidopterous pupae, and the labrum never quite reaches the cephalic margin of the body. Of this group, the genera possessing maxillae extending beyond the caudal margin of the wings, Calpodes (Fig. 78) and Anblyscirtes are undoubtedly more generalized, not on account of the maxillae, but because in all the other members there is considerably more consolidation of the caudal abdominal segments so that they seem intermediate in posi- 

tion between the genera mentioned above and the first group.

The following table will serve to separate the genera of Hesperiidae:

A. Abdominal segments 5-7 never with an elevated ridge or flanged plate along the cephalic margin and always capable of being telescoped; body never with a prominent convexity on the ventral surface in the region of abdominal segments $1-4$.

B. Maxillae extending Iree for a considerable distance beyond the caudal margin of the wings.

C. Maxillae extending beyond the caudal margin of the body; head with a long cephalic projection.

Calpodes Hübner

CC. Maxillae never extending beyond the caudal margin of the body; head, with a long cephalic projection.

Amblyscirtes Scudder

BB. Haxillae never extending free beyond the caudal margin of the wings.

C. Body with a dense covering of long setae and whitish bloom; prothoracic apiracle with a strongly elevated oval area adjacent to its caudal margin, this area chitinized in the centre and surrounded by a dense band of short setae with a longitudinally striate chitinzed rim forming an outer margin.

Pholisora Scudder

CC. Body sparsely covered with short inconspicuous setae; dense whitish bloom never present; prothoracic spiracles with a somerhat circular elevation adjacent to ita caudal margin, which is entirely covered with setae.

Thanaog Boi sciuval

AA. Abdominal segments $5-7$ with an elevated ridge or flanged plate along the cephalic margin which prevents their being telescoped; body with a prominent convexity on the ventral surface in the region of abdominal segments $1-4$.

B. Mandibular area with distinct tubercules usually blaok and bearing stout setae; head slightly narrower than the mesothorax.

C. Prothoracic spiracles semicircular in outline, the opening circular, surrounded by a broad thick band of setae around the caudal half.

D. Borsal furrov or depression on the ninth abdominal 

segment with its caudal margin distinctly crenulate; ventral surface of cremaster with an elongate furrow broadened out at the distal end of the cremaster.

Thorybes Scudder

DD. Dorgal furrow or depresaion on the ninth abdominal segment not distinctiy crenulate; ventral surface of cremaster with a triangular depression broad at the proximal end and narrowed to the distal end of the cremaster.

Epargyreus Hubner

CC. Prothoracic spiracles semicircular in outline, the openings circular and surrounded by a broad thick band of setae, and caudad of this a distinctly elevated chitinized riage forming an outer margin.

Cocceius

BB. Mandibular area smooth, without tubercules; head as broad as the mesothorax.

Eudamus Swainson

The following species were examined:

Calpodes ethlius cramer. Amblyscirtes vialis Edwards.

Pholisora catulius Fabr.

Thanaos brizo Bois. \& Le C., Iucilius Lint.

Thorybes daunus Cramer.

Epargyreus tityrus Fabr. Cocceius pylades Scudder.

Eudamus proteus L.

Family Lycaenidae

The Lycaenidae are small pupae between 8 and $15 \mathrm{~mm}$. in length which have the general shape of arctians although they are generally less curved on the ventral surface (Fig. 79). They retain a small portion of the vertex on each side and the epicranial suture usualiy touches the caudal margin of the head at the meson, making each half of the vertex triangular. The lobes indicating the presence of pillifers, always meet on the meson except in the genus Feniseca. The antennae always extend to the caudal margin of the wings and lie adjacent on the meson, 

concealing the distal ends of the maxillae. The prothoracic legs are shorter than usual, varying from two-fifths to one-third the length of the wings. The mesothoracic legs are about one-half the length of the wings and the metathoracic pair are never visible. The body is usually quite free from projections or elevations, Feniseca being the only exception known and it bears small rounded tubercules on its dorsal surface. The head is limited to the ventral surface of the body, and the suture between it and the prothorax is located on the cephalic margin of the body sometimes forming a glight ridge. The prothorax is longer than is usual in Papilionoidea being about half as long as the mesothorax. There is little, if any, motion possible between any of the abdominal segments and they fit together so as to form a smooth surface. Even the pupal skin after dehiscence shows no separation of the abdominal segments. The surface of the thorax and abdomen is covered with a reticulation of fin elevated lines with small papillae at their intersections and sometimes in the spaces between. These paplilae usually bear cuticular appendages of various types the most peculinr being the fungiform type of the genera Chrysophanus and Heodes. There is no cremaster present in any member of the family. The ventral surface of the abdomen frequently bears groups of small hooked setae. The Genital openings are usually obscured. The anal opening is peculiar in many forms being transverse instead of longitudinal. The prothoracic spiracles are closed by a plug or plate which fills up the opening and usually preaents a honey-combed appearance. The following table will serve to separate the genera 

of Lycaenidae:

A. Exposed portion of maxillae never more than three-fifths the length of the wings; cuticular appendages of the body never fungiform.

B. Ventral surface of the body never with hooked setae caudad of the anal opening; thorax and abdomen usually densely covered with spiculate cuticular appendages; exposed portion of maxillae scarcely more than one-half the length of the wings.

C. Ventral surface of ninth segment with a group of hooked setae on each side of the meson.

D. Thorax with the median line slightly elevated; raised lines of the reticulations very prominent; papiliae short, cylinarical.

Incisalia Minot

DD. Thorax with the median line never elevated; raised lines of reticulations not prorninent; papillae conical.

Uranotes Scudder

CC. Ventral surface of ninth abdominal segment never with hooked setae on each side the meson.

D. Ventral surface of ninth abcominal segment with a group of straight setae on each side the meson; setae on body very dense and about one-fourth the length of the abdominal segments; papillae conical.

Mitura Scudder

DD. Ventral surface of ninth abdominal segment without setae of any kind; setre of body not dense, but long, usually one-half the length of the segment; papillae short, cylindrical.

Thecla Fabricius

BB. Ventral surface of body with hooked setae caudad of the anal opening; papillae more numerous in the spiracular region; thorax aud abdomen sparsely covered with short cutioular appendages with very minute spicules; exposed portion of maxillae three-fifths the length of the vings.

C. Each abdominal spiracle vrith a group of papillae carriag ale; spiracles of the second abdominal segment not adjacent to the wing.

Cyaniri로 Ialman

CC. Each abdominal spiracle surrounded by a group of papiliae; spiracle of the second abdominal segment adjacent to the wing, the distance between them less than the width of the 

spiracle.

Rusticus Fübrer

AA. Exposed portion of the maxillae more than three-fifth the length of the wings.

B. Body of typical lycaenid shape never flattened at the caudal end; cuticular appendages fungiform.

C. Fungiform cuticular appendages small and inconspicuous, not visible with a low power lens; color light yellowish brown, not spotted.

Chrysorhanus Hübner

CC. Fungiform cuticular appendages large and conspicuous, easily vigible with a low power lens; color dark brown with black spots.

Heodes Dalman

BB. Body with the caudal end flattened and curved slightly ventrad.

Feniseca Grote

The following species were examined:

Incisalia niphon Hïibn.

Uranotes melinus Hïbn.

Mitura damon Cram.

Thecla acadica Edw., calanus Hubn. liparops Boisa. \& Le C.

Cyaniris ladon Cram.

Rusticus scudderi Edw.

Chrysophanus thoe Boisa.

Heodes hypophless Boirá.

Feniseca tarquinis Fabr.

\section{Family Papilioniclae}

The pupae of this family are visually long and slender tapering gradually to the pointed caudal end which is called the cremaster although it seldom resembles a true cremaster, and extends very little beyond the anal opening. The body always has two prominent cephalic projections one at each cephalo-lateral angle of the head, a less prominent lateral projection on each side the metathorax at the base of each wing, and a low median carinate ridge which extends along the prothorax onto the 

mesothorax for about half its length, where it forms a more or less prominent projection. From this prominence the ridge divides and extends the remainder of its course on the metathorax and may extend to the abdomen to form the dorso-lateral abdominal ridges. There is also usually present a lateral ridge on each side. These four ridges are continued to the end of the body, and are often present on the tenth segrnent or cremaster when absent from the remaincier of the abdomen. On the ventral surface there is usually a ridge onfeach slde of the face-partg beginning at the cephalic projections and extending to the proximo-lateral angles of the maxillae.

The labrum is in its nomal position and the lobes which indicate the presence of pilidfers seldom meet on the meson, but are separated by a small portion of the labial palpi. The epicranial suture is never present, and the proximal ends of the antennae approach each other very closely on the dorsal surface of the head. The antenrae never extend as far caudad as the wings. The wings are usually somewhat pointed on the ventral surface near the meson and the metathoracic wing is always visible here, extending for a considerable distance caudad of the mesothoracic wings. The maxillae always extend to the caudal margin of the wings, The legs are of the usual length in lepidopterous pupae with the exception of the genus Iphiclides in which the prothoracic legs are about the usual length, but the mesothoracic legs end before the former, a very rare occurrence in this order. The genital openings are located in the usual positions, those of the female being confluent on the ventro-meson of the eighth and 

ninth abdominal segments. Just caudad of the genital openings, at the cephalic margin of the tenth abdominal segment is a small tubercule on each side the meson closely appressed to the surface of the body. The caudal end of the body bears a mass of very short hooked setae. The fourth, fifth, and sixth segments are movable, although they fit closely together to form an even surface and are not capable of "telescoping". At dehiscence they separate to show deep incisions.

The genera of Papilionidae may be separated as follows:

A. Body surface without distinctly carinated ridges; dorsal surface of abdomen always with a row of small rounded tubercules on each side the meson, the largest on segments 4-7, and usually a row of smaller tubercules on each side of the soiracles; ventral aurface with two distinct tubercules on each leg, a transverse row near the caudal margin of the mesothoracic wings, and often on the veins near the margin.

Papilio Linnaeus

AA. Body surface with diatinctly carinated ridges, but never with small rounded tubercules on any part.

B. Body without prominent lateral expansions of the abdominal segments or dorsal carinate ridges.

C. Body with a very low dorso-mesal ridge on the thorax with a small mesothoracic elevation; a prominent carinated ridge at each lateral margin of the body and no dorsolateral ridge; cephalic projections large and prominent; body very strongly convex on the ventral surface in the region of the wings.

Euphoeades Hübner

CC. Body with a low dorso-mesal ridge on the thorax ending in a very prominent mesothoracic elevation; a very lor dorso-lateral and lateral ridge on each side of the abdomen; cephalic projections not very large; body never strongly convex on the ventral surface.

Inhiclides Hübner

B. Body with prominent lateral expansions of the first four abdominal segments, making this the wiest part of the body; abdominal segments with dorsal carinated ridges on each side the meson most prominent on segments 5-7, which are highest in the midale of each segment and curve to each 

margin giving it a scalloped appearance in lateral view. Laertias Fïbner

The following species were examined:

Laertias phileror L.

Iphiclides ajax I.

Euphoeades troilus I.

Papilio daunus, Boisd., eurymedon Boisd., rutulus Boisd., glaucus I., polyzenes Fabr., thoas I., machaon L., zolicaon Boisa.

\section{Family Pieridae}

The pupae of this family resemble the Papilionidae very strongly as to the general shape of the body and arrangement of ridges and projections. They are much smaller, however, and are easily recognized by the fact that they possess a single median cephalic projection instead of two cephalo-lateral projections as In the Papilionidae. The epicranial suture is never present. The labrum is usually slightly cephalad of its normal position and a small portion of the labial palpi is always exposed. The maxillae vary in length from two-thirds the length of the wings to extending slightly beyond their caudal margin. The legs are of normal length. The antennae are more distinctly clubbed than in the Papilionidae and sometimes reach the caudal margin of the wings. The caudal end of the body is very like that of the Papilionidae except that the four ridges are seldom present, and the hooked setae are inserted in a slight concavity. The genital openings are in the usual positions. On the ventral surface of the tenth adominal segment there is a low ridge, circular in outine which encloses the anal opening and terminates at its cephalic end in a small tubercule on each side the meson. These tubercules are located just caudad of the genital openings. 

Similar tubercules and ridges are found in the Nymphalidae but are rather more prominent in that family. The tubercules without the ridges occur in the Paplitonidae.

There is very little question as to whether or not the Pieridae and Papilionidae are related, but as to which is the more specialized seems to be a questionable point with all workers in the group. Aside from the question of prominences or projections, which after all, seems a matter of small importance, there is Iittle of fundamental difference between the two families excepting the length of the thoracic segments which are more generalized in the Papilioniciae, and the ridges and tubercules just mentioned on the ventral surface of the Pieridae, which resemble the Nymphalidae The Nymphalidae seem undoubtedly to be the most specialized of the Papilionoidea, although this is another much debated question. The two families have undoubtedily been developed from a common ancestor and represent parallel lines of development.

The genera of Piericae may be separated by the following table:

A. Distance from cephalic margin of prothorax to the distal end of the cephalic projection much less than the length of the prothorax; ventral line of body often convex but never forming a prominent angle.

B. Thorax with a strongly carinate median ridge, highest at the middle of the mesozthorax, and forming a prominent projection; abdomen with a lateral carinated ridge on each side forming two prominent projections on the second and third segments, the latter more prominent; a median carinated riage from the fourth abdominal segment to the caudal end of the body; ventral line of body practically straight. Pontia Fabricius

BB. Thorax without a strongly carinated median ridge, either without a median ridge or with one of equal height throughout. 

C. Ventral surface of body convex but without any prominent rounded projection; a low lateral ridge present along the wings extending on the abdomen to the caudal end of the body.

Eurymus Swainson

CC. Ventral surface of body produced into a prominent rounded. projection which, near the caudal margin of the wings is as wide as the body just caudad of the wings; body without any prominent ridges, a lateral ridge present along the wings but scarcely indicated on any of the aidominal segments except the tenth.

Eurema Hüoner

AA. Distance from the cephalic margin of the prothorax to the distal end of the cephalic projection about equal in length to the thorax; ventral line of body forming a prominent obtuse angle at a point about equidistant between the cephalic and caudal ends.

Synchloe Hübner

The following species were examined:

Pontia protodice Bo1sd. \& Le C., rapae $L$.

Eurymus chilodice Godart.

Eurema nicivoe Crumer.

Synchloe genutia Fabr.

Family Nymphalidae

The members of this family have been variously subdivided. Some writerg would make several families of the species included here, while othere divide them into subfarnilies and tribes. At present no good characters are known to divide this group into families, but it must be admitted that the same difficulties lie in the wey of dividing ther into the subfamilies and tribes, as proposed by Scudder. Consequently, several subfamily names have been introduced here to facilitate the grouping of the species. The Nymphalidae are distinguished from all other families lacking the epicranial suture, by the fact that both prothoracic and mesothoracic legs extend cephalad to the eyepieces and the mesothoracic legs extend for a short distance 

between the glazed eye-pieces and the antennae. The prothoracic legs are very short, rarely more than one-third the length of the wings. The antennae and maxillae, except in a few instances, reach to the caudal margin of the wings. The proximal ends of the antenmae extend almost to the meson on the dorsum of the head. The labial palpi are represented by a very small portion caudad of the labrum and in many cases are entirely concealed. With the exception of Araea andria the metathoracic wings are not visible on the ventral surface. The genital openings are in the usual position. The circular furrow enclosing the anal opening with the small tubercules caudad of the genital openings, is present in nearly all genera. When tubercules are present on the surface of the body they are usually on the dorsum of the abdornen and are arranged in seven rows, as follows: a dorso-mesal row, a dorso-lateral row on each sicie about half way between the meson and the spiracles, and a dorsal and ventral row on each side of the abdoninal spiracles.

The superfamilies of lymphaliciae may be separated as

follow:

A. With prominent tubercules on the dorsal surface of the body, or at least on the abdornen, a dorso-mesal row, a dorso-lateral row on each side, and a row dorsad and ventrad of each row of spiracles.

Nymohalinae

AA. Without prominent tubercules on the dorsal surface, at least rot arranged in rows as above.

B. Second abdominal segraent with a prominent carinated median elevation, sornewhat constricted at its base.

Basilarchina.e

$B B$. Second abdominal segment without a prominent, carinated median elevation. 

C. Body compressed, with a distinct dorso-mesal carina on the thorax and aboomen; ventral surface of ninth and tenth abdominal segments with hooked setae, the tubercules on the ninth segment covered with very short hooked setae.

Apaturinae

CC. Body not compressed; dorso-mesal carina never present on both thorax and abdomen.

D. Abdominal segments caudad of the wing's ralidy tapering and forming a sort of hemisphere; dorsum of abdomen with a prominent transverse ridge.

E. Head with a prominent transverse ridge, extending along the midale of the eye-pieces and the lateral margin of the body; second, third and fourth abdominal segments of approximately the same length; cremaster directed ventrad; transverse ridge on the fourth abdominal segment.

Anaeinae

EE. Head without a transverse ridge, but with two prominent tubercules; second abdominal segment longer than any of the others; cremaster directed caudad; transverse ridge on the third abdominal segrnent tuberculate for its entire length.

Euploeinae

DD. Abdominal segments caudad of the wings not racidly tapering to form a hemisphere; dorsum of abdomen never with a transverse ridge.

E. lifesothorax prominently elevated; head with a transverse ridge forming slightly produced cephalo-lateral angles; cremater with hooked setae.

Satyrinae

EE. Nesothorax not prominently elevated; head never with a transverse ridge; caudal end of boly without hooked setae; cremaster never present.

Oneinae

Subiamily Nympinalinae

This includes all the genera with prominent tubercules on the surface of the body. There are uaully seven rows of these, mostly on the dorsal surface of the abdomen, as follows: a dorso-mesal row; on each side of this a dorso-lateral rom; and 

a row dorsad and ventrad of the aboominal spiracles on each side. The majority of species have a cephalo-lateral projection on each sile of the head; in some these are very prominent; in others, reduced to small rounded tuberculez or wanting. The body is usually strongly convex near the caudal margin of the wings on the ventral surface and the cremaster is curved ventrad. The cremaster is more prominent in this subfamily than in the family Papilionidae and bears a mass of short hooked setae at its distal end. The species of Nymhalinae have been grouped into three tribes, mostly according to the size and arrancement of the tubercules.

These tiree tribes may be separated as follows:

A. Dorso-mesal tubercules smaller than those of the dorso-lateral rows; cremaster never with prominent lateral projections at the base.

B. Cremaster longer than broad; dorso-mesal tubercules always present on abdominal segments $3-8$ and usually on the second segrnent.

Vanessidi

BB. Cremaster usualiy brotler than lons; dorso-nesal tuberculea often wanting and never present cephalad of the fifth segment.

Argynnidi

AA. Dorso-mesal tubercules equal in size to those of the dorsolateral rows; cremaster always with a lateral projection on each side at the base.

Melitaeiai

Tribe Vanessidi

This includes the species with all the rows of tubercules represented and most of them complete. The tubercules of the dorso-meal row are considerably smaller than those of the dorsolateral row which are usually very prominent. The rows of tuber- 

cules on either sile of the spiracles are always very small. The cremaster is long, and never has prominent lateral tuberculea at its proximal end.

The genera of Vanessidi may be separated by the follow-

ing table:

A. Cephalic prominences conical, with length and breadth approximately equal; dorso-lateral tubercules on the fourth abdominal segment always larger than the othera.

B. Dorso-lateral tubercules on abdominal segments $2-7$ long and sharp, spine-like, the length congiderably greater than the breadth; dorso-mesel tubercule absent on the second abdorninal segrnent.

Euvane gsa Scudder

BB. Dorso-lateral tubercules on abdominal segments $2-7$ not sharp and spine-like; the length scarcely, if any, greater than the breadth; dorso-mesa.1 tubercule present on the second abdominal segment.

C. Dorso-lateral tubercules on fourth abdominal segment at lesst twice the size of the others; median elevation of the mesothorax a compressed carinated ridge and usually very prominent.

Polygonia Hübner

CC. Dorso-lateral tubercules on the fourth abdominal aegrnent very little larger than the others; median elevation of the mesothorax pyramidal and not very prominent.

Aglais Dalman

AA. Cephalic prominences usually blunt, the length less than the breath; dorso-lateral tubercules on the fourth abdominal segment never larger than the others.

3. Cephalic prominences broady rounded, scarcely elevated beyond the outline of the body; no distinct prominence on the median line of the mesothorax.

Junonia Hübner

BB. Cephalic prominences.distinctly elevated beyond the outline of the body; a distinct prominence on the median line of the mesothorax.

Vanessa Fabricius

The following species were examined:

Euvanessa antiopa L. 

Polygonia interrogationis Fabr., comme Harr., faunus Edw., progne Cram.

Aglaıs milberti Godart.

Junonia coenia Hubn.

Vanessa atalanta L., huntera Fabr., carảui L.

\section{Tribe Argynnidi}

The species included here resemble those of the preceding tribe, excepting that the dorso-mesal row of tubercules is only present on a few gegments or is entirely wanting. The cremaster is short and broad and never has a prominent projection on each side at the proximal end.

The genera of Argynnidi may be separated by the following table:

A. Dorso-iateral row of tubercules of approximately equal size.

B. Dorso-mesal row of tubercules present on abdominal segments 4-7; dorso-lateral tubercules much larger than the stignatal rova; carinate ridge present on mesothorax.

Argynnis Fabricius

BB. Dorso-resil row of tubercules absent on all segments; dorsolateral tubercules about equal in size to the dorsal stigmatal row; mesothorax without a carinate ridge.

Euptoieta Douileday

AA. Dorso-lateral row of tubercules of different sizes, the largest on the third abdominal segment.

B. Body with a very strong ventral curve opposite the third and fourth abdominal segments; mesothorax with a strongly elevated median ridge throughout its length; head projections very prominent, irregularly bi-lobed. Agraulis Boigo. \& Le C.

BB. Body without a strong ventral curve; mesothorax with a small ridge on the caudal half; head projections short, pointed.

The following species were examined:

Argynnis cybele Fabr.

Euptoieta claudia Crarn. 

Agraulis vanillae L.

Brenthis myrina Cram.

Tribe Melitaeidi

The species in this group have the dorso-mesal and

dorso-lateral tubercules of approximately equal sire but none of them are very large and are usually rounded. The cremaster always has a prominent projection on each aide of the cremaster at ita proximal end.

The genera of Melitaeidi may be separated as follows:

A. Tubercules of the dorgal spiracular row not present on the second abdominal segment; no tubercules present on the eighth abdominal segment.

B. Dorgum of abdomen with a distinct transverse ridge on the fourth segment; dorsal spiracular row of tubercules not distinct on any of the segments.

Phyciodes Hubner

$B B$. Dorsum of abdomen without a transverse ridge on the fourth segment; dorsal spiracular row of tubercules very large on the third and fourth abdominal segrnents.

Charidryas Scudder

AA. Tubercules of the dorsal spiracular row present on the second abdominal segtaent; tubercules present on the eighth abdominal segrnent.

B. Tubercules of the eighth abdominal segment nearly as large as the others, the abdorninal tubercules all broadly rounded and never longer than broad; cremaster with a deep depression on the dorsal surface and a circular depression on the ventral surface, the lateral tubercules very prominent, rounded, smooth and polished.

Euphyaryas Scudder

$B B$. Tubercules of the eighth abdominal segment much smaller than the others, the abdominal tubercules all somewhat pointed. and longer than broad; cremaster never with a deep depression on the dorsal surface, but with a long narrow furrow on the ventral surface, the lateral tubercules somerhat triangular in outline and slightly rugose like the cremaster. 

The following species were examined:

Phyciodes tharos.

Charidryas nycteis D. \& H.

Euphydryas phaeton Drury.

Cinclidia harrissii.

\section{Subfamily Basilarchinae}

The genus Basilarchia Scudder differs from all the genera of Nymphalinae with which it is generally included on account of the absence of the rows of tubercules. It has the two cephalic projections as in many Nymphalinae and a very large carinated one on the dorsum of the second abdominal segment. This is somewhat oval in outline as seen in lateral view, being constricted at the base. The body is not prominently excurved in the region of the appendages as in the Nymphalinae, but is of the same general shape. It agrees with the Nymphalinae only in the characters common to all Nymphalinae and is therefore placed in a separate subfamily.

\section{Species examined:}

Basilarchia astyanax Fabr., arthemis Drury, archippus Cram.

\section{Subfamily Apaturinae}

The species of this subfamily, included by Scudder in the Nymphalinae, show no characters which unite them with that subfamily. The group, according to Scudder, included the genera Clorippe and Anaea, which differ so widely in the pupa that they could not well be combined in the same subfamily. The name Apaturniae has been retained for the genus Chlorippe Boiaduval. These pupae are strongly compressed with a prominent median dorsal carinated ridge. There are two cephalic projections and the 

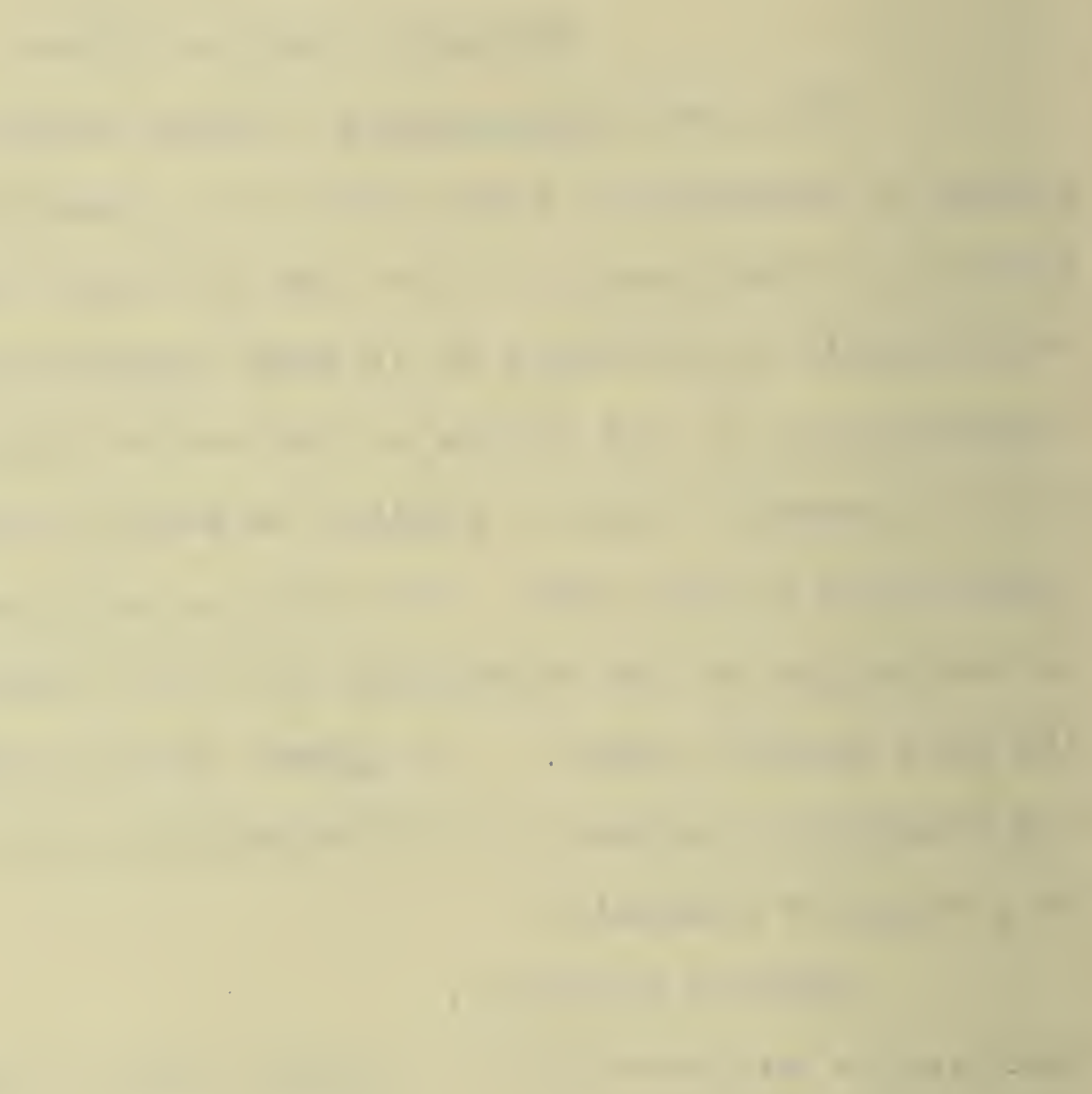

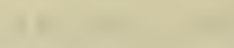

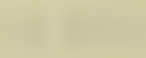


ventral surface of the body forms a straight line while the dorsum is strongly arched. The antennae are slightiy elevated and tuberculate. The genital openings are sunken and almost concealed. On either side of the anal opening near its cephalic end there is a small tubercule covered with hooked setae. The cremaster is short and triangular, and the hooked setae are nearly all on the ventral surface.

Species examined:

Chlorippe celtis Boisd. \&. Le C., clyton Boisd. \& Le C.

\section{Subfamily Anaeinae}

This subfamily includes a single genus Anaea Hübner, which was included with Chloripge in the tribe Apaturidi by Scudder. The pupae are so different, however, that they have in common only the ordinary nymphalid characters. The body is never compressed, but the abdominal segments caudad of the wings taper very rapidy and form a hemisphere. The long cremaster is inserted near the center of the hemisphere and curves ventrad. The fourth segment has a prominent transverse ridge. The ventral surface of the abdominal segments caudad of the wings is very short and the genital openings are concealed. The head has a prominent transverse ridge at the cephalic end which extends caudad through the midale of the eye-pleces and along the lateral margin of the body. The metathorax has a rather prominent rounded ridge on the meson. The antennae and maxillae extend to the caudal margin of the wings.

Species examined:

Anaea andria scudder. 

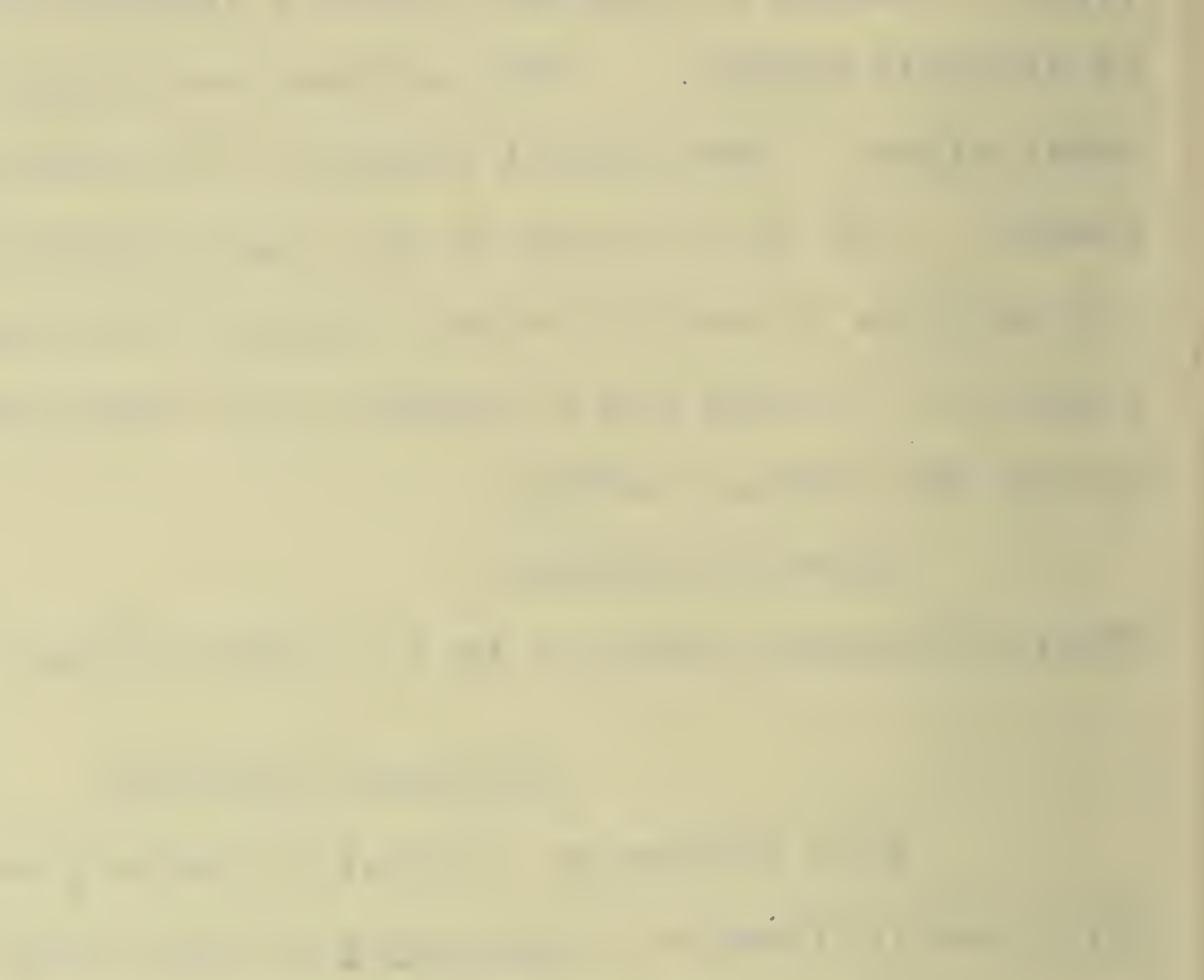

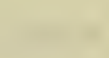

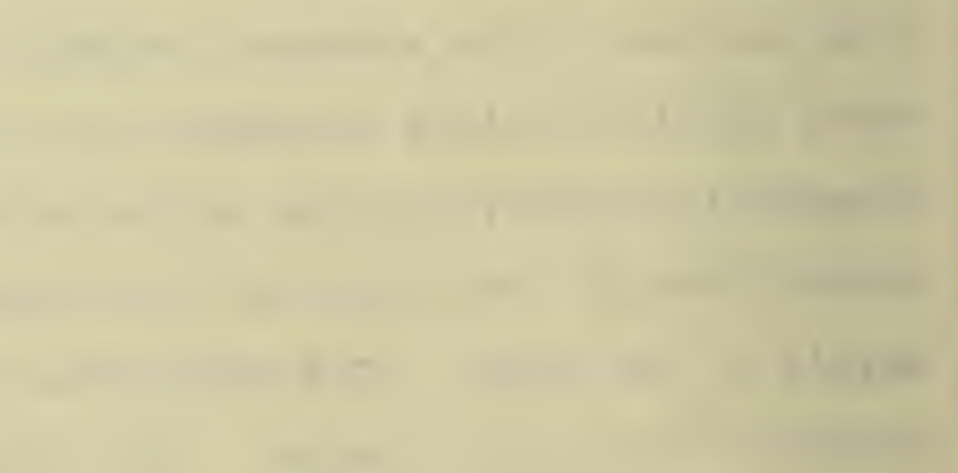




\section{Subfamily Euploeinae}

This subfamily is equivalent to the family Lymnadiae of some authors. It includes two genera of which only Anosia has been examined. The general shape of the body is very like that of the genus Anaea, but it has the second abdominal segment very long, as well as the thorax, and the cremaster extends caudad. There is never a ridge on the head, but it has a tubercule at each cephalo-lateral margin. The transverse ridge is on the third segment and is tuberculate. The maxillae do not reach the caudal margin of the wing in Anosia and the anternae lie adjacent on the meson caudad of them.

Species examined:

Anosia plexippus L.

\section{Subfamily Satyrinae}

The Satyrinae are similar in shape to the Nymphalinae but have no tubercules on the surface of the body and but few prominent ridges. The head always has a prominent transverse ridge at the cephalic end and this often forms slight cephalolateral angles. There is also a slightly carinated ridge at each lateral margin of the body extending as far caudad as the second abdominal segment. The metathorax always has a median elevation which sometimes forms a prominent angle. The circular ridge surrounding the aral cpening is not strongly elevated but the tubercules are prominent on each side of the genital opening on the ninth segment.

The genera of this subfamily may be separated by the following table: 

A. Cremaster broader than long, with hooked setae present on the ventral surface; genital opening never with a tubercule on each side.

Cissia Doubleday

AA. Cremaster longer than broad, the hooks always inserted at the distal end, never on the ventral surface; genital opening always with a distinct tubercule on each side.

B. Mesothoracic elevation rounded; cremaster concave at tip with the hooked setae inserted in the hollow; body surface with fine indeterminate striations.

Cercyonis Speyer

BB. Mesothoracic elevation with a distinct angle; cremaster not concave at tip; body surface smooth.

Satyrodes Scudder

The following species were examined:

Cissia eurytus Fabr.

Cercyonis alope Fabr.

Satyrodes canthus Linn.

Subfamily Orneiae

The genus Oneis Hubner agrees with none of the distinguighing characters of the subfamily Satyrinae and has not been included with the members of that group. The body has the general shape of a lycaenid, and the segments seem as devoid of motion (FIg. 80). In other respects it is a typical Nymphalid. The antenrae do not quite reach the caudal margin of the wings and overlay the maxillae at their distal end so that the antennae are adjacent on the meson. Their proximal ends are very near the meson on the dorsal surface of the head. There is no distinct ridge surrounding the anal opening, nor are any tubercules present caudad of the genital openings. There is no cremaster, nor hooked setae at the caudal end of the body.

Only one species was examined:

Oeneis semidea Say. 

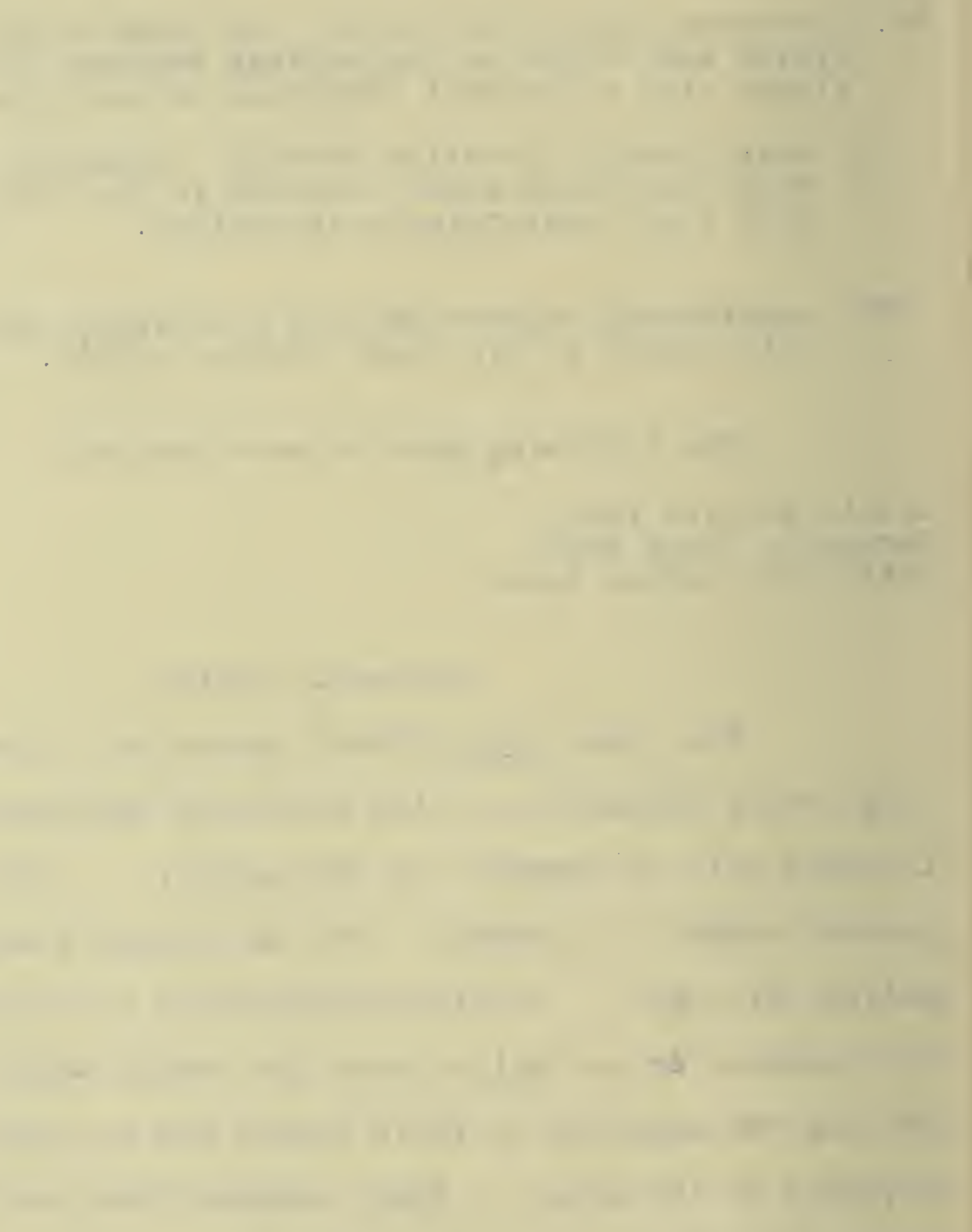

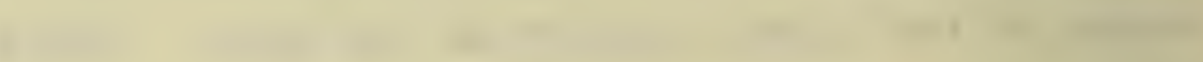

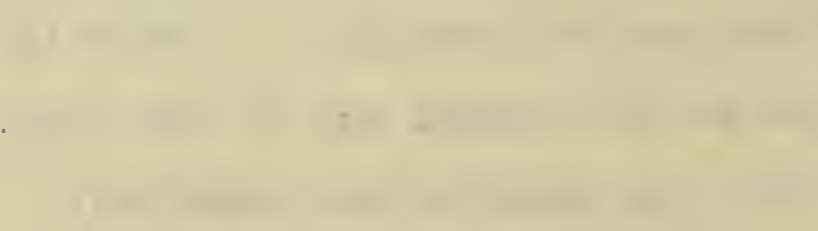


CC. Specialized Pupae without Pillifers.

This inciudes the remaining superfanilies of Lepicoptera. The seventh abdominal segment is fixed in both sexes in all the families except the Evermeniidae in which this segment is fixed in the male. None of the species included here have dorsal movement between any of the segrents cephalad of the fourth. In this they differ from the superfamilies Pyralidoldea and Papilionoidea, some members of which retain dorsal movement of the third abdominal segment. This group includes ald the most specialized families. The origin of most of these is doubtful. The Noctuoldea show the strongest relationship to the Pyralidoidea, the Notodontoidea to the Gelechioidea. AlI the evidence at presentpoints to the fact that the Pyralidoidea and Gelechioidea have descended from a cormon ancester closely allied to the Yponomeutoidea. The Sphingoidea and Saturnioidea which show considerable relationship to each other, seem to have arisen from a common stem with the more generalized Bombycoidea, which in their turn seem nearly related to the Noctuoidea and Notodontoidea. 

Superfamily Yponomeutoidea

The families included here show well developed labial palpi, and have a large fortion of the prothoracic femora exposed. All show the maxillary palpi except the Coleophoridae, and the same arrangement of parts prevails throughout the superfamily. The epicranial suture is present in all families. The prothorax is always very short on the meson, but much longer on each lateral margin so that each half is triangular. The appendages always reach beyond the caudal margin of the fourth segment, and in some cases are almost as long as the body. They are soldered firmly to each other but are free from the body wall. Abdominal segments 1-4 are longer than any of the others. There are usually spines or setae present at the caudal end of the body but seldom a cremaster. They are usually less than lomm. in length.

The families may be separated by the following table:

A. Cremaster present, but short, with hooked setae at the distal end; ninth abdominal segment with a deep lateral cavity; seventh abdominal segment free in the male.

Epermenildae

AA. Cremaster absent; ninth abdominal segment never with a deep lateral cavity; seventh abdominal segment fixed in both sexes.

B. Maxillary palpi present; caudal end of body without lateral prolongations ending in spines.

Yponomeutidae

BB. Maxillary palpi never present; caudal end of body with lateral prolongations ending in sharp spines.

Coleophoridae

\section{Family Epermenildae}

This family, which has usually been combined with the Elachistidae, or by some writers with the Scythridae, is here associated with the Yponomeutidae, the only important differences 

between the two families being the freedom of the seventh abdominal segment in the male and the presence of a very short cremaster in Epermeniidae. Another difference is that in Epermeniidae the Wings and other appendages are somewhat elevated at the meson and slope to each lateral margin. A comparison of Figs. 68 and 81 , $82,83,85$ will show the similarity in arrangement of parts of the two families mentioned above.

Species examined:

Eperminia pimpinella Murtf.

\section{Family Yponomeutidae}

The genera comprised in this family resemble each other very strongly in all important characteristics, but nevertheless possess very clear generic distinctions. They closely resemble certain of the generalized gelechiids and many author have associated those genera with the Yponomeutids (Figs. 88, 89). The presence of a distinct fronto-clypeal suture and the peculiar arrangement of the antennae in the family Gelechildae, together with the apparent loss of the labial palpi, seems to separate it very clearly from the Yponomeutidae, in which the fronto-clypeal suture is never diatinct and the antennae never are adjacent on the meson except in Zelleria (Fig. 81). The typical arrangement of parts is seen in Figs. $81,82,83,84,85,86$ making further description unnecessary. The abdominal spiracles are all considerably produced, and tubular, being longest in Plutella. There is no cremaster present in any of the genera.

The genera of Yponomeutidae may be separated by the following table: 

A. Prothoracic spiracles produceả, tube-like; setae at caudal end of tenth segment hooked; maxillae more than three-fourth the length of the wings.

Plutella Schrank

AA. Prothoracic spiracles not produced, slit-like; setae at caudal end of tenth segment straight, or occasionally slightly curved at end; maxillae much less than three-fourths the length of the wings.

B. Caudal end of tenth segment showing four straight setae, generally two directed laterad and two ceudad; maxillary palpi touched by both prothoracic and mesothoracic lege.

C. Maxillary palpi long, reaching the proximo-lateral angles of the maxillae; labial palpi never becoming wider than at their proximal margin.

Yponomeuta Latreille

CC. Naxillary palpi short, never reaching the proximo-lateral angles of the maxillae; labial palpi wider throv.gh most of their length than at the proximal margin.

Zelleria

BB. Caudal end of tenth segment showing eight setae; four of these on the ventral surface extenaing laterad and sometimes slightly curved at the tip; mesothoracic legs never reaching cephalad to the maxillary palpi.

Argyresthria

Species examined:

Plutella maculipennis Curtis.

Yponomeuta padelius I., malinellus Zelier.

Zelleria celastrusella Kearf.

Argyreathria freyella Wlsm.

Family Coleophoridae

This family has usually been associated with the Elaschiatidae, but since the division of that family the name means very little, unless we use it to include the genus Elachista and others closely related, which certainly would not include Coleophoridae. They seem, rather, to be more closely allied to the Yponomeutidae and are so consiciered here. They differ 

mainly in the loss of the maxillary palpi and the lateral extensions of the ninth abdominal segment (Fig. 87). The apendages are usually very long, extending nearly to the caudal margin of the body, and often beyond it, when the movable segments are contracted. The abdominal segments from the first to the sixth are very much longer than the remaining segments. The following species were examined:

Coleorhora caryaefoliella Clem., vernoniaella Cham., malivorella. Riley.

Superfamily Gelechioidea

This superfamily includes those pupae which possess a distinct epicranial suture, with the caudal portions of the antennae lying adjacent on the meson and visually separating at their distal ends to expose the metathoracic legs. The maxillary palpi are usually present, but labial palpl and prothoraclc femora are seldorn exposed. The body is usually ovate in outline as seen in dorsal or ventral view, widest in the thoracic region and somewhat depressed. The superfamily is closely related to the Yronomeutoidea. It includes here two groups representing two distinct lines of development: the group retaining the frontoclypeal suture, including the families Lavernidae, Scythridae, Gelechilaae and Chrysopeleiidae; and those in which it is not distinct or absent, including the families oecophoridae, Stenomidae, Cosmopterygidae and Elachistidae. The latter group may represent a distinct superfamily when all its allied genera have been studied, but at present there is no evidence to warrant such a conclusion. 

The following table will serve to separate the families

of Gelechioidea:

A. Fronto-clypeal suture always distinct for its entire length, sometimes forming a prominent curve or angle at the meson.

B. Labial palpi exposed for their entire length.

C. Femora of the prothoracic legs viaible; maxillary palpi either reaching the proximo-lateral angles of the maxillae or approaching them very closely; tenth abdominal segment with stout spines at the caudal end.

Lavernidae

CC. Femora of the prothoracic legs never visible; maxiliary palpi minute; tenth abdoninal segment with hooked setae at the caudal end.

Scythridae

BB. Labial palpi never exposed for their entire length, usually concealed.

c. Maxillary palpi present and usually reaching the proximolateral angles of the maxillae; antennae usually adjacent on the meson for the caudal two-fifth of their length, separating at distal ends to show the metathoracic legs.

Gelechiloae

CC. Maxillary palpi never present; antennae adjacent on the meson for the caudal tro-fifths of their length but not separated at their distal ends.

Chrysopeleifiae

AA. Fronto-clypeal suture never distinct for its entire length and never reaching the meson.

B. Abdorinal segments 4-6 movable, with very deep incisions between the segments on the corsal and ventral surfaces; body depressed.

c. Naxillary palpi large, usually reaching the proximo-lateral angles of the maxiliae; hooked setae never present on the ventral surface of the ninth abdominal segment.

Decophoridae

CC. Maxillary palpi minute; hooked setae always present on the ventral surface of the ninth abdominal segment.

Stenornidae

BB. Abdominal segments 4-6 never all movable; incisions between the segments of equal depth on all surfaces; body not cepressed. 

c. Maxillary palpi present; sixth aboioninal segment movable. Cosnopterygidae

CC. Maxiliary palpi absent; no abdominal segments movable.

Elachistidae

\section{Family Lavernidae}

The pupae belonging to this family are more generalized than any other members of the superfamily and closely resemble pupae belonging to the family Yponomeuticlae. They have been included here on account of the digtinct fronto-clypeal suture, present in all except the more specialized Gelechioliea and also because the prothorax, which is so short on the meson in Yponomeutidae with each half triangular in outline, in this family loses that condition and becomes almost as long on the meson as at the lateral margins, so that each half is subquadrangular. This is the only family of Gelechioidea which retains both labial palpi and exposed portions of the prothoracic femora. The appendages have the characteristic arcangement of the superfamily (Eig. 88) except that the antennae do not separate near their distal end to expose a portion of the metathoracic legs, but these are seen caudad of the antennae adjacent on the meson. The wings are long and pointed in Lophoptilus, but rounded in Laverna. The first four abdominal segments are longer than the remaining caudal ones in this family, and the appendages are soldered to them, but are free for the remainder of their length. This family has been considered as a subfamily of Elachistidae by most authors, and has usually included Cosmopteryx which is a much more speciallzed genus. 

The following table will serve to separate the genera

of Lavernidae:

A. Head long, somewhat pointed, the length more than half the greatest width; fronto-clypeal suture meking an acute angle at meson; spines of the tenth segment exterding dorsad and not visible in ventral view; exposed part of third leg about one-fifth the length of the portion of the antennae lying adjacent on the meson.

Lophoptilus

AA. Head short, blunt, the length about equal to half the greatest width; fronto-clypeal suture making an obtuse angle at meson; spine of tenth segment extending laterad and visible in ventral view; exposed part of third leg about equal in length to the portion of the antennae lying adjacent on meson.

Laverna Curtis

Family Scythridae

The pupae of this family also resemble the Yponomeutidae in some respects, and have been included with them by some authors. Others have associated the family with the Elachistidae, while Stainton included it with the Gelechiliae as the genus Eutalis. The antennae in this family meet on the meson, but do not separate to show the distal ends of the metathoracic legs as is the general rule in this superfamily. Instead, the mesothoracic wings lie adjacent on the meson caudad of the antennae, and the appendages are firmly soldered to each other and to the body (Fig. 89). As the appendages extend caudad for about half the length of the seventh abdominal segment, it follows that there can be no motion posstble between any of the abdominal segments, unless there be slight dorsal motion. The prothorax is tyoically gelechid in character. The abdominal spiracles are considerably produced and tubular, their length varying in the different grecies. The setae of the body are nearly all hooked, and a few longer ones are 

present at the caudal end of the body. Only one genus of this family was available for study.

The following species were examined:

Scythris eboracencis Zell., impositella Zell.

\section{Family Gelechiidae}

The pupae of the Gelechiliae never show any portion of the labial palpi, unless it should be a very small triangular area caudad of the labrum, between the halves of the marillae. The prothoracic femora are never exposed (Fig. 81, 93, 94). The fronto-clypeal suture is always distinct and usually extends almost straight across between the proximal ends of the antennae, but occasicnally each half is directed cephalad near the meson so that an angle is formed at their junction. The caudal parts of the anternae usually lie adjacent on the meson for about twofifths of their length and usualiy cover the caudal ends of the maxillae and sometimes of the prothoracic and mesothoracic legs. They usualiy separate at their distal ends to show the metathoracic legs or what will be referred to as such in this paper. There was not enough available material in condition for dissection to determine whether the maxillae ever reached the caudal margin of the wings and overlaid the metathoracic legs, as might easily be the case.

The maxillary palpi are present in all, but do not always reach the proximo-lateral angles of the maxillae. They are always reached by both prothoracic and mesothoracic legs. The wings vary somewhat in length, but are usually firmly soldered down, and the abcomsnal segments are somewhat depressed on the 

ventral surface, forming a shallow cavity into which the wings sre fitted and, therefore, are not elevated above the surface of the body. There are usualiy very deep incisions between the segments, especially on the dorsal and ventral surfaces. Hany species have the incision deeper on the ventral surface so that the caudal end of the body may be strongly curved ventrad. The pucee are usually very active, and many of them are aole to move after the fashion of click-beetles. The body is entirely covered with setae in some genera, while others have a fringe of setae along the margin of certain slightly projecting ridges and occasional depressions found usually on the seventh abdominal segment. There seems doubt as to the generic standing of the folloring species: Aristotelia physaliella, Gnorimoschema lavernella and Recurvaria variella; at least they vary from other species examined in the genus. In the case of Axistotelia it has been impossible to determine which species was the type of the genus.

The genera of Gelechilo.e may be separated as follows:

A. Body setae very long and heavily chitinized, often as long as the segments of the abdomen, and as seen uncier high power, usualiy forked at the apex; fronto-clypeal suture curving cephaladfrom the proximal ends of the anternae to the cephalic margin of the bociy; cremaster always present; dorsal cephalic margin of segments two, three and four of the abomen with a slight rounded projection on each side the meson, edged with a dense fringe of whitish setae directed cephalad, ceudad of this a prominent elevation bearing a similar fringe of setae on the sumit (Fig. 92).

B. Dorsal surface of the cephalic margin of the movable segments with a prominent cavity on the meson having heavily chitinized ediges. 

BB. Dorsal surface of cephalic margins of the movable segments Without any cavity; a strongly chitinized riclge separating the cephalic margin from the remainder of the segment, cerhalad of this a band of short spines, then a prominent furrow, the Iurrow and the remainder of the cephalic margin being deeply punctate.

Ypsolophus Fabricius

AA. Body setae never modified; segments two, three and four of the abdomen never as described in $A$.

B. Entire body with a dense covering of whitish hair visible to the unaided eye, giving the pupa a furred appearance.

C. Maxillary palpi iong, reaching the proximo-lateral angles of the maxillae; antennae lying adjacent on the meson for about tio-fifths their length; cremaster short and blunt, the end set with about elght stout curved setae; length $8-10 \mathrm{~mm}$.

Anacamosis Curtis

CC. Waxillary palpi short, never reaching the proximo-lateral angles of the maxillae; antennae just meeting on the meson; cremaster, with a sharp point curved dorsad, with curved setae at the sides and base; length 5-5mm.

Arigtotelia (a) Hübner

BB. Entire body never covered with setae.

c. Seventh abdominal segnent with a dense fringe of setae on some portion.

D. Fringe of setae confined to the cephalic and lateral edges of a prominent lateral cavity.

E. Body smooth, not depressed; cephalic edge of the lateral cavity trizlobed (Fig.93).

Evippe Chambers

EE. Body with small spines, strongly depressed; cephalic edge of the lateral cavity bizlobed.

Telphuga Chambers

DD. Fringe extending around the segment or nearly so.

T. Fringe extending around the segment in a straight line; body not noticenbly depressed, the surface smooth.

Recurvaria (a) Hawortin

EE. Fringe extending around the segrnent in a more or less wavy line; body noticeably depressed and very broad inn thoracic region, surface with punctures or spines. 

F. Abdominal segments eight to ten distinctly tapering to the caudal end of body; fringe of seventh segment extending in a ravy line around the body and edging two very large lobes on the dorsal surface.

Trypanisma Clemens

FF. Abdominal segments eight to ten not tapering but blunt and slightly rounded at caudal end of the body; fringe extending in a wavy line around the seventh semment, without prominent lobes on the dorsal surface.

Gelechia Hübner

CC. Seventh abdominal segment without any fringe of setae.

D. Caudal end of body with short stout projecting spines.

E. Caudal end of body with one such spine on the dorsomeson projecting dorsad; fronto-clypeal suture.

Phthorimaea Meyrick

EE. Caudal end of body with a median spine and one on each lateral margin; fronto-clypeal suture extending cephalad from the base of each antennae to the cephalic margin of the head.

Sitotroga Heinemann

DD. Caudal end of body with straight or curved setae.

E. Hooked setae present at the caudal end of the body.

F. Antennae reaching the caudal margin of the wings, their caudal ends separated to show the metathoracic legs.

G. Caudal end of body with at least five long hooked setae on each side the meson; antennae slightly enlarged at their proximal ends making the cephalic end of the body somewhat truncete.

Recurvaria (b) Haworth

GG. Caudal end of body never with more than two Iong curved setae on each side the meson; cephalic end of body rounded.

Aristotelia (b) Hübner

FF. Antenna never reaching the caudal margin of the wings nor separating at their caudal ends to expose the metathoracic legs.

Gnorimoschema (a) Busck

TE. Hooked setae never present at the caudal end of the body; a few short, straight setae present. 

The following species were examined:

Trichotaphe flavocostella Clem.

Ypsolophus citrifoliellus Cham., eupatoriellus Cham.

Anacampis sp., rhoifructella clem.

Aristotelia (a) salicifungiella Clem.

Aristotelia (b) physaliella Cham.

Evippe prunifoliella Cham.

Telphusa quercinigracella Cham., palliderosacella Cham.

Recurvaria (a) apicitripunctella clem.

Recurvaria (b) variella Cham.

Trypanisma prudens Clem.

Gelechia cercerisella Cham., discoocellella Cham., serotinella Busck.

Phthorimaea sp.

Sitotroga cerealella Olivier.

Gnorimoschema (a) lavernella Cham.

Gnorimoschema (b) gallaesolidaginis Riley.

\section{Family Chrysopeleiidae}

This family includes the genus Chrysopeleia which was formerly included with the Elachistidae. It has the same arrangement of parts as in the genus Elachista but retains the fronto-clypeal suture and has no cremaster (FiE. 95). Until more is known of the relationships of this genus it seems better to place it in a family by itself. The appendages are slightly elevated and firmiy soldered to each other and to the body. They extend well onto the seventh abdominal segment so that there appears to be no motion possible between any of the body segments. There is no cremaster present and only a few short straight setae at the caudal end of the body. The abdominal spiracles are produced and tubular. The pupae are very small, being only about $3 \mathrm{~mm}$. In length.

Species examined:

Chrysopeleia ostryaeella Cham. 



\section{Fanily Oecophoridae}

This family includes those pupae in which the frontclypeal suture is not rresent for its entire length and which have large maxillary palpi, usually reaching the proximo-lateral angles of the maxillae. All the species examined showed the presence of very fine setae arranged in groups over the surface of the abdomen, but these were hard to locate in Psilocorsis. The incision between the segments are very deep in all members of the family. Of the three genera studied, Pgilocorsis, Agonopteryx and Depressaria, the former seemed more nearly related to the Stenomidae, while the other two were typical gelechiids, except that the fronto-clypeal suture was never distinct. It seems probably that a revision of the group might separate these genera. The table to genera will indicate the principal differences. The body is usually strongly depressed and 5-10 mm. In length.

The following table will serve to separate the genera:

A. Femora of the prothoracic legs exposed.

B. Wings pointed, extending onto the sixth abdominal segment; proximal end of each antenrae elevated and roughened with transverse ridges; cremaster present.

Psilocorsig Clemens

BB. Winge not pointed, and never extending beyond the caudal margin of the fourth abdominal segment; proximal end of each antenna never elevated nor roughened with transverse ridges; cremaster never present.

Depressaria Faworth

AA. Prothoracic femora never exposed.

Agonopteryx Hübner

The following species were examined:

Psilocorsis obsoletella Zell., quercicella Clem.

Depressarla heracliana De.G.

Agonopteryx nebulosa zell. 



\section{Stenomidae}

The Stenomidae include most of the genera formerly grouped under the name Xylorictidae. The appendages are arranged as in the Gelechildae and the maxillary palpi are minute (Fig. 96). A small portion of the labial palpi is usually apparent. The appendages are firmly soldered to each other and to the body - wall. They extend slightly beyond the caudal margin of the fourth abdominal segment, so that there are three free segments, the fourth, fifth and sixth. The margins of these free segments are serrate along the edges of the incisions which are very deep, especially on the ventral surface, and permit the caudal end of the body to be very sharply curved ventrad, reaching almost to the caudal margin of the wings. The fronto-clypeal suture is visible for a short distance mesad of the proximal end of each antenna but it never reaches the meson. There are many curved setae present on the ventral surface of the ninth abdominal segment. The body is always more or less depressed, and in Stenoma is about $8 \mathrm{~mm}$. in length, in Menesta $3 \mathrm{~mm}$. The genus Menesta, formerly included in the Gelechildae, seems more closely allied to Stenoma and is included here. Stenoma possesses peculiarly modified setae on the body surface.

The genera may be separated as follows:

A. Antennae modifled at their proximal ends, forming an enlarged corrugated area; hooked setae on the ventral part of the ninth abdominal segment never on a distinct prolongation.

Stenoma Zelier

AA. Antennae never modified at the proximal end; hooked setae of the ventral part of the ninth abdominal segment on a distinct prolongation. 



\section{Family Cosmopterygidae}

This family name as used by most authors is equivalent to Lavernidae or Momphidae, and the genera included under all of these names are usually associated with each other. The Cosmopterygidae are much more specialized; however, as they retain neither visible labial palpi nor prothoracic femora (Fig. 99). The appendages are firmly soldered to each other and to the body wall as far as the caudal margin of the sixth abdominal segment, which allows freedom of movement to this segment. There are some generalized characters present, however, in the length of the first six abdominal segments which are as long as in Yponomeutidae and in the prothorax which is shorter on the meson than at each lateral margin. The abdominal spiracles are slightly produced and tubular. There is a very short cremaster present bearing eight hooked setae of which four are longer than the remainder. The pupae are about 4mm. in length.

Species examined:

Cosmopteryx clandestinella Busck.

\section{Family Elachistidae}

This family has been variously subdivided in the past few years, for like the Tineidae, it included a large number of species which did not form a natural group. Some authors do not retain this family name, but as the nomenclature of the group appears to be still in a rather unsettled condition, this name is retained for the present to include the genus Elachista. The appendages are arranged as in other gelechilds, but there is no trace of maxillary palpi (FIE: 100). The surface of the body 

is covered with large rounded tubercules and the dorsal surface shows three distinct longitudinal elevations or ridges, one on the meson, the other near each lateral margin bearing the spiracles on the summit. The wings and other appendages are firmly soldered to each other and to the body-wall, and there appear to be no free segments. The prothorax is typically gelechiid and the mesothorax shows a decided alar furrow on each side. There is a distinct cremaster present, but it shows no hooked setae. The pupae are suspended from a stem or leaf after the manner of some papilionids with a silken girth around the body. The pupae average $3.5 \mathrm{~mm}$. in length.

Species examined:

Elachista praelineata Braun (M.S.)

\section{Superfamily Noctuoidea}

This superfamily includes three families, Noctuidae, Liparidae, and Arctiidae. The Synomidae also belong to this group, but as only one species of this family was examined and this showed no characters to separate it from the Arctuidae, the Syntomidae are not discussed as a separate family. The Noctuoidea and Bombycoldea include all the speclalized families which retain labial palpi.

\section{The families of Noctuoidea may be separated thus:}

A. Body seldom with setae arranged around scars of larval verrucae, if present, then the femora of the prothoracic legs exposed, or a long cremaster present bearing hooked setae at the distal end; prothoracic femora usually visible, if not then the mesothoracic leg usually extending cephalad to the eye-pieces. 

AA. Body always with setae arranged around the acars of larval verrucse; femora of the prothoracic legs never visible.

B. Maxillae never more than two-fifth the length of the wings; body setae conspicuous; labial palpi usually visible.

Liparidae

BB. Maxillae two-thirds the length of the wings, or longer; body setae inconspicuous; labial palpi seldom visible.

Arctildae

Family Noctuidae

This family, with a few exceptions, is characterized by the presence of labial palpi and of maxillae which extend to the caudal margin of the wing, or veryclosely approximate this length. Very many of the genera have a large portion of the prothoracic femora exposed. Those which do not show any portion of the prothoracic femora have the mesothoracic leg extending cephalad to the eye-pieces, with a few exceptions in the genera Homopryalis, Plusiadonta and Anomis. Those lacking labial palpi have setae arranged around the scars of larval verrucae as in the Arctildae. They differ from these in having hooked setae on the cremaster, and in lacking flanged plates on the abdominal segments. Maxillary palpi are found in some members of the subfamilies Agrotinae, cuculdianae and Hypeninae. Since there was not enough material available for study to furnish a basis for subfamily characters, the genera have been grouped as seemed best for purposes of classification. As far as possible the names of subfamilies as used by Hampson in the "Catalogue of Lepidoptera Phalaneae" have been adopted. This arrangement could not be followed throughout, however, and so it must be remembered that the subfamily names used here are adopted as a matter of convenience and do not stand 

for the genera which Hampson grouped together. His generic and specific names have been adopted as far as possible. As to the phylogeny of the group, too little material has been examined to warrant a decided opinion on the subject. It seems probable, however, that most of the subfamilies discussed represent the ends of many lines of development. There are various stages of development found in all groups, and there are some members of each subfamily studied, except the Phytometrinae and Mominae which show the epicranial suture.

The subramilies mentioned above which retain maxillary palpi are undoubtedly the most generalized, the Mominae which show neither labial palpi, prothoracic femora, maxillary palpi, nor an epicranial suture are undoubtedly the most specialized, but nothing can be said with certainty as to the other groups. No attempt has been made to arrange the subfamilies in phylogenetic order, either in the tables or in the discussion of subfamilies.

The subfarilies of Noctuidae may be separated by the following table:

A. Prothoracic legs reaching cephalad to the eye-piece, mesothoracic legs never reaching as far cephalad; prothoracic femora usually visible.

B. Cremaster, or caudal end of the body, with all the setae curved or hooked, never with any long straight setae.

C. Setae of the cremaster usually all of the same size and length, either slightly curved or hooked; never with six or eight hooked setae of which the mesal ones are larger and longer than the remainder.

Acronyctinae

CC. Setae of the cremaster or caudal end of the body usually of two sizes. 

D. Body never with scars of larval verrucae bordered with setae, especially on the dorsum of the abdomen and in the spiracular region; labial palpi and prothoracic femora always visible.

F. Wings and maxillae produced at meson into a distinct rounded projection extending onto the fifth abdominal segment; labrum located near the cephalic end of the body; body never heavily chitinized.

Phytometrinae

EE. Wings and maxillae never extending beyond the caudal margin of the fourth segment; labrum in the normal position; body always heavily chitinized.

Cucullianae

DD. Body with rounded or oval areas bordered with setae, as in the Arctiidae, especially noticeable on the dorsum of the abdomen and in the spiracular region; labial palpi and prothoracic femora never visible.

Mominae

$B B$. Cremaster or caudal end of the body never with all the setae curved or hooked.

C. Cremaster or caudal end of body with at least two long straight stout setae, l-2mm. in length, ratəly with additional hooked setae.

Hadeninae

CC. Cremaster or caudal end of body never with long, straight, stout setae.

D. Cremaster bifurcate, narrowed at the caudal end; dorsum of movable abdominal segments with one or more rows of deep circular pits with dark, chitinized margins.

Agrotinae

DD. Cremaster short, broader at the distal end, very thin and plate-like, the caudo-lateral angles produced into short rounded lobes, with two or three small rounded projections between often bearing small delicate setae; dorsum of the movable abdominal segments never with pits; bodies strongly rugose, the abdominal segments spinose.

Agaristinae

AA. Prothoracic and mesothoracic legs both reaching cephalad to the eye-piece or to the maxillary palpus where this is present; prothoracic femora seldom visible. 

B. Cremaster usually present; curved or hooked setae always present at the caudal end of body, usually eight in number.

C. Body always covered with a whitish bloom.

Catocalinae

CC. Body never covered with a whitish bloom.

Hypeninae

BB. Cremaster or setae never present at the caudal end of the body; fifth abdominal segment with a row of spines along the caudal margin extending from the sculpturing of the dorsum almost to the meson on the ventral surface.

Sarrothripinae

\section{Subfamily Agrotinae}

This subfamily, as here considered, includes those pupae with a stout, rugose, more or less bifurcate cremaster and with a row of large circular pits with heavily chitinized margins along the cephalic margin of some of the abdominal segments usually between the fourth and seventh. In these pupae, the prothorax is very long, at least two-thirds the length of the mesothorax and the epicranial suture is sometimes present in the genus Agrotis. The labial palpi are always present and exposed for their entire length, and the prothoracic femora are seen in some of the genera. The mesothoracic legs, antennae and maxillae are of practically the same length and usually extend to the caudal margin of the wings (Fig. 102). The metathoracic legs are seldom visiole and only the protioracic legs extend cephalad to the eyepieces, and these do not separate the sculptured eye-piece and the antenna. The body is stout and when retracted the length is about three times the width.

The genera of Agrotinae may be separated as follows: A. Femora of the prothoracic legs viaible. 

B. Dorsal cephalle margin of the movable abdominal segments with a single even row of pits, numbering less than fifteen; epicranial suture present; cremaster often with a row of four setae near its proximal end.

Agrotis Ochsenheimer

BB. Dorsal cephalic margin of the movable abdominal segments vith an interrupted rov of pits numbering more than fifteen; eplcranial suture never present; cremaster never with a row of four setae near its proximal end.

Hapalia Hubner

AA. Femora of the prothoracic legs never visible.

Noctua Linnaeus

The following species were examined:

Agrotis badinodis Grote, bicarnea Guenee.

Hapalia incivis Guenee.

Noctua clandestina Harris.

\section{Subfamily Cucullianae}

Only two specimens of one genus Graptolitha were available for study, so little can be aaid as to subfamily characters. These differ from members of other subfamilies except the Catocal1nae in having all the setae at the caudal end of the body hooked. There are two setae at the meson very much larger and more heavily chitinized than the remaining setae which are usually four in number. In other respects, as the length of prothorax, size and shape of body, arrangement of appendages, presence of eplcranial suture, labial palpi, femur of the prothoracic legs and traces of the mazillary palpi, they reserable the Agrotine and also the Hadeninae, as the movable abdominal segments are finely punctate along their cephalic margin.

Species studied:

Graptolitha laticinerea Grote, antennata Malker. 



\section{Subfamily Hadeninae}

This subfamily includes pupae having stout straight setae or spines at the caudal end of the body. These usually number two and are from 1-2mm. in length and may be inserted into a short cremaster or directly into the caudal end of the body (Fig. 103). One genus, Cirphis, has additional slender hooked setae. The prothorax is very long as in Agrotinae, at least twothirds the length of the mesothorax. The epicranial suture is present in the genera Polia, Hadena, Lycophotia and Eriopus. The appendages, which in Agrotinae are of the same length and generally reach the coudal margin of the wings, are in this subfamily unequal in length. The maxillae usually reach the caudal margin of the wings but the mesothoracic legs are shorter and the antennae in some forms equal these or are very much shorter. Except for Cirphis and Monima the abdominal segments are punctate. These two genera have the movable abdominal segments pitted as in the Agrotinae. The prothoracic leg extends cephalad to the eye-piece, but there is never a long point extending cephalad between the antennae and the sculptured eye-piece.

The genera of Hadeninae may be separated by the following table:

A. Dorsum of movable abdominal segments with a row of deep pits along the cephalic margin.

B. Caudal end of body with a very short cremaster ending in two straight sharp setae with four slender hooked setae in a row at the proximal end, the hooked setae about half the length of the straight ones.

Cirphis Walker

BB. Crewater very ahort, with a long otrsigh seta ingerted in each caudo-lateral angle; hooked setae never present. 

AA. Dorsum of movable abdominal segments never with a row of deep pits along the cephalic margin.

B. Mesothoracic leg never reaching cephalad to the eye-piece; prothoracic femora always exposed.

C. Caudal end of the abdomen with four closely approximated spines.

Rhodophora Guenee

CC. Caudal end of body with oniy two spines.

D. Spiracles noticeably modified, usually with a prominent depression near their caudal margin; spiracular opening directed somerhat caudad; cephalic third of the movable abdominal segments usually slightly elevated and densely punctate.

E. Cremaster slender, pointed, spines closely approximated, abdominal spiracles with a darker, elevated, crescentshaped area almost surrounding the spiracle and with a deep cavity larger than the spiracle directly caudad of it; prothoracic spiracles not modified.

Meliana Curtis

EE. Cremaster short, blunt; area around each abdominal spiracle slightly elevated and darker in color, a prominent cavity caudad. the caudal margin of the spiracle; prothoracic spiracles also modified, the opening extending onehalf the distance between the antennae and the meson.

F. Chitinized ridge along the caudal margin of the abcominal spiracles distinctly serrate; clypeal region not prominently elevated and without deeply impressed lines.

Laphygma Guenée

FF. Chitinized ridge along the caudal margin of the abdominal spiracles not distinctly serrate; clypeal region prominently elevated and with deeply impressed lines.

Prodenia Guenee

DD. Spiracles normal, without any prominent elevations or depressions adjacent; cephalic third of the movable abdominal segments usually not elevated, segments Functate.

E. Epicranial suture present and distinct.

F. Cephalic third of movable abdominal segments with fine punctures, the remainder of the segments smooth; no cremaster present. 

FF. Abdominal segments all finely punctate and with wavy impressed lines, more densely punctate along cephalic margins of the movable segments; a short, distinct, rugose cremaster present.

Hadena Schrank

EE. Epicranial suture wanting.

F. Abdominal segments 5 to 7 very finely punctate on the cephalic third.

Chloridea Nestwood

FF. Abdominal segments with very large, shallow, punctures, at least on the cephalic third of segments 4 to 7 .

G. Abdominal segments all punctate; segments 4 to 7 having the punctures very large on at least the cephalic two-thirds of each segment and fine punctures on the remainder.

Pyrrhia Füoner

GG. Abdominal segments $1-7$ punctate; segments $4-7$ with larger punctures on the cephalic half of each segment and usually with finer punctures on the remainder.

Polia Ochsenheimer

BB. Metathoracic leg reaching to the eye-piece; cephalic margin of tenth abdominal segment with a row of deep oblong rits; prothoracic femur never exposed.

Eriopus Treitschke

The following species were examined:

Cirphis unipuncta Haworth, phragmitidicola Guen.

Rhodorhora gaurae Sm. \& Abb., florida Guen.

lisliana albilinea Hübn.

Laphygma frugiperda $\mathrm{Sm}$. \& $\mathrm{Abb}$.

Prodenia ornithogalli Guen.

Iycophotia margaritosa Havorth.

Hadena vulgaris Grote.

Chloriciea obsoleta Fabr., virescens Fabr.

Pyrrhia umbra Hüfn.

Polia renigera Stephens, picta Harris, meditata Grote.

Eriopus floridensis Guen.

Monima alia Guen. 

Subfamily Agaristinae

The members of this group show remarkable uniformity and it is rather difficult to separate the genera. This subfamily has been given family rank by some authors, and while the species included here differ from the typical noctuid in many respects, still no structural characters could be found to warrant their separation from the Noctuidae. The entire body surface is very rough and spinose while the cremaster is short, broad and decidedly flattened with its caudo-lateral angles produced into rounded lobes, with the caudal margin often crenulate. There are sometimes short straight setae present along the caudal margin. The antennae, mesothoracic legs and maxillae usually reach the caudal margin of the wings, ox approach it very closely. The prothoracic leg extends cephalad to the eye-pieces. The epicranial suture is always present. The labial palpi are always visible, but the femora of the prothoracic legs are always concealed except in occasional specimens. The abdominal spiracles are somethat elevated and are surrounded by a heavy dark chitjnized border. The openings appear to be fringed with fine setae.

The genera of this subfamily may be separated as follows:

A. Antennae always reaching the caudal margin of the wings; the row of spines along the caudal margin of the abdominal segments not larger than the spines of the segment; ninth abdominal segment never with scattered spines larger than those of the other segments.

B. Dorsum of the abdominal segments rugose and densely spinose on the firgt nine segments. 

BB. Dorsum of abdominal segments rugose and moderately spinose on the first seven segments; the eighth and ninth segments roughened, but with very few spines.

Alypia Hübner

$A A$. Antennae never reaching the caudal margin of the rings; the row of scines along the caudal margin of the abdominal segments larger than those of the segment; ninth abdominal segment with scattered spines larger than those of the other segments.

Psychomorpha Harris

The following soecies were examined:

Euthisanotia grata Fabr., unio hübn.

Alypia octomaculata Fabr.

Psychomorpha epimenis.

Subfamily Acronyctinae

The subfamily Acronyctinae as typified by the genus Acronycta has little to distinguish it from, other subfamiliea except that the cremaster is short and vsualiy mound-like and the setae are always of the same size and length. With this genus there are here included several others, which probably do not form a natural group, but all of which possess cremastral setae of the same size and length. in all the members of the group only the prothoracic leg extends cephalad to the eye-pieces. All of theae except the genus Acronycta have prominent projections on the head and prothorax. The epicranial suture is present only in Fulonche. The labial palpi are well developed in all and the prothoracic femora are visible only in Eulonche, Acronycta and Achatodes. The maxillae do not reach the caudal margin of the wings in any of the genera. The metathoracic legs are always visible and in Eulonche the mesothoracic legs are adjacent on the meson. In Plusiadonta they extend to the caudal margin of the wings, but in 

none of the other genera. The antennae are usually equal in length to the mesothoracic legs and never reach the caudal margin of the wings. The genus Eulonche and a few species of Acronycta are very peculiar in that there are setae on the body arranged as in the Arctildae (Fig. 102). These are easily observed on the mesothorax and the parts of the abdomen where the sculpturing is not so dense. There are also a few short spines present on the tenth segment at the base of the cremaster.

The genera of Acronyctinae may be separated as follows:

A. Cephalic end of body with two large, rounded, rugose projections on the head, one on each side the meson.

B. Dorsum of abdomen very rugose on segments one to seven except for \& smooth caudal margin; groups of long setae present on thorax and abdonen; epicranial suture present.

Eulonche Grote

BB. Dorsum of abdomen never rugose, but with large lunate punctures on the cephalic third of segments 3 to 7; groups of long setae never present; epicranial suture absent.

Achatodes Guenee

AA. Cephalic end of body with a single median projection, or without projections.

B. Cephalic end of body with a single median projection, either on the head or prothorax.

C. A prominent projection on the body near the cephalic margin of the prothorax; abdominal secments $1-3$ with a broad smooth transverse ridge near the caudal margin; movable abdominal segments with thin flanged plates; cremaster very short and broad with a short, stout, slightly curved seta inserted in each caudo-lateral angle. Homopryalis Grote

CC. Projection always present on the head; setae at the caudal end of the body always hooked.

D. Distinct cremaster not present; a large sharp point at each caudo-lateral angle of the body with some smaller ones and three short hooked setae inserted on each side; body distinctly punctate with a smooth band at the cavdal margin of each segment; projection on the head 

blunt at the end and directed ventrad.

Plusiadonta Guenee

DD. Distinct cremaster present, its caudo-lateral angles produced and pointed, with two hooked setae inserted on the ventral side of each; body not punctate, slightly rugose; projection on the head narrowed to a rounded point.

Anorni요 Hửbner

BB. Cephalic end of body smooth, cremastral hooks slightly curved.

Acronycta Treitschke

Species studied:

Acronycta americana Harris, populi Filey.

clarescens Guenee, hamamelis Guenee.

Eulonche oblinita Sm. and Abb.

Achatodes zeae Harris.

Homopyralis discalis Grote.

Plusiadonta compressipalpis Guenee.

Anomis erosa Hübner.

Subfamily Phytometrinae

The members of this subfamily differ markedly from those of the other subfamilies of Noctuidae. The labrun is never in its normal position but is located near the cephalic end of the body, while the wings and maxillae extend beyond the caudal margin of the fourth abdominal segment. The wings are produced into a sharp point near the meson of the ventral surface. The labial palpi are always visible and a large portion of the prothoracic femur is exrosed. The dorsal cephalic margins of the movable abciominal segments have a number of prominent furrows with slightly serrate ridges between. The prothorax is not as long as in the previously mentioned subfamilies, being only two-fifths the length of the mesothorax and the caudo-lateral angies are somewhat produced. The dorsal surface of the body shows frominent grooves along the caudal 

margin of the metathorax and the first four abdominal segments.

The edges of these grooves are somewhat serrate. The cremaster is somewhat cylindrical and rugose with two long hooked setae and four shorter ones.

The two genera studied are very closely related and may be separated as follows:

A. Antenna reaching the caudo-lateral angle of the mesothoracic leg; cremaster with length and breadth approximately equal and longer than its longest setae.

Phytometra Haworth

AA. Antenna much shorter than the mesothoracic leg and never reaching its caudo-lateral angle; cremaster always longer than broad and about equal in length to its longest setae.

Syngrapha Hübner

The following species were examined:

Phytornetra brassicae Riley.

Syngrapha falcigera Kirby.

\section{Subfanily Mominae}

The only genus studied in this group was Charadra. This resembles the Arctilaae very much more than it does most Noctuidae, in the shape of the body, in the presence of setae arranged around the scars of larval verrucae, and in the absence of epicranial suture, visible labial palpi and femora of the prothoracic legs. The antennae are broader at the proximal end than is typical in Noctuidae. The appendages are arranged more as they are in Noctuidae and there is a cremaster present, as long as the ninth and tenth abdominal segments, which bears hooked setae. The only Arctildae known which have long cremasters, are provided with flanged plates on the movable abdominal segments and the cremastral setae are never hooked. The prothoracic leg extends cerhalad 

between the glazed eye-piece and the antenna, but the mesothoracic leg never reaches the eye-pieces. The body is slightly punctate along the cephalic margins of the movable abdominal segments. The pupae are found in thin silken cocoons which differ from those of the species of Arctildae in that none of the larval hairs are used in 1ts construction. The only species studied was Charadra deridens Guenee.

\section{Subfamily Hypeninae}

The only genus available for study of this group as given in Dyar's list was Plathypena. As Balsa possesses the characters which distinguish this from other subfamilies, it is included here for the present. These characters are the presence of two long and six short hooked setae at the caudal end of the body and the fact that the prothoracic legs and the long point of the mesothoracic legs extend cephalad to the eye-piece, or in Balsa to the maxillary palpus which is always present in this genus. Plathypena shows the epicrarial suture present, but it is not found in Balsa. Both genera have the spiracles slightiy produced and in Plathypena they are on small elevations. The labial palpi are present in both, but the femora of the prothoracic legs are visible only in Balsa.

The genera may be separated as follows:

A. Dorsum of prothorax, metathorax and first three abdominal segments with a distinct median ridge; antennae and mesothoracic legs reaching the caudal margin of the wings and longer than the maxillae; caudal margin of mesothorax never with a row of shallow depressions. 

AA. Dorsum of body never with a median ridge; antennae and mesothoracic legs not reaching the cavdel margin of the wings and not longer than the maxillae; caudal margin of mesothorax with a row of shallow depressions.

Balsa Walker

The following species were examined:

Flathypena scabra Fabr.

Balsa malana Fitch.

\section{Subfamily Catocalinae}

This group is distinguished from all other noctuids by the presence of a whitish "bloom" on the surface of the pupa which is retained even in alcoholic specimens. Both prothoracic and mesothoracic legs extend cephalad to the eye-piece. The labial palpi are always present, but the femur of the prothoracic leg is seldom visible. The epicranial suture is found throughout the genera Catocala and Eunetis but is lacking in the remainder of the subfarily. The anternae, mesothoracic legs and maxillae either reach the caudal margin of the wings or very closely approach it. The cremaster is usually very short or absent and the setae at the caudal end of the body are usually of two sizes, inserted at aifferent levels except in the genus Eunetis. This generic name is applied to certain species of the genus Catocala of Dyar's list, which have a short cremaster, slightly broader at the caudal end, bearing about eight slightly curved setae which are usually directed towards the meson.

The following table w1ll serve to separate the genera

of Catocalinae:

A. Epicranial suture present; body tapering rapidy from the fifth abdominal segment so that it is more slender in appearance than the typical noctuid, the lateral margins of the 

abdominal segments $3-10$ as seen in dorsal view convergent and not stronerly convex.

B. Cremaster, if present, very short and narrowed at the caudal end, and with eight long hooked setae of two sizes, some larger and more heavily chitinized than the others.

Catocala Schrank

BB. Cremaster broadened at the caudal end, usually with eight short stout setae which are slightly curved and usually directed towards the meson.

Eunetis Hübner

AA. Epicranial suture not present; body of typical noctuid shape with the lateral margins of the abdominal segments 8-10 distinctly convex as seen in doral viev.

B. Head with a distinct tubercule near the base of each antenna. Euparthenos Grote

BB. Head rithout a aistinct tubercule at the base of each antenna.

C. Thorax and appendages with deep indeterminate transverae striations; median cudal spines of the cremaster somewhat enlarged near the tip; metathoracic legs never apparent.

Pheocyma Hubner

CC. Thorax and appendages approximately smooth; median cavdal spines of cremaster never enlarged near the tip; metathoracic legs always apparent below the maxiliae.

D. Cremaster with spines practically all of the ame size; no two being larger and longer than the others.

Caenurgia MaIker

DD. Cremaster with two spines larger and longer than the others.

Zäle Hubner

The following species were examined:

Euparthenos nubilis Hubn.

Pheocyma Iunifera Hubn.

Caenurşia erechtea Cramer, crasiiuscula Haworth.

Zale calycanthata Sm. \& Abo., lunata Drury.

Catocala illecta valker, unijuga Waiker, oriseis Edwaris, verecunda Hulst, aholibah strecker, ilia Cramer, iunubens Guen.,

neograma Sm. \& Abi., pacta Iinn., sponsa Linn.

Eunetis blandula Hulst., ultronia Hubn., grynea Cramer. 



\section{Subfamily Sarrothripinae}

This group is readily distinguished because it has neither cremaster nor setae at the caudal end of the body; probably due to the fact that its members are found in thick cocoons. The dorsal surface of the body is very irregularly rugose with spinous elevations and there is a distinct row of spines along the caudal margin of the fifth abdominal segment extending from the rugose area on the dorsum around nearly to the meson of the ventral surface. A few spines are present in a similar position on the fourth abdominal segment. The epicranial suture is always present, the labial palpi are visible for their entire length and only a small portion of the prothoracic femur is exposed, or it may be entirely concealed. The maxillae never reach the caudal margin of the wings, being about seven-eighths of its length with the mesothoracic legs meeting just caudad of them. The antennae always reach to the caudal margin of the wings while the mesothoracic legs do not, but are slightly longer than the maxillae. Both prothoracic and mesothoracic less extend cephalad to the eye-piece, the mesothoracic legs extending between the aculptured eye-piece and the antenna.

The members of this subfamily have been treated as the family Nycteolidae by some authors, but there is no evidence in the pupa to separate them from the family Noctuldae.

The following species were examined:

Sarrothripus revayana Scopoli, proteella Dyar. 



\section{Family Arctiidae}

The nembers of this family all possess distinct setae arranged around the scars of the larval verrucae. These are seldom conspicuous enough to be seen with the naked eye as in Liparidae, but are easily visible with the aid of the microscope. The labial palpi are never viaible, unless as small triangular areas caudad of the labrur, except in Halisidota where the palpi are exposed for their entire length. The femora of the prothoracic legs are never visible. The shape of the body is characteristic, being slightly concave on the dorsum in the region of the metathorax (Fig. 104). Certain genera of Noctuidae, Acronycta, Eulonche and Charadra, also show setae arranged around the scars of larval vermucae. In the two genera first named, both labial palpi and prothoracic femora are exposed, while Charadra possesses a long cremaster bearing hooked setae. Those genera of Arctildae with a cremaster never have hooked setae, but all cremastral setae are flattened at the distal end. The epicranial suture is never present in any member of this family. The prothorax usually is long, often one-half the length of the mesothorax as in most Noctuidae. The genus Ctenucha, included with the Syntomidae in Dyar's list, showed no characters to distinguish it from the Arctiidae and it is probable that other genera of this family should be included here.

The genera of Arctiliae may be separated as follows: 

A. Abdominal segments 5 to 7 never with a flanged plate along the cephalic margin, or with deep furrows between these segments when the body is retracted; maxillae nearly as long as the rings; mesothoracic wings never meeting on the meson caudad of the appendages.

B. Dorsal surface of abdomen flattened; body broadly rounded at caudal end and bearing a row of short setae which are slightly curved at tip; body brown, concolorous.

C. Labial palpi showing for about one-sixth of the length of the maxillae; body 18 to $20 \mathrm{~mm}$. In length; dorsal surface of abdomen never with depressed areas.

Halisidota Hübner

CC. Labial palpi never showing, except as a small triangular piece about a millimeter in length; body 12 to $15 \mathrm{~mm}$. in length; dorsal surface of abdomen with depressed areas on meson of each segment at caphalic margin and one on each side adjacent to the spiricles.

Euchaetias Lyman

$B B$. Dorsal surface of abtomen not flattened; body tapering at caudal end; color yellowish or chestnut brown strikingly marked with black.

C. Distinct cremaster present.

Haploa Hübner

CC. Distinct cremaster never present.

D. Antennae about seven-eightins the length of the wings; maxillae never reaching the caudal margin of the wings.

Utetheiga Hüner

DD. Antennae as long as the wings; maxillae always reaching the caudal margin of the wings.

Ctenucha Kirby

AA. Abdominal segments 5 to 7 with a flanger plate along the cerhalic nargins, and with deep furrows between the movable segments when the body is retracted; maxillae never as long as the wings, usually about two-thiras the length; mesothorecic wings always meeting on the meson caudad of the appendages.

B. Abdominal segrnents 4 to 6 with a similar flanged plate adjacent to the caudal margin of the segment.

C. Appendages, and usually the thorax, roughened with indeterminate transverse striations; abdominal segrents thickly, coarsely punctate. 

D. Head with a small tubercule at the proximal end of each antenna; antennae always much shorter than the prothoracic legs.

Estigmene Hübner

DD. Head without a tubercule at the proximal end of each antenna; antennae as long or longer, than the prothoracic leริs.

E. Body usually 18-20mm. in length, stout; setae of the cremaster of various sizes and lengths, the shortest ones only about half the length of the longest, and ir regularly arransed, always fifteen or more in number.

D1ac고르 Hübner

EE. Body seldom over $12 \mathrm{~mm}$. in length, varying from 10 to 15inm., rather slender; setae of the cremaster of practically the same size and length, arranged in two transverse rows, with four in the dorsal and eight on the ventral row, never as many as fifteen in number.

Hyphantria Harris

CC. Thorax and appendages smooth and polished; Dody sparsely, finely punctate.

Ecpantheria Hübner

BB. Abdominal segments 4 to 6 never with a flanged plate adjacent to the caudal margin.

C. Distinct cremaster always present and long, bearing setae at the caudal end; antennae about equaling the maxillae in length, usually three-fourths the length of the wings. Apantesis Walker

CC. Distinct cremaster never present; a row of setae at the caudal end of the body; antennae very much shorter than the maxillae, being about one-half the length of the wings. Isia Walker

The following species were examined:

Halisidota tessellaris S. \& A.

Fuchaetias egle Drury.

Haploa clymene Brown.

Utetheisa bella L.

Ctenucha virginica Charpentier.

Fetigmene acraea Drury.

Diacricia virginica Fabr.

Hyphantria cunea Drury.

Ecpantheria deflorata Fabr.

Apantesia virgo L., michabo Grt., arge Drury, phyllira Drury, nais Drury.

Isia isabelia S. \& A. 



\section{Family Liparidae}

This family, like the Arctiidae is characterized by the presence of setae arranged around the scars of larval verrucae. In the Liparidae the setae are long and coarse, and easily visiole to the unaided eye. With the exception of Porthetria all the genera examined showed a characteristic arrangement of appendages (Fig. 105). In this genus the labial palpi were usually concealed by the maxillae, although a large number of pupae showed it present as in Fig. 105. The epicranial suture is never present. The maxillae are always short, never more than two-fifths the length of the wings. The legs are usually shorter than in most pupae, the mesothoracic legs never reaching the caudal margin of the wings. The antennae are pectinate and are longer and broader in the male than in the female. The cremaster is always present, smooth, longer than broad and bears short hooked setae at the distal end.

Most of the speciea examined showed a remarkable uniformity of characters, and considerable difficulty was encountered in separating the genera. The difficulty lies in the fact that there is considerable difference between the sexes, not only in the length and breadth of the antennae, but in the size and arrangement of other appendages. In Hemerocarnoa the adult females are apterous, and the wings in the pupa are not as long as in the males. The wings of the females reach slightly over the cephalic margin of the fourth abdominal segment while in the male they reach to the caudal margin of that segment. In Hemerocampa the dorsum of the first three abdominal segments is covered on each side the meson 

with gmall vesicles.

The following table will serve to separate the genera

of Liparidae:

A. Spiracular furrows never present on the cephalic margins of the movable abjominal segments; labial palpi present and well developed; long setae not present on the face-parts near the caudal margin of the head, on the clypeus, or the sculptured eye-pleces.

B. Labial palpi about equal in width to each maxilla; cremastral setae about one-third the length of the cremaster.

C. Dorsal surface of abdomen densely covered with long setae; body brown, concolorous except sometimes for the lighter transverse conjunctiva; antennae with the ste: $1 n$ of the flagellum very broad and distinctly elevated.

D. Abcominal segments elght to ten, as viewed from the dorsal aspect, distinctly narrowed and tapering; clypeus and labrum on a level with the other face parts; cremaster directed caudad; antennae of male reaching about half the distance along the mesothoracic legs, and distinctiy pointed.

Dasychira Stephen

DD. Abdominal segments eight to ten, as viewed from the dorsal aspect, not narrowed and distinctly tapering; clypeus and labrum both elevated above the level of the other face-parts; cremaster directed dorsad; distal half of the antennae of the female distinctly narrowed and pointed, reaching about half the distance along the mesothoracic legs.

Olene Hübner

CC. Dorsal surface of abdomen not very densely covered with setae; body white, variously marked with brom or viceversa; antennae in both sexes with the stem of the flagellum scarcely indicated and the distal end always rounded, in the male, extending about one-half the length of the wings and curved mesad so that they often meet, in the female never extending for one-half the distance along the resothoracic legs and never meeting on the meson.

Hemerocampa Dyar

BB. Labial palpi only half the width of each maxilla; cremastral setae about half the length of the cremaster; antennae in the male broad for almost its entire length and extending about three-fourthe the length of the wings, adjacent or meeting on the meson, in the female pointed at the distal end and extending about half the distance along the mesothoracic legs 

AA. Spiracular furrows always present on the cephalic margins of the movable abdominal segments and extending almost to the meson, five or six in number and separated by sharply carinated ridges; caudal portion of face-parts, clypeus and glazed eyepieces with coarse setae similar to those on the body; labial palpi often concealed, but sometimes visible as in the remainder of the family.

Porthetria Hübner

The following species were examined:

Dasychira pudiounda L.

Olene manto Strecker.

Hemerocampa leucostigma S. \& A.

Porthetria dispar L.

Euproctis chrysorrhoea L.

Superfamily Bombycoidea

This superfamily includes those families in which the body is more or less densely covered with setae and which usually retain the labial palpi. They seein to be more nearly related to the Saturnioidea than to any other superfamily although the Lasiocampidae show certain points of relationsip with the Liparidae. All the members of the superfamily, so far as known, are found in thick silken cocoons, much like those of the Saturnildae.

The families of Bombycoidea may be separated as follows:

A. Eplcranial suture present; labial palpi visible.

Lasiocampidae

AA. Epicranial suture never present; labial palpi concealed by the maxillae, except for a small triangular area at the prozimal end.

Bombycidae

\section{Family Bombycidae}

This family includes the genus Bombyx which is domeaticated in various parts of the world (Fig. 107). The body is covered with rather coarse short setae which are somewhat longer 

at the caudal end of the body. The epicranial suture is never present. The appendages are arranged much as in Lasiocampidae. The labial palpi are almost concealed, being ove laid by large ovate appendages, appearing to be heavily veined which are presumably the maxillae, as no dissections have been made of this species. The mandibles are represented by strongly elevated tubercules. The coxae of one pair of legs, probably the mesothoracic, are adjacent on the meson caudad of the maxillae. The legs are short, and both prothoracic and mesothoracic pairs lie adjacent on the meson. The antennae are pectinate, broad at the proximal end and rapidy narrowed, ending in a point opposite the distal ends of the prothoracic legs. The mesothoracic wings lie adjacent on the meson caudad of the mesothoracic legs. The movable segments may be retracted so that only their caudal margins are visible. There is no cremaster present. The pupa strongly resembles those of certain species of Saturniidae and it is quite probable that they had a common ancestor, although the Bombycidae are undoubtedly more generalized. The only species in American is Bombyx mori $I$.

\section{Family Lasiocainpidae}

The members of this family usually have mouth-parts and appendages arranged as in the Liparidae (Fig. 106). The epicranlal suture is always present and the vertex is longer than that found in any but the more generalized forms. The maxillae are short, never more than one-third the length of the wings, and extend very slightly beyond the distal ends of the labial palpi, 

or often are not so long. The antennae are broad and pectinate, and never extend as far caudad as the prothoracic legs. The coxae of the prothoracic legs and sometimes of the mesothoracic pair are often visible caudad of the maxillae and labial palpi. The prothoracic legs are slightly more than one-half the length of the wings and the mesothoracic legs never reach the caudal margin of the wings. The setae of the body are very conspicuous, except in Tolype, but are not arranged around the scars of larval verrucae. The movatie segments are capable of being retracted till cnly their caudal margins are visible. There is never a cremaster Fresent and no hooked setae at the caudal end of the body. The body is broadly rounded at the caudal end and the body setae are usually a little longer and coarser in this region. This family is considered by many authors to be more specialized than any of the Saturnioidea, but the presence of the epicranial suture and exposed labial palpi shows that they are much more generalized.

The genera of Lasiocampidae may be separated as follows:

A. Entire surface of body, except the appendages, with a dense covering of fine short setae, giving it a furred appearance; abdorninal segments eight to ten considerably narrower than the remainder of the abdomen.

Malacosoma Hüioner

AA. Entire surface of body except appendages never with a dense covering of aetae so as to give it a furred appearance, either with a very svarse covering, or without visible setee; abdominal segmenta eight to ten not noticeably narrower than the remainder of the abdomen.

B. Body sparsely covered with very fine short setae, excepting at the caudal end where they are longer and coarser; tenth segrnent broadly rounded at the caudal end.

c. Lateral surface of ablomen on either side of the spiracles with the setae much thicker thin on the dorsum; dorsal surface of abdomen very coarsely punctate. 

CC. Lateral surface of abdomen on either side of the spiracles never with the setae more numerous than on the dorsum; jorsal surface of aboomen very finely punctate.

Cosmotriche Hibner

BB. Body without any visible covering of setae; tenth segment abruptly narrowed at the caudal end, suggesting a cremaster. Tolype Hübner

The following species were examined:

Vilacosoma anericana Fabr., disstria Hubn.

Lasiocampa quercus $I_{3}$. (Europe).

Cosmotriche potatoria L. (Europe).

Tolype velleda stoll

\section{Superfamily Notodontoidea}

The families included here never have the entire labial palpi exposed, but a very small triangular or polygonal area is sometimes visjile just caulad of the labrum. Some genera of Geometridae have the prothoracic femora exposed, while the epicranial suture is present in some of the members of each family. Although the larvae of Geometridae are easily recognized, and are very readily distinguished from those of the Notodontidae, the pupae show much closer relationships and it is difficult to draw a hard and fast line between the two families. The three families included here have probably had a common ancestor, and although the Dioptidae retain the epicranial suture it must be considered the most specialized, as both Geometridae and Notodontidae show more generalized characters in some of tiseir genera.

The following table may be used to separate the families of Notodontoidea:

A. Antennze never extending beyond the caudal margin of the wings; dorsum of abdomen never with a prominent hooked seta on each side the meson of segments seven to ten. 

B. Naxiliae usually more than three-fifths the length of the rings, if not, then the caudal end of the body with hooked setae, or the spiracles of the third abdominal segment concealed by the wings and those of the sixth segment farther ventrad than those of the other segments; prothoracic femora often exposed; a deep furrow usually present on the dorsum of the abdomen between the ninth and tenth segments; caudal margin of mesothorax never with a row of deep pits with smooth tubercule-like areas between.

Geometridae

BB. Maxillae seldom exceeding three-fifth the length of the wings, if so, then the caudal margin of the mesothorax with a row of deep pits with smooth tubercule-like areas between them; or with the entire body surface coarsely punctate; abdominal spiracles of the third segrment concealed by the wings, and those of the sixth never farther ventrad than the remainder; prothoracic femora never exposed; a furrow never present on the dorsum of the abomen except in Datane where the cremaster is of the type shom in Fig. 112 .

Notodontidae

AA. Antennae extending beyond the caudal margin of the wings; dorsum of abdomen with a prominent hooked seta on each side the meson of segments seven to ten.

Dioptidae

\section{Family Geometridae}

The pupae in this family never have the labial palpi exposed except as small triangular or polygonal areas caudad of the labrum. The maxillary palpi are never present. The epicranial suture is present in some of the genera in Groups $A$ and $C$. Some of the genera have the femora of the prothoracic legs exposed. In all the genera examined, the prothoracic leg and sometimes the mesothoracic leg extended cephalad between the glazed eye-piece and the antenna. The prothoracic and mesothoracic legs are longer than is usual in most families, the former being usually three-fourths the length of the wings, while the latter always extend to the caudal margin of the wings. Many of the genera show the fronto-clypeal suture extending from 

the proximal endis of the antennae and airected caudad towards the invaginations for the anterior arms of the tentorium. The suture is very distinct for the cephalic part and is often indicated by a slight furrow for the remainder of the distance. In the genus Haemotopsis there is a prominent cephalic projection bearing hooks which hold the suspensory threads, as this pupa is not found in a cocoon. The antennae vary little throughout the family, they are generally equal in width or wider than the prothoracic leg and usually extend to the caudal margin of the wings. The mesothoracic wings usually extend farther caudad than in the nearly related families, reaching nearly to the caudal margin of the fourth abdominal segment, although not visible in ventral view. The mesothorax is very short in some genera, particularly in those of Group D, where it is never twice the length of the prothorax. The prothoracic spiracles very often have a decided projection adjacent to their caudal margin which is usually flattened or tuberculate in form and often covered with very fine short setae. The abdominal spiracles are sometimes produced and in nearly all genera, the sixth or sometimes the sixth and seventh spiracles are considerably farther ventrad than the remainder. The abdomen is usually coarsely punctate, sometimes roughened with deep transverse striations. A cremaster of some kind is always present. One of the most intieresting structures of the abdomen is the dorsal furrow between the ninth and tenth segments. This is usually deep and fringed with very fine setae. This furrow frequently projects caudad on the lateral surface of the body and this is frequentiy separated from the dorsal furrow. This 

dorsal furrow is present in all members of Group A except Ennomos and in a few members of Group D. These dorsal furrows are found in other families notably the Gelechiliae and some Pyralididae.

The attempt to classify the pupae of Geometridae was seriously hampered by lack of material. Reared material was very hard to obtain, as the larvae develop slowly and seem to be very susceptible to disease. The available material, moreover, did not seem to fall in vith any of the existing schemes of classification, so that the only practical solution of the difficulty was to divide them into groups according to the pupal characters. These may or may not be natural groups, but they will serve to indicate relationships in some degree. According to the pupal characters there seem to be two large groups, one with hooked setae on the cremaster, the other without them. As the presence of hooked setae is a more generalized character, these groups should be the more generalized, and the presence of the epicranial suture strengthens this view. Group A includes representatives of the subfamilies Sterrhine, Ennominae and Hydriomeninae as listed by Dyar. Group B includes for the present only the genus Haematopsis. Group C includes the genera Alsophila and Brephos and must also be considered as a generalized group as the epicranial suture was present in the former. Bxephos has usually been considered as the most generalized geometrid, but no epicranial suture was located. The maxillae are also much shorter in Alsorhila. In Group $D$ the epicranial suture is never present. Spiracular furrows are frequentiy found in Groups $A$ and $D$. The 

adult females of some of the geometrid species are apterous. Although abundant material of one such species, Paleacrita vernata, was examined, the pupal wings were found as well developed in the female as in the male.

The groups of Geometridae may be separated as follows:

A. Cremaster with hooked setae.

B. Setae of the cremaster always of two sizes, usually either the two or four farthest caudad much larger than the othera; dorsurn of abdomen usually with a deer furrow between the ninth and tenth abdominal segments; body never with a bifurcate projection at the cephalic end.

Group A

BB. Setae of the crenaster always of the same size; dorsum of abdomen never with a furrow between the ninth and tenth segments; body with a long bifurcate projection at the cephalic end, densely covered with hooked setae.

Group $\underline{B}$

AA. Cremaster never with hooked setae.

B. Cremaster a stout T-shaped spine.

Groux C

$B B$. Cremaster always bifurcate.

Group D

Group A

This group includes species in which the cremastral setae are of two sizes, and which generally show the epicranial suture and a dorsal furrow between the ninth and tenth abdominal segments. Spiracular furrows are also frequently present. The genera included in this group may be separated as follows:

A. Epicranial suture alvays present; prothoracic femora always exposed, usually a lare portion; spiracular furrows never present; dorsun of abdonen never with a distinct furrow between the ninth and tenth segments, and also on the lateral surface of the tenth segment. 

B. Dorsum of fifth abdominal segment with a distinct furrow on the cephalic margin; caudal margin of the furrow between the ninth and tenth abdominal segments with finely serrate edges and without setae.

Hyơrịa Hiübner

BB. Dorsum of fifth abdominal segment never with a distinct furrow on the cephalic margin; caudal margin of the furrow between the ninth and tenth abdominal segments coarsely serrate.

C. Prothoracic and mesothoracic leg extending cephalad between the glazed eye-piece and the antenna, the mesothoracic leg extending almost as far cephalad as the prothoracic; caudal margin of the furrow between the ninth and tenth abdominal segments without setae; cremaster distinctly constricted at the proximal end and circular in outline.

Eois Fübner

CC. Prothoracic leg extending cephalad between the glazed eye-piece and the antenna, the mesothoracic leg never reaching farther cephalad than the caudal margin of the eye-piece; caudal margin of the furrow between the ninth and tenth abdominal segments usually fringed with fine setae; cremaster not constricted at the proximal end, triangular in outline.

D. Cremaster with the hooked setae of nearly the same size, the median caudal setae being only slightly larger than the others; three setae inserted along each side of the cremaster, the other two cephalad of these and slightly mesad.

Tephroclystig Hübner

DD. Cremaster with the hooked setae of wiclely differing sizes, the two median caudal setae being much larger and longer than the others, a smaller seta is adjacent on each side while the others are arranged in a transverse row just cephalad of the caudal setae.

Cinglis Guenée

AA. Epicranial suture never present.

B. Prothoracic femora exposed, but only a very narrow portion.

C. Spiracular furrows present on the fifth abdominal segment; ventral surface of head with a prominent transverse ridge extending from about the micile of the glazed eye-piece; body setae arising from small dark brown or black papiliae. 

CC. Spiracular furrows never present on the fifth abdominal segment; ventral surface of head never with a transverse ridge; body setae arising from small pits.

Sabulodes Guenée

BB. Prothoracic femora never exposed.

C. Antennae distinctly elevated and covered with five or six rows of small round tubercules; distinct ridges or flanged plates present along both margins of the movable segments.

D. Cremaster with the two median caudal spines very much larger than the otherg; distinct furrow always present between the ninth and tenth abdorninal segments; color d.ark brown.

Nacophora Hulst

DD. Cremaster with the four caudal spines about the same size and much larger than the others; distinct furrow never present between the ninth and tenth abdominal segments; color usually white, sometimes partly brown.

Ennoraos Treitschke

CC. Antennae elevated but never with distinct rows of tubercules; ridges or flanged plates never present on the movable segments.

D. Haxillae about tro-thiras the length of the wings; prothoracic, mesothoracic and metathoracic legs all meeting on the meson caudad of the maxillae.

Xanthotype Warren

DD. Maxiliae always more than two-thirds the length of the wings; prothoracic and mesothoracic legs never meeting on the meson caudad of the maxillae.

E. Spiracular furrows present on the cephalic margin of the fifth abdominal segment, with more or less interrupted ridges between; cremaster with the four caudal setae always larger than the others.

Aniㅡㄹ Stephens

EE. Spiracular furrows never present on the cephalic margin of the fifth abdominal segment, cremaster with two caudal setae larger than the others.

F. Furrow on the dorsum of the abdomen between the ninth and tenth segments never fringed with fine setae; body white marked with small irregular black areas. 

FF. Furrow on the dorsurn of the abdomen between the ninth and tenth segments fringed with fine setae; body brown, concolorous.

Cosymbia Hubner

\section{Group B}

The pupae of this group are easizy distinguished by the long bifurcate projection at the cephalic end of the body which is covered with hooked setae. There are never spiracular furrows present on the cephalic margins of the movable segments. The mesothoracic legs meet on the meson caudad of the maxillae. The body is very slender and never punctate. This group includesthe genus Haematopsis.

\section{Group C}

The species of this group are distinguished by the peculiar T-shaped cremaster.

The genera may be separated as follows:

A. Epicranial suture present; prothoracic and mesothoracic legs meeting on the meson caudad of the maxillae.

Alsorhila Hubner

AA. Epicranial suture never present; prothoracic and mesothoracic legs never meeting on the meson caudad of the maxillae.

Brephos Ochsenheimer

\section{Group D}

This group is characterized by the presence of a bifurcate cremaster. The epicranial suture is never present, but a portion of the prothoracic femora is exposed in many genera.

The following table will serve to separate the genera of this group:

A. Prothoracic femora visible. 

B. Cephalic margin of the fifth abdominal segment with one deep spiracular furrow with strongly chitinlzed edges, just cephalad of each spiracle.

C. Prothoracic spiracle with a broad, very strongly elevated ridge or oval tubercule adjacent to its caudal margin which is covered with fine short setae; surface of spiracular furrow with distinct punctures.

Phygostegania

CC. Prothoracic spiracle with only a very narrow, slightly elevated ridge adjacent to its caudal margin, usually covered with setae; surface of spiracular furrow without distinct punctures.

D. Dorsal surface of abdomen with a distinct furrow between the ninth and tenth segments, its cavdal margin finely serrate; surface of soiracular furrow almost smooth. Ectropis Hübner

DD. Dorsal surface of abdomen never with a furrow between the ninth and tenth segments; surface of the spixacular furrows strongly rugose.

Cleora

BB. Fifth abdominal segment without spiracular furrows; cephalic margin of the segment deeply punctate, the punctures sometimes confluent; prothoracic spiracles with a broad strongly elevated ridge or tubercule adjacent to its caudal margin; dorsal surface of abdomen without a distinct furrow between the ninth and tenth segments.

Cymatorhora Hübner

AA. Prothoracic femora never visible; deep spiracular furrows almays present on the cephalic margin of the fifth abdominal segment; prothoracic spiracle always with a prominent elevation adjacent to its caudal margin.

B. Dorsal surface of abdomen never with a furrow between the ninth and tenth segments; abdominal spiracles very strongly produced; cremaster often showing two lateral setae on each side near the proximal end.

Paleacrita Riley

BB. Dorsal surface of abdomen with a distinct furrow between the ninth and tenth segments; its caudal margin coarsely serrate; a prominent lateral depression or furrow present on the lateral surface of the tenth abdominal segment.

C. Maxillae four-fifths the length of the wings or less; mesothoracic legs meeting on the meson just caudad of the maxillae; antennae more than twice as wide at the proximal as at the dista.l end. 

CC. Maxillae always mare than four-fifths the length of the wings; mesothoracic legs never meeting on the meson caudad of the maxillae; antennae of almost the same width throughout, never twice as wide at the proximal as at the distal end.

Erannis Hübner

The following specieg were exanined:

Group A

Hydria undulata $I$.

Fois induciata Guenee.

Tephroclystis interruntofasciata Packara abinthiata clerck, Cinglis similaria malker.

Philobia enotata Guenée.

Sabulodes lorata Grote, transversata Drury.

Nacophora quernaria $\mathrm{Sm}$. \& Abo.

Ennomos subsignarius Hitoner, magnarius Guenee.

Xanthotype crocataria Fabricius.

Ania limbata Haworth.

Cingilia catenaria Drury.

Cosymbia serrulata Packara.

Group B

Haematopsis grataria Fabricius.

Group $\underline{\mathrm{C}}$

Alsophila pometaria Harris.

Brephos infans iroschler.

Group D

Pysostegania pustularia Guenee.

Ectropis crepuscularia Denis \& Schiff.

Cleora pampinaria Guenée.

Cymatophora ribearia Fitch.

Paleacrita vernata Peck.

Lycia cognataria Guenee.

Erannis tiliaria Harris.

Family Notodontidae

The pupae of this family never show more than a small

triangular or polygonal proximal portion of the labial palpi, and

maxillary valpi are never present. The femora of the prothoracic 

legs are never exposed. The epicranial suture is present in the genera Apatelodes and Ichthrura. The maxillae never reach the caudal margin of the wings. The antennae are always widest at their proximal ends, and there the width exceeds the greategt width of the prothoracic legs. Each antenna tapers gradually to a pointed tip and these often lie adjacent on the meson caudad of the other appendages. The metathoracic legs are seldom vistble. The mesothoracic leg never reaches cephalad to the eye-pieces. The abdomen is always punctate and in most species the punctures are large. A cremaster is usually present and there are various tjpes as in Figs. 111, 112, 113. Packard aivided the Notodontidae into six subfamilies. The pupae examined show that these subfamilies were well founded, but only tables to genera are given here as so few species of Notodontidae were examined. The species are listed, however, under the subfamily names.

Some authors believe that the genus Apatelodeg belongs to the European family Eupterotidae, and is incorrectly listed with the Notodontidae. As no pupae of Eupterotidae have been examined, it is impossible to say whether pupal characters would justify this change. There are, however, no pupal characters as far as observed which would prevent its being included with the Notodontidae. The two species differ widely and are possibly not congeneric.

The following tables will serve to separate the genera of Notodont1dae: 

A. Maxillae one-third or less the length of the wings; both prothoracic and mesothoracic leg's meeting on the meson caudad of the maxillae; abdomen very finely punctate.

B. Thorax and abdomen thickly covered with very fine, short setae; cephalic margin of first abdominal segment with a smali tubercule on each side the meson; cremaster a stout spine about one millimeter in length with two short recurving hooks at the tip, each of which bears two or more very fine setae.

Melalopha Hübner

BB. Thorax and abdoren never thickly covered with fine, short setae; cephalic margin of first abcominal segment wi thout tubercules; cremaster never as described above, or absent.

C. Abdominal segments 2 to 7 with aistinct, flanged plates at both cephalic and caudal margins, the cephalic plate interrupted by deep pits, giving it the appearance of a row of square tubercules; appendages not at all elevated, making a smooth even surface; cephalic end of body not elevated between the antennae; short cremaster sometimes present.

Apatelodes Packard

CC. Abdominal segrents 2 to 7 never with flanged plates; appendages distinctly elevated; cephalic end of body elevated between the antennae; cremaster never oresent.

Harpyia Ochsenheimer

AA. Maxillae always more than one-third the length of the wings; never with both prothoracic and mesothoracic legs meeting on the meson; abdomen usually rather coarsely punctate.

B. Maxillae from one-half to three-fifths the length of the wings; mesothoracic legs meeting on the meson caudad of the raxiliae; appendages roughened with deep indeterminate striations; abominal segrnents coirsely punctate; a distinct, deep furrow on the dorsum between the ninth and tenth abdominal segmenta; cremaster short, bifurcate, each half with several short spiny processes, usually directed laterad.

Datana walker

BB. Haxillae nore than three-fifths the length of the wings; neither prothoracic nor meaothoracic leosmeeting on the meson caudad of the maxillae; appendages usually with shall.ow indeterminate striations; a distinct furrow never present on the dorsum between the ninth and tenth abdominal segments; cremaster not as described above.

C. Entire body surface with coarse, deep punctures; cephalic margins of the movable abdominal segrnents with large lunate punctures and $a$ distinct ridge, with a row of large, 

very distinct punctures just cephalad of the ridge; cremaster short, rugose, slightly bifurcate, bearing six long hooked setae; mesothorax never with a deeply pitted caudal margin.

Synmerista Hibner

CC. Body usually punctate on the abdomen, but not on the appendages; movable abdominal segments sometimes with a slight riage along the cephalic margin, but never with a distinct row of larger punctures caudad of the ridge; cremaster bifurcate, but never with hooked setae; mesothorax with a row of deep pits along its cevdal margin with smooth black areas between, and partly covering them.

D. First abdominal segment with a small tubercule on each side the meson at the cephalic margin of the segment; entire dorsal surface of the tenth segment distinctly elevated and very rugose; points of the cremaster aivergent.

Hyparpax Hübner

DD. First abdominal segment without tubercules; entire dorsal surface of the tenth segment not elevated and rugose.

E. Wings always touching on the meson; maxillae never as long as the wings; cephalic end of body sometimes with two sharp, heavily chitinized spinous projectiong.

Schizura Doubleday

EE. Wings adjacent on the meson but not touching; maxillae ialily as long as the wings; cephalic end of body without heavily chitinized spinous projections.

Heterocampa Doubleday

The following species were examined:

Melalophinae

Melalopha inclusa Hubn., anicalis Walk.

Apatelodinae

Apatelodes torrefacta S. \& A., angelica Grote.

Cerurinae

Harpyia borealis Boisd.

Pysaerinae

Datana ministra Drury, modesta Beutenmulier, av.gusii G. \& R., chiriquensis Dyar, contracta Walk., drexelil Hy. Edwards, integerrima G. \& R., major G. \& R., palmi i Beutenmuller, robusta strecker.

Notodontinae

Symmerista albifrons $S$. \& A. 

Heterocarninae

Hyparpax aurora S. \& A.

Schizura ipomoeae Doubleday, concinna S. \& A., unicornis S. \& A. Hetercampa guttivitta Walk., bilineata Pack.

\section{Family Dioptidae}

The pupae of this family closely resemble those of the Geometridae, but are more specialized than most of the genera in that family, although they show the epicranial suture (Fig. 115). The appendages are arranged very much as in the Geometridae, but there is no trace of labial palpi, maxillary palpi or prothoracic femora (Fig. 114). The antennae are filiform extending beyond the caudal margin of the wings and about half the length of the fifth abdominal segment. Each prothoracic leg extend cephalad between the glazed eye-piece and the antenna. The distal ends of the prothoracic and mesothoracic legs and the maxillae are overlaid by the antennae which lie adjacent on the meson at their distal ends. The abdomen is elevated at the meson to form a low ridge and there are prominent hooked setae present on segments seven to ten as well as on the cremaster. This family contains a single American species, Phryganidia californica Packard. The family has usually been placed between the Noctuidae and Notolontida.e, and widely separated from the Geometridae. The pupa shows no relationship to the noctuids, and is much more highly specialized than most members of that family.

Superfamily Sphingoidea

The members of this superfamily retain but one generalized character, the presence of exposed portions of the prothoracic 

femora in some of the more generalized forms. The shape of the pupa is almost as distinctive as that of the larva, being usually fusiform, often with the head distinctly narrower than the thorax, giving the body a "shouldered" appearance. The epicranial suture is never present, the only distinct head suture remaining being that adjacent to the proximal end of each antenna. The wings and maxillae are unusually long in most members of this superfamily and various means are taken to accomodate the extra length, particularly of the maxillae. The fourth abdominal segment is usually longer on its ventral surface than on the dorsal and the wings are seldom broady rounded at their caudal margins, but usually somewhat pointed. The position of the head is also changed in many species and found almost, or entirely, on the dorsal surface of the body. The mandibles are often very conspicuous, being represented by strongly elevated tubercules. The prothoracic legs are usually about one-half the length of the wings and the mesothoracic legs three-fourths of their length. The metathoracic legs are seldom visible. The antemae are for the most part filiform and vary from two-fifths to three-fourths the length of the wings. In the subfamily Ambulicinae the antennae are considerably wider at their proximal end and slightiy pectinate, being larger and longer in the male, and the whole appearance of the body reminds one strongly of the saturniidae. These are in many reapects the most specialized of the Sphingoidea, and some of them are found in cocoons. It is an interesting fact that the most specialized forms in nearly all of the subfamilies examined, showed relationship to the saturnitae. This 

group is therefore considered as related to the Saturnioidea but more generalized. Certain of its members resemble in some respects the Pyralididae and Gelechiidae. A cremaster is always present, usually triangular in outline and often slightly bifurcate at the distal end. The abdomen often shows three or four transverse depressions on each segment which correspond to the annulet-like rings on the body of the larva. Except in rare instances the scar of the caudal horn of the larva ia visible on the dorsum of the eighth abdominal segment. This group will be fully discussed in a paper which will give descriptions and tables for the identification of practically all of the North Anerican species whose life history is known.

\section{Superfamily Saturnioidea}

The pupae of this superfamily retain none of the generalized characters found in the families previously discussed and all the sutures of the head are obliterated, even those adjoining the proximal ends of each antenna. The body is usually heavily chitinized and although there are always a few setae present, these are rarely visible to the unaided eye. The superfamily is distinguished by the presence of oroady pectinate antennae, in the Ceratocampidae for about one-third of the length while in the Hemileucidae and saturniidae they are broady vectinate to the distal end, and generally have the stem of the flagellum elevated. The greatest width of each antenna is at least one-fifth of its length, is often much wider, and they seldom extend farther caudad than the prothoracic legs. There 

is a marked difference in the sexes, the antennae of the male being much broader, somewhat longer and often meet on the meson, covering nearly all of the appendages except the wings. The legs are shorter than in most superfamilies, the prothoracic and mesothoracic legs usually either meeting or lying adjacent on the meson. The maxillae never reach the caudal margin of the wings, and their greatest length is not more than one-third the length of the wings, but they are usually much shorter. The mesothoracic wings always lie adjacent on the meson and the metathoracic wings are often visible on the meson in the Saturniidae. The family Ceratocampidae has a row of broad triangular apines set on the edge of a flanged plate along both cephalic and cavdal margins of the movable abdominal segments. They usually possess very long crematers, which are always bifurcate at the distal end. The Hemileucidae have short cremasters, while there are none present in the Saturnildae and few of the genera have spines at the caudal end of the body. A paper on this superfamily, giving tables for the identification of families, genera and species, has been published in the Annals of the Entomological Society of America, Volume 7, 1914, and Volume 8, 1915, so that further discussion of the family is unneceasary. 



\section{Phylogeny .}

The characters used as a basis for determining the phylogeny of the order are primarily: (1) the number of movable segments; (3.) the freedom of the appendages; (3) the number of suturespresent in the head; (4.) the relative length of the body segments; (5.) the presence or absence of visible labial palpi and maxillary palpi; (6.) the presence of an exposed portion of the prothoracic femora in specialized pupae; and (7.) the method of dehiscence.

In the most generalized forms there is corplete freedom of motion possible between the head and thorax, and between all the segments of the thorax and abdomen, with the exception of the eighth, ninth, and tenth abdominal segments, which are always fixed. As specializetion proceeds, there is a gradual loss of motion; first between the head and thorax, then between the segments of the thorax, and last of all, between the different segments of the abdomen. The loss of motion in the abdomen begins first at the cephalic end, but by the time that complete motion of the second segment has been lost, there begins a loss of motion of the seventh segment. This takes place first in the female and there is a large series of forms including the superfamilies Gracilarioidea, Tortricoidea and Aegerioidea which retain freedom of motion in the seventh segment of the male, while there is taking place at the cephalic end of the abdomen the losa of motion of the third abdominal segment. There are, hovever, a few genera of Gracilarioidea which have lost freedom 

of motion of all the body segments and which form the most specialized end of that series. The pupae, which have lost motion of all the abdominal segments except the fourth, fifth, and sixth, are those usually referred to as obtected pupae. There are few pupae more specialized than those of the superfamily Gracilarioidea which retain freedom of motion of the seventh abdominal segment in the male, but there are a few generalized forms both in the Pyralidoidea and Papilionoiciea in which this is the case, and also the family Epermenildae of the Yponomeutoidea. These three superfamilies are considered as more specialized than the Gracilarioidea. As the number of movable segments determines the position of a superfamily in the series it is readily seen that these superfamilies must be considered as more generalized than those in which motion is lost in the seventh segment in the male. It will be remembered that a segment is spoken of as movable when there is no motion possible between its caudal margin and the segment caudad of it. As the appendages become soldered to the body wall on the ventral surface there is no motion possible of this part of the segment if the inciaion between its caudal margin and the next segment is covered by the wings; therefore it cannot be considered as a free segment. In many cases, however, dorsal movement of such segments is posible, which gives the segment freedom of movement in certain directions, as for instance, in curving the caudal end of the body cephalad on the ventral surface, well illustrated in the movements of most tortricias. Such forms must be considered as more generalized than those which have lost entire 

motion of the segment and thus the Pyralidoidea and Papilionoidea must occupy a lower position than the Yponomeutoidea, whose members have lost dorsal motion of the third abdominal segments, while the other two suferfamilies mentioned retain it. There are certain specialized forms in other superfamilies in which motion is lost in all the body segments notably in the family Elachistidae of the Gelechioidea and in certain genera of the family Nymphalidae in the Papilionoidea. There are also many genera in various families which retain movement in only one segment.

The appendages of generalized pupae are entirely free from each other and from the body wall and are often consideraily spread out from the surface of the body so that the pupae strongly resemble those of the Trichoptera. In these forms there is but a slight degree of chitinization in any part of the body. The appendages are gradually soldered dom, however, first to each other, while a.II remain free from the body wall, and then there takes place a gradual soldering down of the appendages to the body wall, beginning first at the cephalic end of the abdomen. In many pupae the appendages are soldered to two, three, or four abdominal segments while the portion of the appendages caudad of these segments remain free and allow freedom of motion of the abciominal segments underneath. Such a condition exists in many gencra of the Aegerioidea and Gelechioidea. The pupae with free appendages could only exist successfully in protected situations from which an easy egress was possible and so they are only 

found in cocoons, or in mines in leaves and stems of plants. Pupae with any other environment lost the freedom of the appendages much more ragidly as in the case of the Lyonetildae and some of the Papilionoidea.

The number and arrangement of the sutures present in the head has already been discussed in the chapter on external morphology, pages 12 to 14 . These sutures are gradulily obliterated beginning with the clypeo-labral, which is lost among very generalized pupae. The epicranial suture is one of the last to disappear, and its presence indicates the degree of specialization in many of the higher forms, as it is retained in some members of many superfamilies which are high in the series.

The fronto-clypeal suture is visibie for a part of its length in most pupae, and is especially distinct for its entire length in some of the Gelechioidea, but dehiscence often shows the presence of this suture when it was impossible to locate it on the pupa. The part of this suture adjacent to the proximal end of each antenna is the last head suture to be obliterated and is lacking only in the Saturnioidea.

The segments of the body are more nearly of equal length in generalized forms, especially in the abdomen. The prothorax is short in the Micropterygoidea and becomes gradually longer in the specialized superfamilies. The metathorax is long in gereralized forms and nearly equals the mesothorax in length. As specialization proceeds, the mesothorax becomes longer and the metathorax much shorter so that the comparative length of these 

two segments furnishes another means of determining the position of a superfamily in the series. The abdominal segments also become consolidated, first at the caudal end of the body, where they gradually become shorter than the cephalic segments. After motion is lost in the cephalic segments, they too, gracually shorten, until the movable segments are much longer than any of the others.

The presence of visible maxillary and labial palpi also furnish an easy means for the identification of generalized forms. The labial palpi are retained throughout the series, but are gradually overlaid and concealed by the maxillae, but their presence or absence indicates the degree to which specialization has proceeded along a given line. Labial palpi are vigible to some extent in some members of all superfamilies except the Saturnioiciea. The maxiliary palpi are usually the first to disappear but these palpi are often present in the pupa, when lacking in the adult. The maxillary palpi in generalized forms reach the proximo-lateral angles of the maxillae but gradually decrease in length until they are visible only as a small triangular area caudad of the glazed eye-piece.

When the appendages are free, their position is considerably laterad of that which they gradually assume as they become soldered to each other. The legs are folded in such a way that in generalized forms almost the entire femur of the prothoracic leg is exposed. Later the tibia and tarsus of this leg is folded so that their position is nearer the meson than formerly 

and the femur is entirely concealed. The presence of an exposed portion of the prothoracic femur is a generalized condition which is retained by forms exceedingly specialized in other respects, and is found in some genera of Sphingidae.

As to the method of dehiscence, there are several things to be noted, although all too little is knom of this interesting phase of pupal life. There is a tendency for the generalized forms to emerce from the mine, cocooll, burrow or other place of protection as a pupa and consequently the body is provided with some structure which assists in its progress. The appenaages and body segments are usually separated from each other at dehiscence and the body splits along the median line of the vertex and thoracic segments, the vertex carrying the glazed eye-pieces with it. The front with the antennae are completely separated from the rest of the head parts in some forms, by a splitting along the epicranial suture on the dorsum, and along the fronto-clypeal suture on the ventral surface. Then the fronto-clypeal suture is not entire it voualy splits for a part of its length, thus allowing it to be considerably elevated. In specialized forms it is usually the imago which emerges, the pupal skin being left behind in the cocoon or other place of protection. The appendages and body segments remain firmly soldered together and the imago escakes through the opening made by the splitting of the vertex when present, the prothorax and the mesothorax, or if this is not sufficient an irregular opening is made in the cephalic end of the body which does not follow the line of any suture. In these 

forms the eye-pieces remain attached to the other face parts. The phylogeny of any group is usually determined by the developnent of a single character. Many workers have used the venation of the wings to arrange a series of genera or species in phylogenetic order. Others have used the genitalia, or the arrangement of setae. The pupae present many and varied characters which may be used to arrange such a series. In this investigation a series was arranged for each of the characters previously mentioned and these were combined to form the arrangement shown in Fig. 116. These characters have the advantage over those used by previous authors in that they comprised practically all of the important structures of the body and are all found on the same individual. It is quite probable that other characters might be used to indicate the development of the order, such as the number and arrangement of the genital apertures, the form of the spiracles and the arrangement of setae, none of which have been investigated suficiently to admit of their use in this paper. 

VI. Bibliography.

1889. Scudder, S. H., The Butterflies of the Eastern United States and Canada. 3 vols.

1891. Jackson, Hatchett. Momology of the Lepidoptera. Trans. Iinn. Soc. London, Zool., Ser. 2, Vol. 5.

1891. Poulton, E. B. The External Morphology of the Lepidopterous Pupa. Trans. Iinn. Soc. London, ZooI.

Ser. 2, Vol. 5, pp. 245-263.

1893. Chapman, Dr. T. A. Some Neglected Points in the Pupae of the Heterocerous Lepidoptera. Trans. Ent.

Soc. London, Vol, 42, pp. 97-119.

1893. Chapman, Dr. T. A. On a Lepidopterous Pupa (Micropteryx purpurelia) with Functionaliy Active liandibles. Trans. Ent. Soc. London, Vol. 42, pp. $255-265$.

1894. Chapman, Dr. T. A. Some Notes on the Microlepidoptera Whose Larvae are External Feeders. Trans. Ent. Soc. London, Vol. 43, pp. 335-350.

1895. Packard, Dr. A. S. Attempt at a New Clasgification of the Lepidoptera. Monograph of the Bombycine Noths of America North of Mexico, Part I, Memoirs of the National Academy of Sciences, Vol. 7, pp. 56-83.

1896. Chapman, Dr. T. A. Notes on Pupae - Orneodes, Eperminia, Chrysocorys and Pteroxhorus. Trans. Ent. Soc. Iionäon, Vol. 45, pp. 129-147.

1900. Tutt, J. W. A Iratural History of the British Lepidoptera. Vol. 2, pp. 38-100. 

VII. Acknowledgments.

The subject for this investigation was suggested by Professor A. D. WiacGillivray in September, 1912. Since that time many species of Lepidoptera have been collected, both in the larval and pupal stage and reared to maturity. The Graduate School of the University of Illinols has made liberal appropriations for the purchase of material and a large series of named Fupae has been obtained from the American Entomological Company, Ward's Natural Science Establishment, the Kny-Scheerer Company, the New England Entomological Exchange, the New Jersey Entomological Company, Mr. Mm. Beutenmuller, A. H. Manee of Southern Pines, N.C., E. J. Oslar of Denver, Colo,, and Miss Annette F. Braun of Cincinnati, 0. Dr. L. O. Howard, Chief of the Division of Entomology of the U.S. Department of Agriculture, Mr. August Burck of the U. S. National Nuseun, Dr. Wm. Barnes of Decatur, III. have furnished a number of rare species which contributed in no small measure to the progress of the investigation. The collections of the IIIinois State Laboratory of Natural History have been freely available, and for this courtesy Professor S. A. Forbes deserves our hearty thanks. Dr. T. H. McDunnough of Decatur, III. and Miss A. F. Braun of Cincinnati, 0 . have assisted in the identification of bred material, thus making available many species that otherwise could not have been used. The collections furnished by Miss A. F. Braun and $\mathbf{H} r$. Wm. Bevtenmulzer deserve especial mention. Miss Braun collected, bred, and determined more than one hundred species of the so-called microlepidoptera 

which really formed the working basis for this part of the investigation. Most of the work done on the Sphingidae has been from specimens furnished by Mr. Beutenmuller who has coilected a large series of forms. Mr. Samuel Henshaw of the Museum of Comparative Zoology at Harvard very kindly loaned a large series of Papilionoidea most of which were collected by Dr. S. H. Scudder and described in his "Butterflies of the Northern United States and Canada". Professor J. G. Needham of the Department of Entomology at Cornell University also loaned a large number of species from the collections of the University, which were especially valuable, and which could not be obtained elsewhere. It would be impossible in this brief space to enumerate the many ways in which Professor MacGillivray has assisted in the preparation of this paper. His interest in the work has been unfailing, and whatever of value it may contain is due to his inspiration, encouragement and helpful criticism. 



\section{Explanation of Plates}

The following plates show in outline the princinal structures of pupae of many of the families discussed in this pacer. No attempt has been made to show all of the setae, spines or tubercules which may occur, but only those which are most important and of taxonomic value.

The following abbreviations have been used:
a antennae
dit
dorso-lateral row of tubercules

al-alo abdominal segments $1-10$

af alar furrow

amt dorso-mesal row of tubercules

ao

anal opening

dat dorso-spiracular row of tubercules

ar anal rise

at invaginations for the anterior arms of the tentorium

cl clypeus

cls clypeo-labral suture

cam caudal margin of an abdominal segment

es epicranial suture

f front

fcs fronto-clypeal suture

fl femur of the prothoracic leg

f2 femur of the mesothoracic leg

$\mathrm{cm}$ cephalic margin of an abdominal segment

cr cremaster

cs cremastral setae

cxl coxa of the prothoracic leg

fp flanged plate

g genae

ge glazed eye-plece

go genital opening

Ib labrum

cxa coxa of the methoracic leg

11 prothoracic leg

12 mesothoracic leg

cx3 coxa of the metathoracic leg

13 metathoracic leg 

Ip labial falpi

md mandibles

$m p$ maxiliary palpus

ms mesothorax

mt metathorax

msp mesothoracic spiracle

mx maxilla

p prothorax

pf piziffer

psc proleg scar

s spiracle

se sculptured eye-piece

sf spiracular furrow

$t$ tegulae

ts tubercule scar

v vertex

vst ventro-spiracular row of tubercules

wI mesothoracic wing

w2 metathoracic wing 



\section{Plate I}

1. Wnemonica auricyanea. Ventral view, male.

2. linemonica auricyanea. Lateral view, female.

3. Inemonica auricyanea. Dorsal view, female.

4. Wnemorica auricyanea. Dorsal view, caudal end of abdomen, male.

5. Mnemonica auricyanea. Ventral view, caudal end of abdomen, male.

6. Mnemonica auricyanea. Dorsal view, cavdal end of abdomen, female.

7. Mnemonica auricyanea. Ventral view, caudal end of abdomen, female.

8. Sthenopis thule. Ventral view, male.

9. Sthenopis thule. Lateral view, male.

10. Sthenopis thule. Dorsal view, male.

11. Thyricopteryx ephemeraeformis. Ventral view, male.

12. Thyridopteryx ephemeraeformis. Lateral view, male.

13. Thyridopteryx ephemeraeformis. Dorsal view, male.

14. Thyriciopteryx ephemeraeformis. Ventral view, female.

15. Prionyxstus robiniae. Face-parts, male.

16. Zeuzera pyrina. Ventral view, male. 

Plate 1

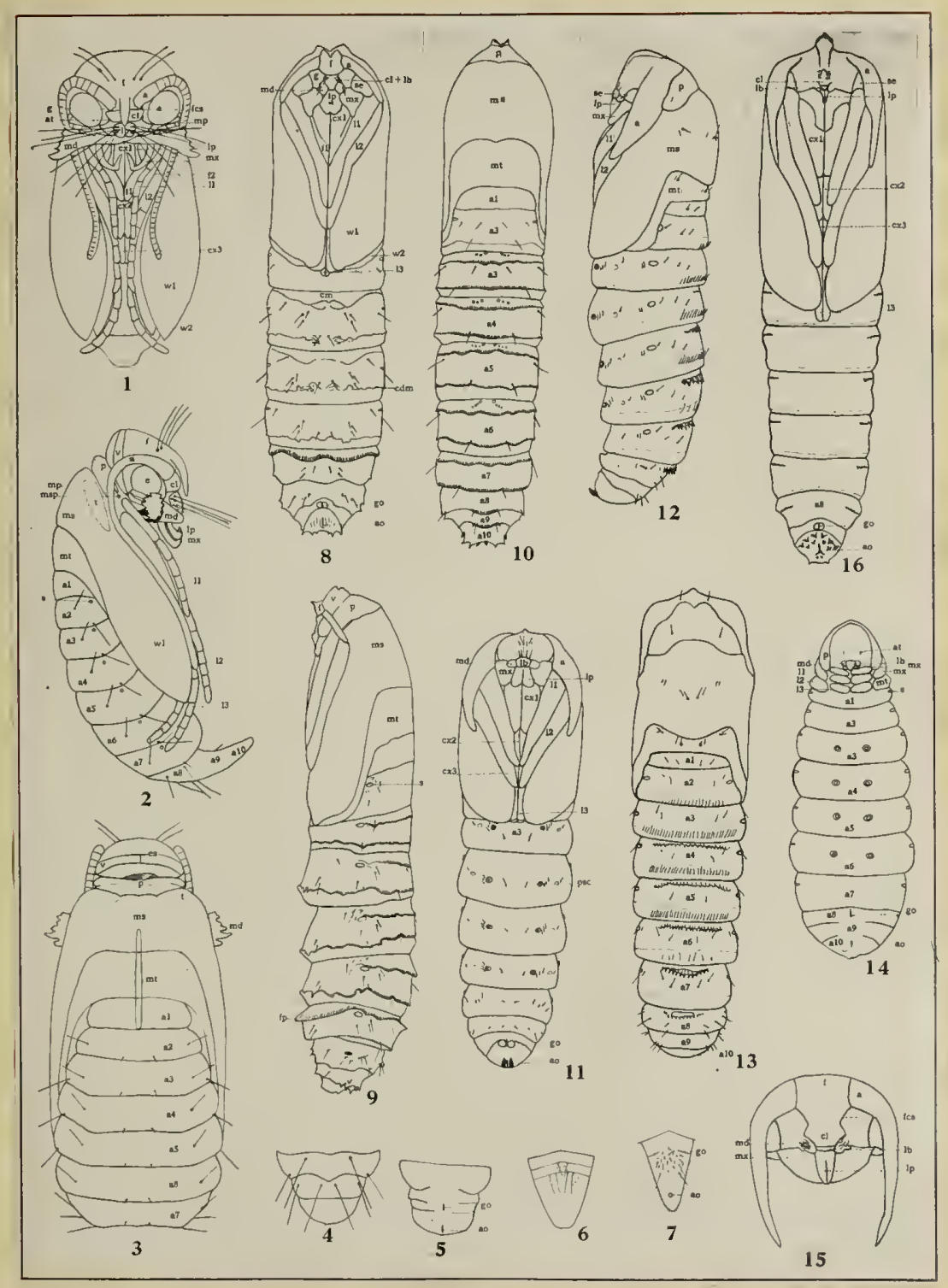





\section{Plate 2}

17. Lagoa crispata. Ventral view, female.

18. Lagoa crispata. Dorsal view, female.

19. Euclea viridis. Ventral view, female.

20. Euclea viridis. Dorsal view, male.

21. Euclea viriais. Mesothoracic spiracle and adjacent parts.

22. Euclea viridis. Cephalic view of head and prothorax.

23. Prolimacodes scapha. Ventral view, male.

24. Harrisina americana. Ventral view, female.

35. Harrisina americana. Dorsal view, female.

26. Prodoxus quinquepunctella. Face-parts.

27. Prodoxus quinquepunctella. Ventral view.

¿7a. Prodoxus quinquepunctella. Tubercule of the eighth abdominal segment, lateral view.

28. Hycocolnus mortipennelius. Ventral view, female.

29. Hypocolpus mortipennelius. Dorsal view, female.

30. Tinea pellionella. Ventral view, male.

31. Tinea pelilonelia. Dorsal view, male. 

Plate 2

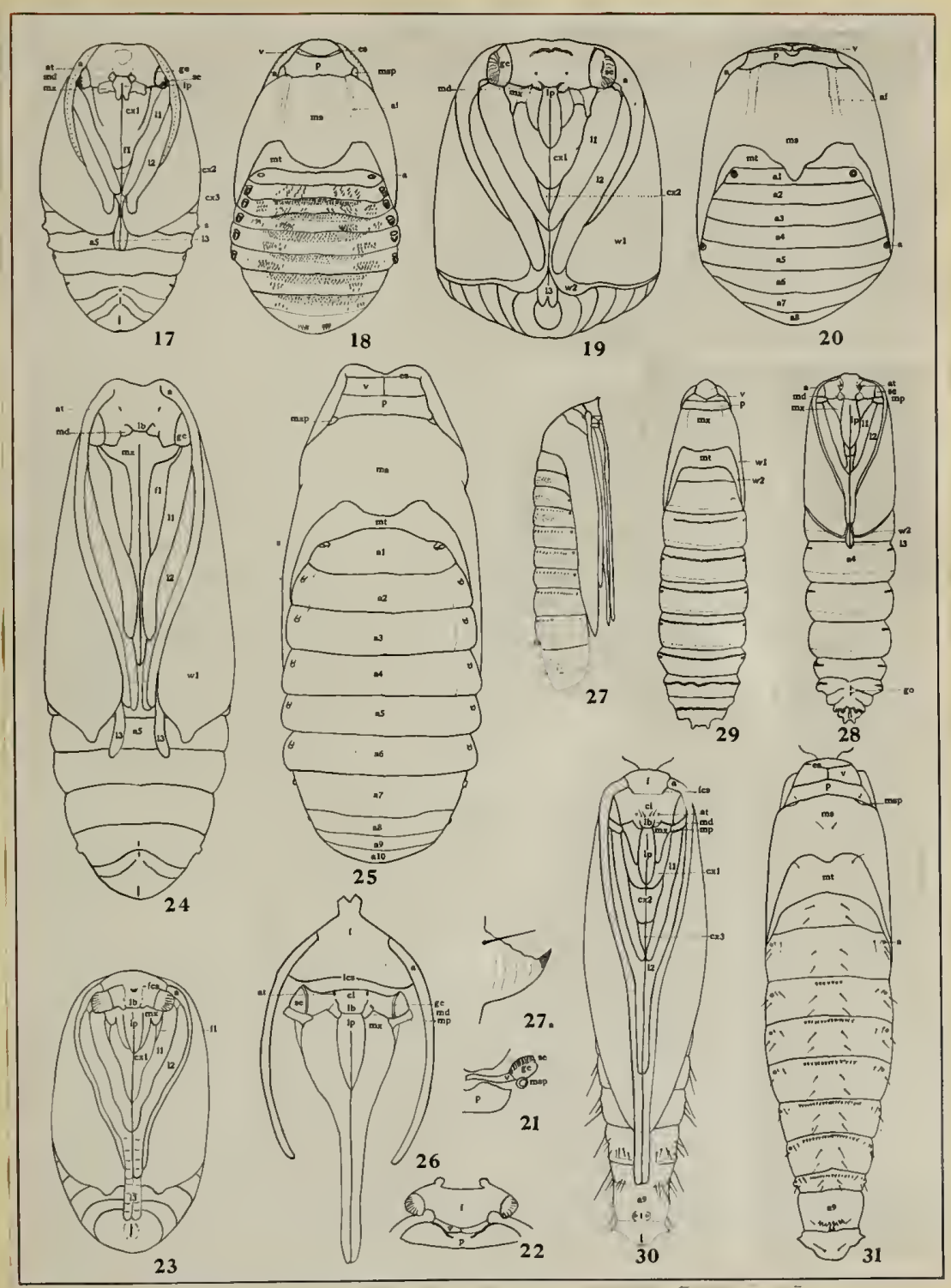


LIOKAARY
UNIVERSITY THE

OF ILLINOIS 


\section{Plate 3}

32. Brenthia pavonacella. Ventral view, female.

33. Brenthia pavonacella. Dorsal view, male.

34. Choreutis gnaphiella, Ventral view, female.

35. Choreutis gnaphiella. Dorsal view, female.

36. Podesesia syringae, Ventral viow, female.

37. Synanthedon pictipes. Dorsal view, head, thorax and abdominal segments $1-3$.

37a. Synanthedon pictipes. Dorsal view, abdominal segments 8-10.

38. Ancylis comptana. Ventral view, male.

38a. Ancylis comptana, Anal rise, lateral view.

39. Ancylis comptana. Dorsal view, male.

40. Exartema ferriferanun. Ventral view, male.

41. Peronea minuta. Lateral view, male. 

Plate 3

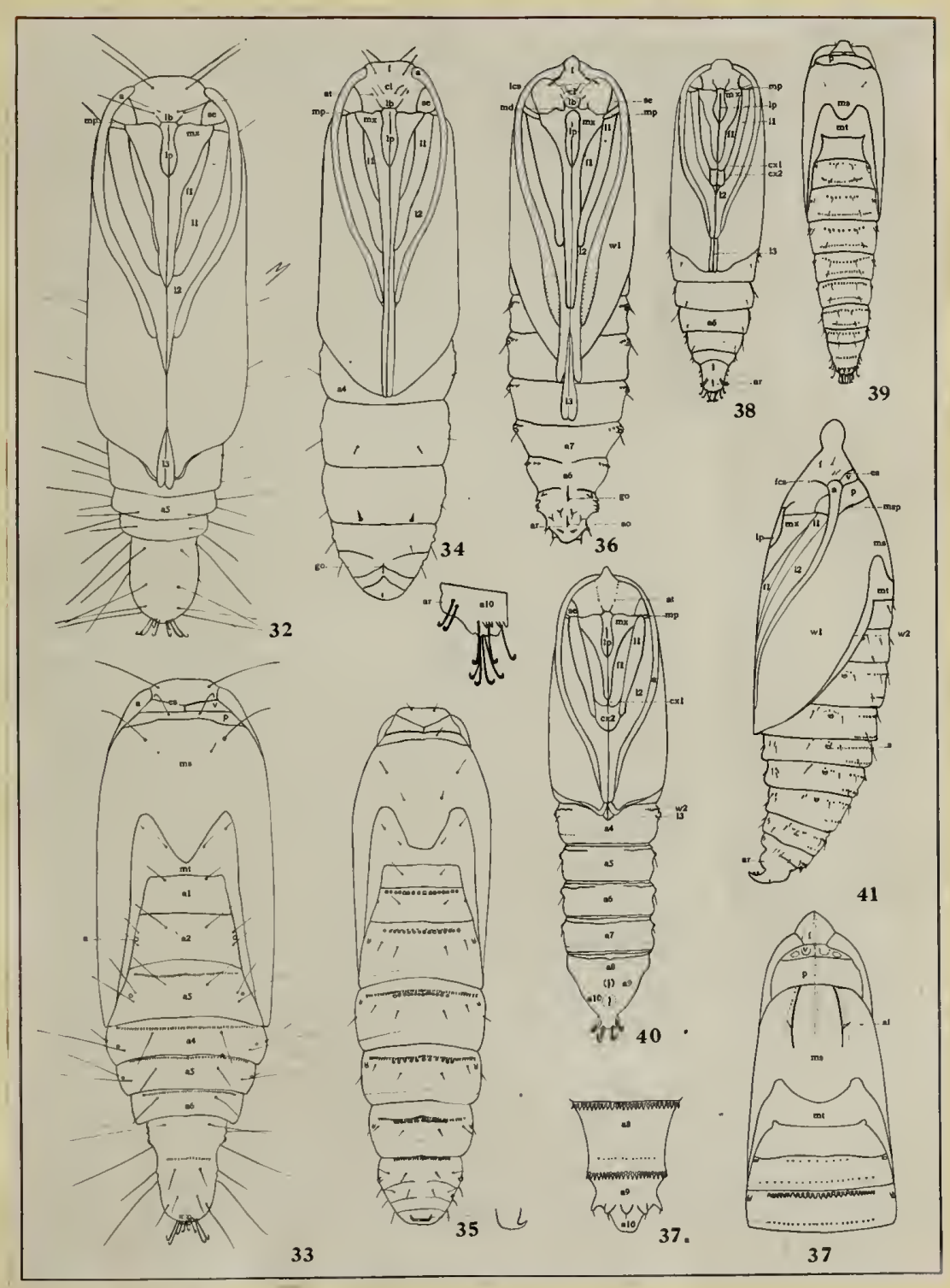


LIOKARY

OF THE

UNIVERSITY OF ILLINOIS 


\section{Plate 4}

42. Peronea minuta. Ventral view, female.

43. Peronea minuta. Showing the connection of the eye-pieces with the vertex after removal of antenrae at deniscence.

44. Archips argyrospila. Ventral view, female.

45. Gracilaria negundella. Ventral view, male.

46. Gracilaria negundella. Terminal segments of antenna.

47. Gracilaria sassafraselia. Cephalic end of prothoracic and mesothoracic lege, with adjoining area supposed to be the location of the maxillary palpus.

48. Nepticula platanella. Ventral view, male.

49. Nepticula platanella. Dorsal view, male.

50. Antispila cornifoliella, Ventral view, male.

51. Coptotriche zelleriella. Ventral view, male.

52. Covtotriche zelleriella. Dorsal view, male.

52a. Coptotriche zelleriella. Lateral view, caudal end of abdomen.

52b. Coptotriche zelleriella. Tips of strongly chitinized setae.

53. Lischeria malifoliella. Dorsal view, female. 
Plate 4

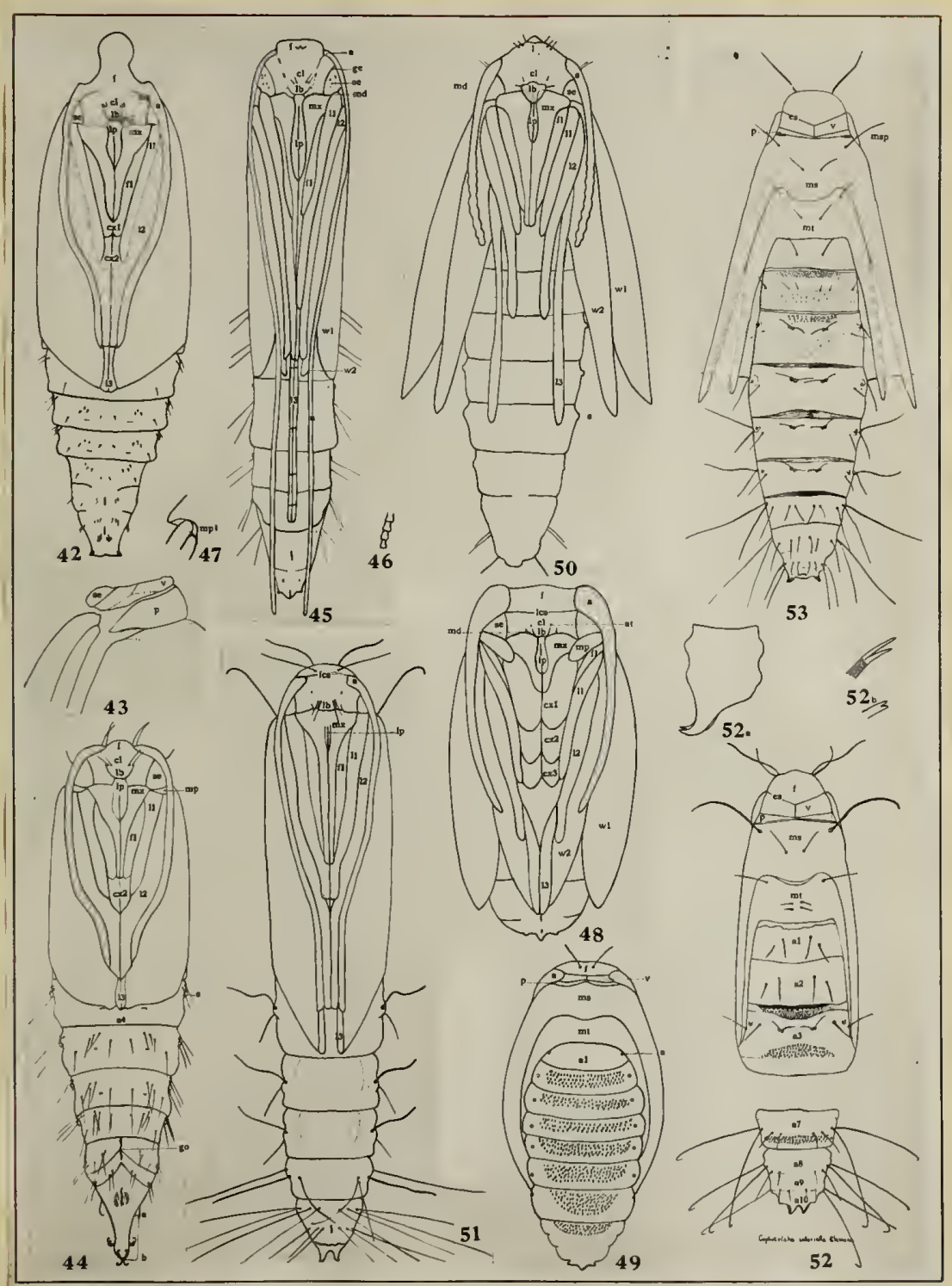


LISKARY

OF THE

UNIVERSITY OF ILLINOIS 


\section{Plate 5}

54. Tischeria heliopsisella. Dorsal view, male.

54a. Tischeria heliopsisella. Lateral view, caudal end of abdomen.

55. Bucculatrix sp. Ventral view, male.

56. Bucculatrix sp. Dorsal view, female.

56a. Bucculatrix sp. Lateral view of head.

57. Bedellia somnulentella. Ventral view.

58. Bedellia somnulentella. Dorsal view.

59. Proleucoptera smilaciella. Ventral viev.

60. Proleucortera smilaciella. Dorsal view.

61. Cameraria hamadryadella. Ventral view, male.

62. Cameraria hamadryadella. Dorsal view, male.

62a. Cameraria hamadryadella. Lateral view, head.

6ab. Cameraria hamadryadella. Dorsal view fifth and sixth abdominal segments, female.

63. Gracllaria negundella. Dorsal vievi, male. 

Plate 5

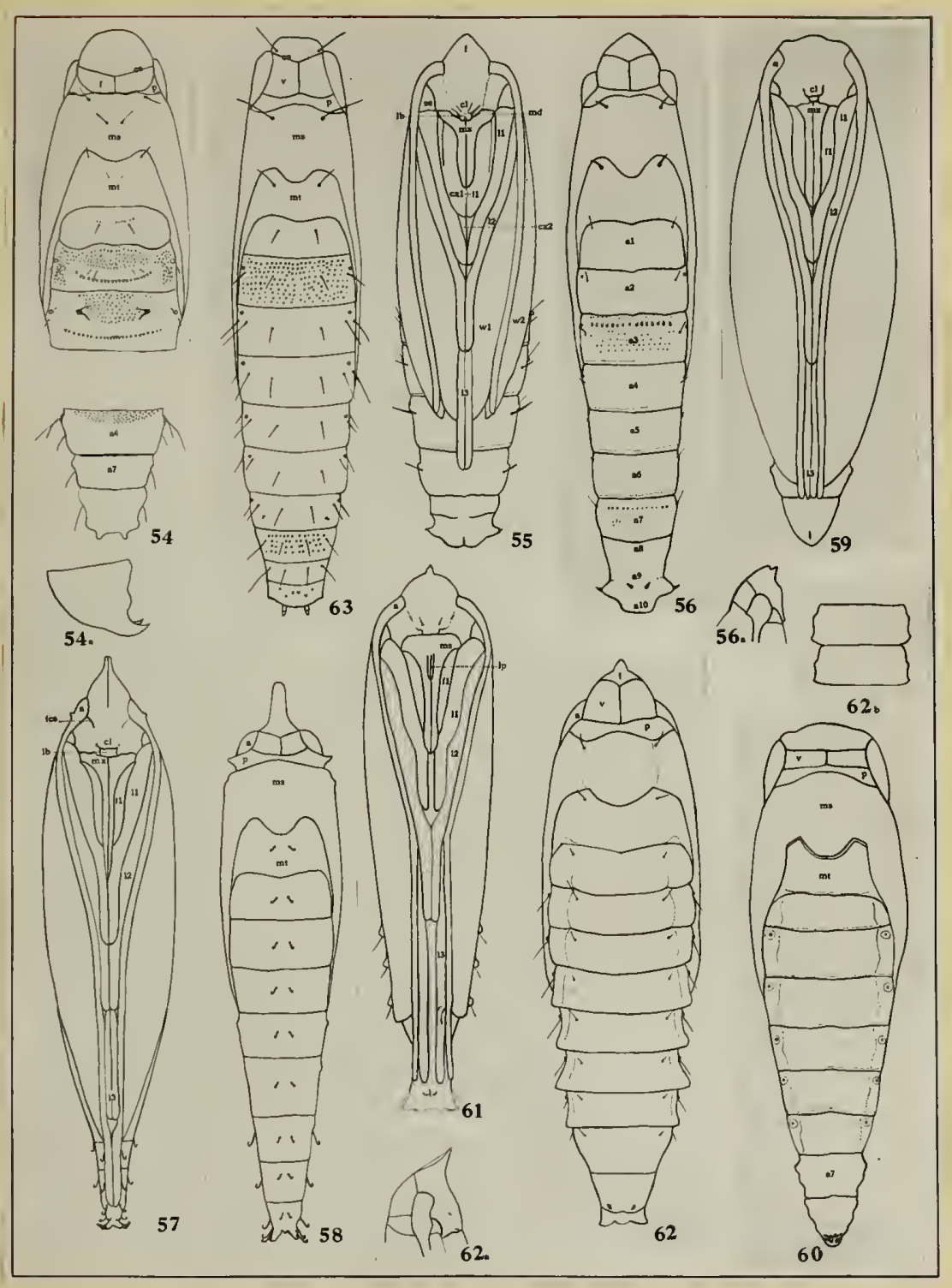


LIBRARY

UNIVERSITY OF ILLINOIS 


\section{Plate 6}

64. Lithocolletis argentinotella. Ventral view, female. 65. Lithocolletis argentinotella. Dorsal view, male. 66a. Lithocolletis luciaicostella. Dorsal viev, cremaster. 66b. Lithocolletis tiliacella. Dorsal view, cremaster. 67. Phyllocnistis insignis. Ventral view, male. 68. Eperminia pimpinella. Ventral view, male. 69. Galleria melonella. Lateral vieri, male. 70. Oxyotilus tenuidactylis. Ventral view. 71. Oxyptilus tenuidactylis. Dorsal view. 72. Atteva aurea. Ventral view, male. 73. Atteva aurea. Dorsal view, male. 74. Ephestia kuehniella. Ventral view, female. 75. Mineola indiginella. Dorsal view. 

Plate 6

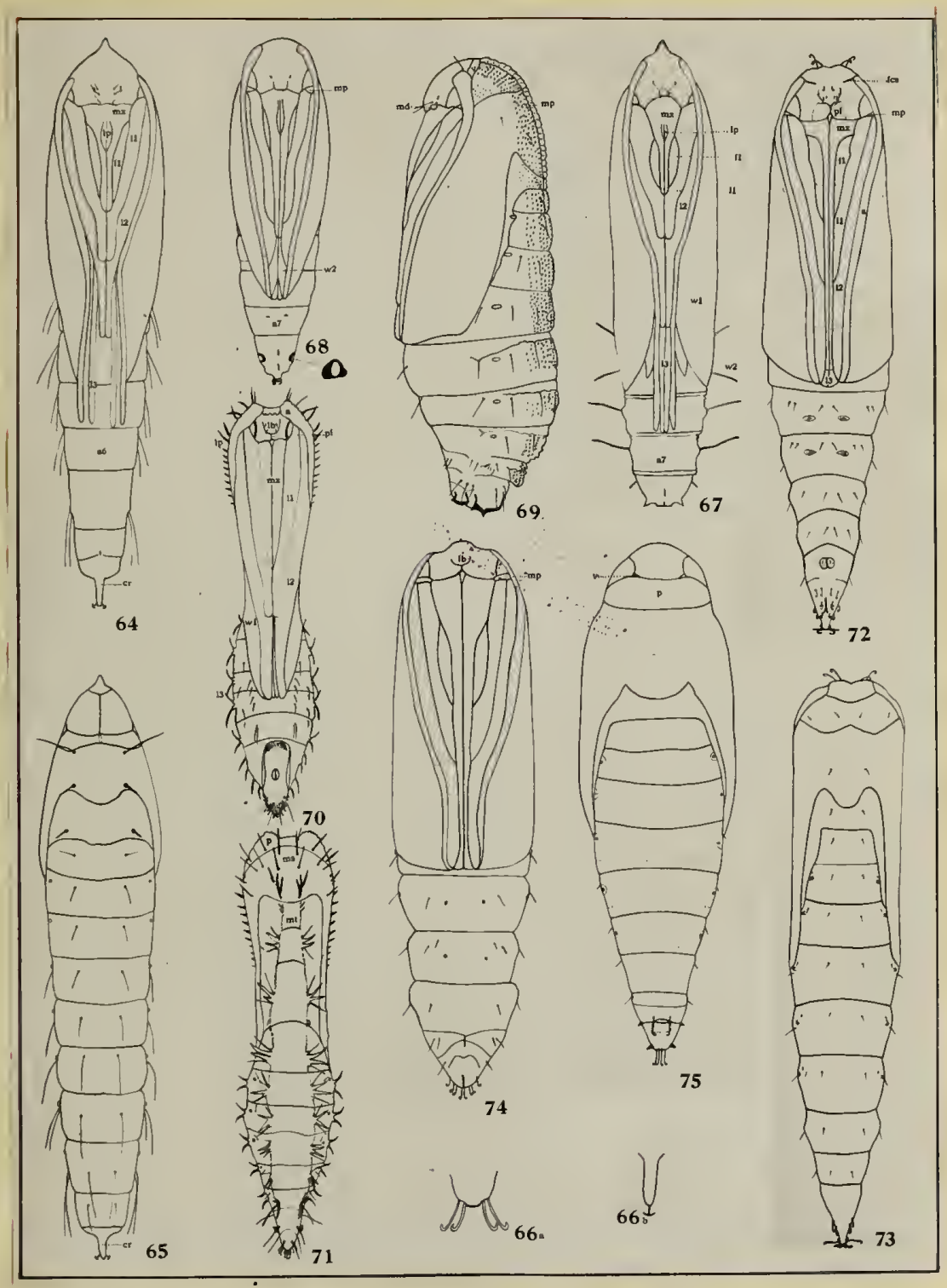


E 


\section{Plate 7}

76. Pyrausta futilalis. Ventral view, female.

77. Epargyreus tityrus. Lateral view.

78. Calpodes ethlius. Ventral view.

79. Cyaniris ladon. Ventral view.

80. Oeneis semidea. Ventral view.

81. Euvanessa antiopa. Lateral view, fifth abdominal segment.

82. Zelleria celastrubella. Ventral view, male.

83. Yponomeuta malinellus. Ventral view.

84. Plutella maculipennis. Dorsal view.

85. Argyresthria freyelia. Ventral vier, female.

86. Argyresthria freyella.... Dorsal view, female.

87. Coleophora malivorella. Ventral view.

88. Lophopt1lus eloisella. Ventral view, female.

882. Lophoptilus eloisella. Lateral view, caudal end of abdomen. 89. Scythris eboracensis. Ventral viev. 

Plate 7

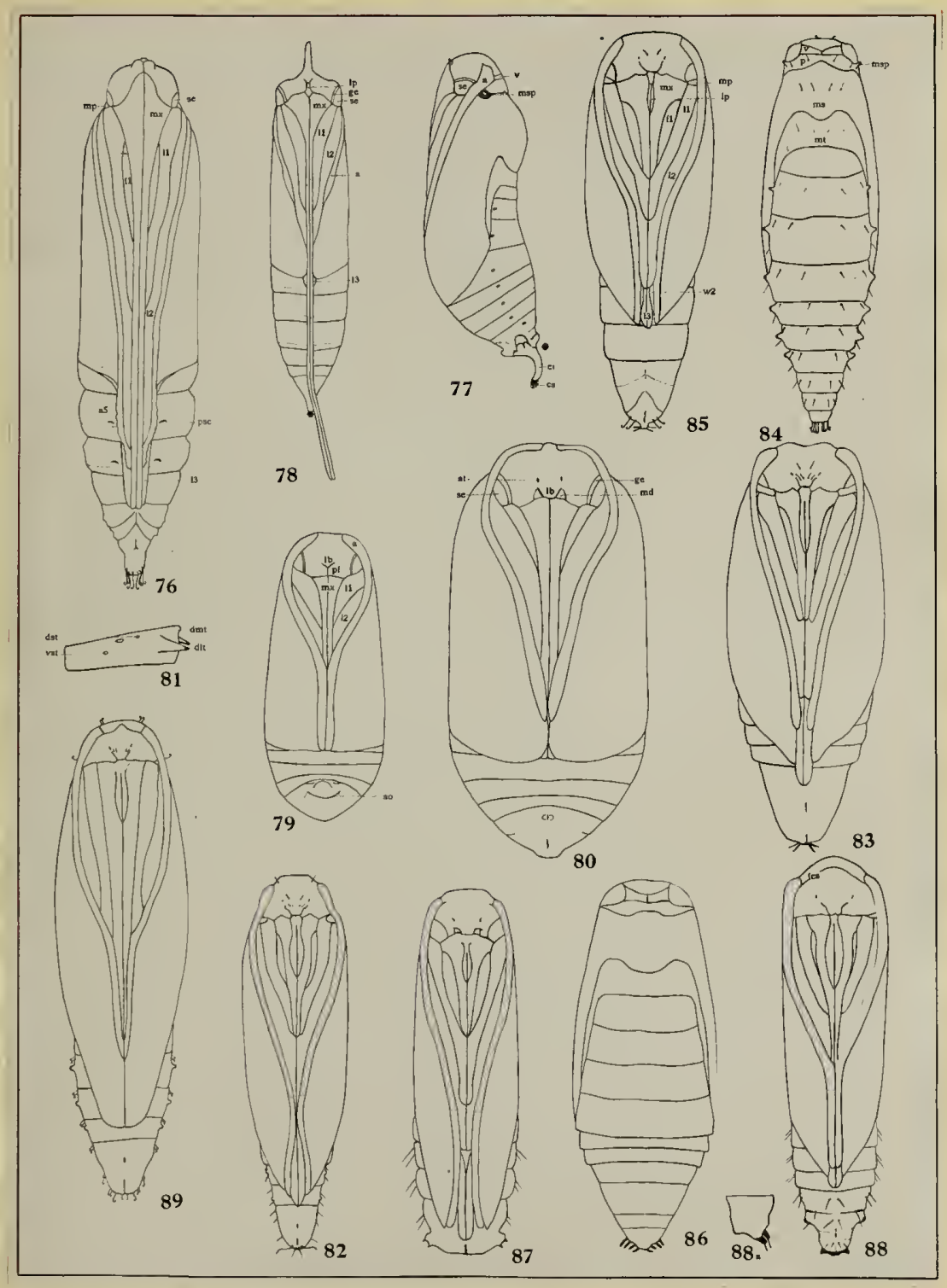


LIDKARYY

OF THE ILLINOIS
UNIVERSITY OF 


\section{Plate 8}

90. Gelechia serotinella. Ventral view.

91. Trichtotaphe flavocostella. Dorsal view.

92. Trichtotaphe flavocostella. Ventral view.

93. Evippe prunifoliella. Ventral view.

93a. Evippe prunifoliella. Lateral view caudal end of abdomen.

94. Yosolophus citrifoliella. Ventral view.

95. Chrysopeleia ostryaeella. Ventral view.

96. Stenoma schlageri. Ventral view.

96a. Stenoma schlageri. Dorsal and lateral views, fourth abdominal segment.

966. Stenoma schlageri. Tips of large lateral setae.

97. Psilocorsis quercicella... Ventral view.

98. Psilocorsis quercicella. Lateral view.

99. Cosmopteryx clandestinelia. Ventral view.

100. Elachista praelineata. Ventral view. 

Plate 8

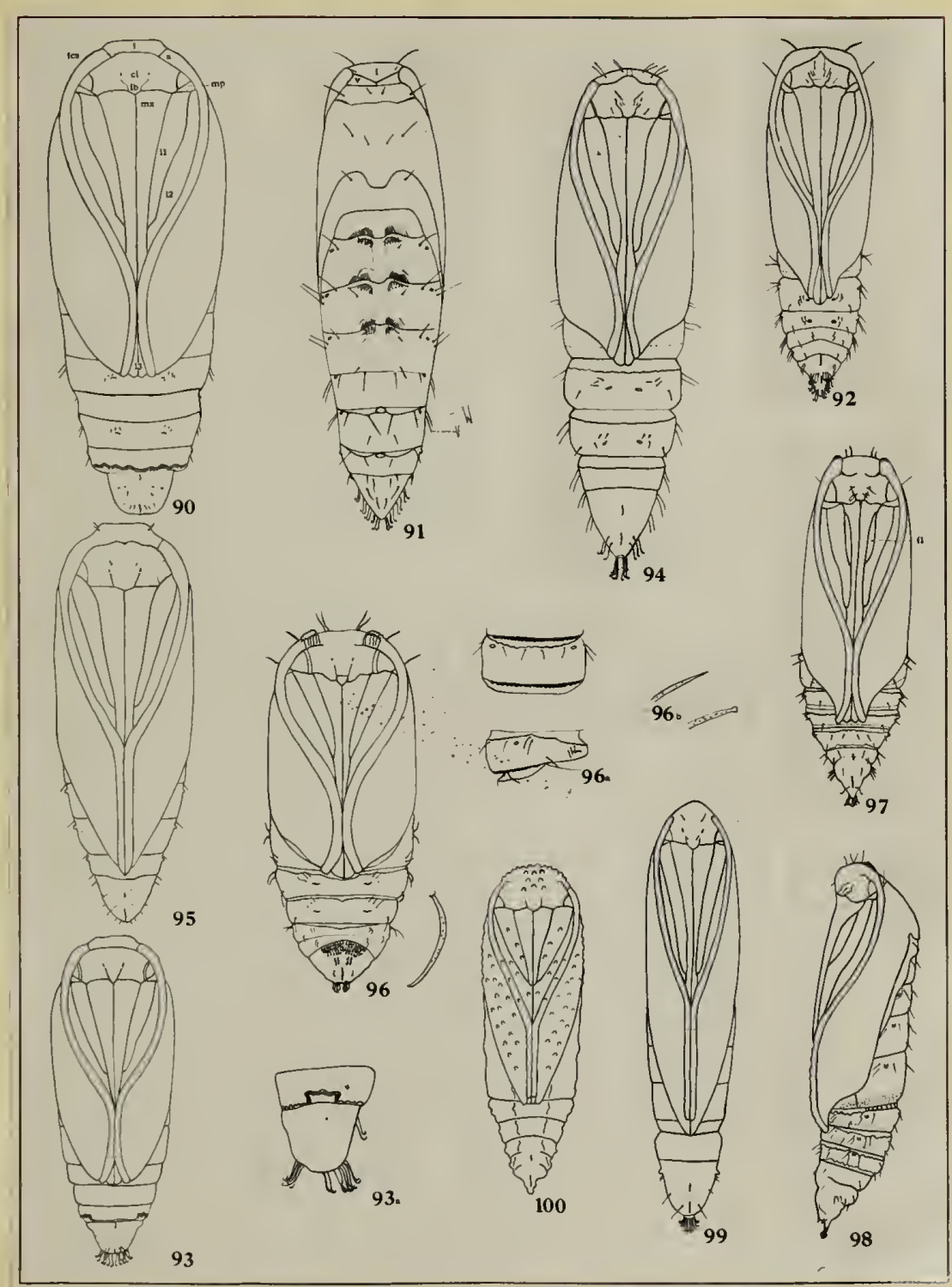





\section{Plate 9}

101. Agrotis bicarnea. Dorsal view.

102. Cirphis unipuncta. Ventral view.

103. Eulonche oblinita. Ventral view.

104. Isia isabella. Lateral view.

105. Hemerocampa leucostigma. Ventral view.

105. Malacosoma disstria. Ventral view.

107. Bombyx mori. Ventral view.

108. Brephos infans. Ventral view.

109. Hydria undulata. Dorsal view, cremastral setae not present.

110. Cymataphora ribearia. Dorsal view, caudal abaominal segments and cremaster.

11. Tephroclystis absinthiata. Dorsal view, caudal abdominal segments and cremaster.

112. Melalopha inclusa. Dorsal view, caudal abdominal segments and cremaster.

113. Datana augusii. Dorsal view, caudal abdominal segments and. cremaster.

114. Schizura ipomeae. Dorbal view, caudal abdominal segments and cremaster.

115. Phryganidia californica. Ventral view.

116. Phryganidia californica. Dorsal view. 

Plate 9

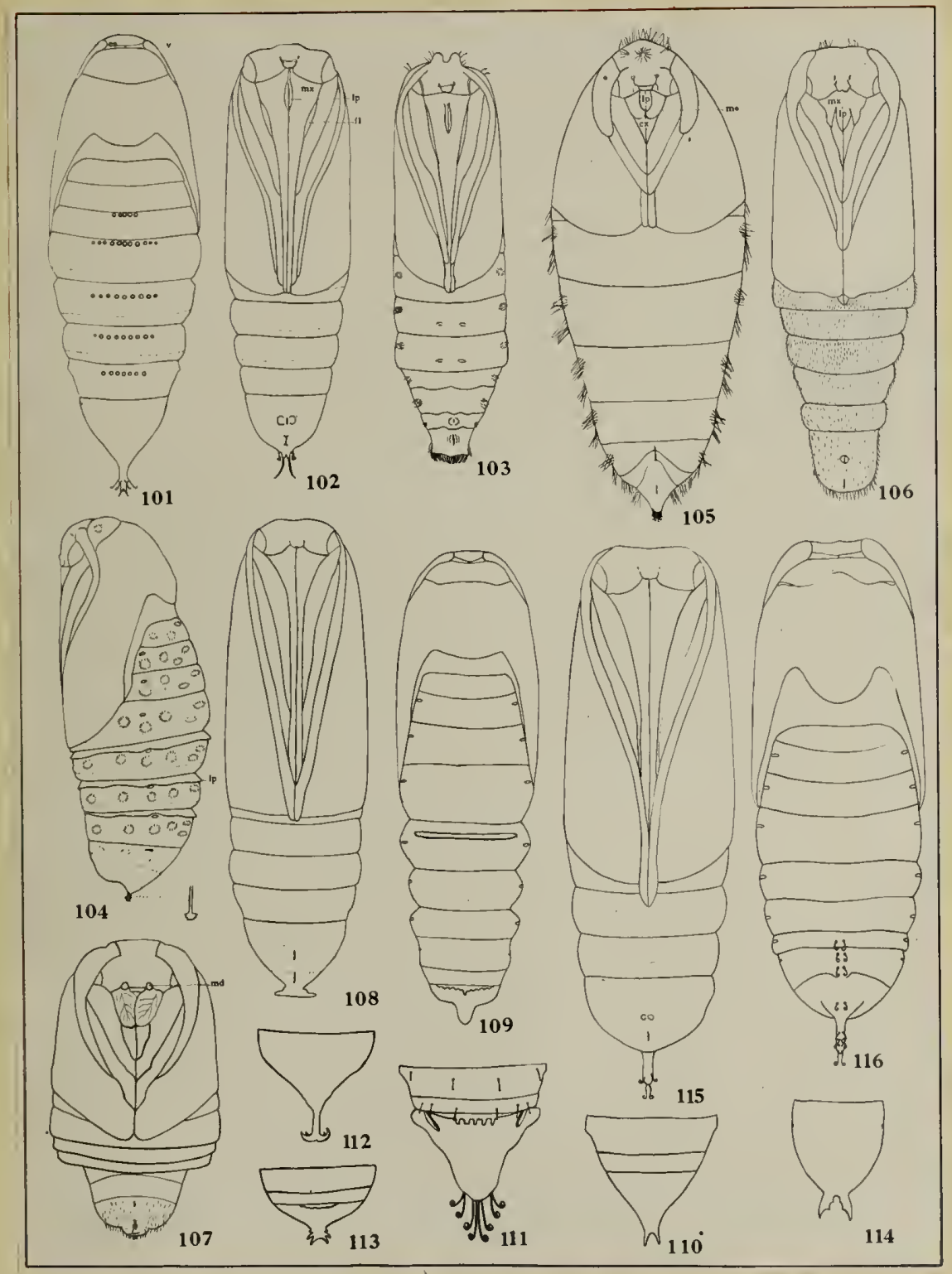


LiskatiY

OF THE

UNIVERSITY OF ILLINOIS 
$+$
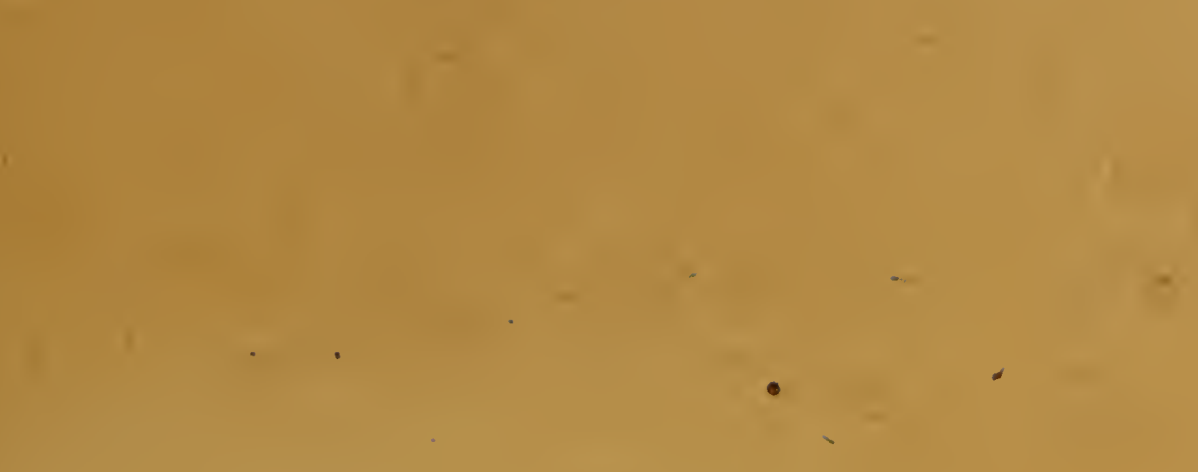

$\ldots$ 
